\title{
Zur Geschichte der Geowissenschaften im Museum für Naturkunde zu Berlin. Teil 5: Vom Mineralogischen Museum im Hauptgebäude der Universität zu den zwei geowissenschaftlichen Institutionen im Museum für Naturkunde - 1856 bis 1910
}

\author{
Günter Hoppe ${ }^{1}$ \\ Mit 17 Abbildungen und 1 Tabelle
}

\section{Zusammenfassung}

Im vorhergehenden 4. Teil der Artikelserie wurde die Zeit behandelt, in der das Gesamtgebiet der Geowissenschaften von dem Mineralogen und Kristallographen Christian Samuel Weiss im Mineralogischen Museum vertreten wurde und in der sich die Spezialisierung in Teilgebiete durch auftretende weitere Lehrkräfte zeigte. Nach dem Tod von Weiss im Jahre 1856 wirkte sich diese Entwicklung auch auf die Leitung des Mineralogischen Museums aus und führte schließlich zur Teilung in zwei Institutionen. Der vorliegende Artikel, der bis zum 100jährigen Jubiläum der Universität im Jahre 1910 reicht, behandelt dies in folgenden Kapiteln; 1) das Mineralogische Museum unter dem Mineralogen Gustav Rose als Direktor und dem Geologen und Paläontologen Ernst Beyrich in der Zeit von 1856 bis 1873,2) das Mineralogische Museum unter Ernst Beyrich als Direktor, dem Mineralogen Martin Websky und dem Geologen und Petrographen Justus Roth in den Jahren von 1873 bis 1888 nebst Aufteilung in zwei Institutionen, 3) die Projektierung und den Bau des Museums für Naturkunde in den Jahren von 1873 bis 1889,4$)$ die beiden geowissenschaftlichen Institutionen in den Jahren 1888 bis 1910, 4a) das Geologisch-Paläontologische Institut und Museum unter den Geologen und Paläontologen Ernst Beyrich, Wilhelm Dames und Wilhelm Branco (Branca) nacheinander als Direktoren und 4b) das Mineralogisch-Petrographische Institut und Museum unter dem Mineralogen und Petrographen Carl Klein und danach dem Mineralogen und Kristallographen Theodor Liebisch als Direktoren.

\begin{abstract}
The preceding fourth part of this series of articles dealt with the period (of time), when the whole field of earth sciences in the Mineralogical Museum was represented by one person, the mineralogist and crystallographer Christian Samuel Weiss. At that time the specialisation of earth sciences into different fields was already becoming evident from the practices of other academic teachers. After Weiss died in 1856, this process influenced the direction of the Museum of Mineralogy in such a way that it was divided into two institutions. This article covers the interval up to the Humboldt University's $100^{\mathrm{th}}$ anniversary in 1910. It is structured as follows: 1) The Mineralogical Museum under the directorship of the mineralogist Gustav Rose and the palaeontologist Ernst Beyrich from 1856 until 1873;2) the Mineralogical Museum under the directorship of Ernst Beyrich, the mineralogist Martin Websky and the geologist and petrographer Justus Roth from 1873 to 1889 , and its division into two institutions; 3) the planning and construction of the Museum für Naturkunde from 1873 to 1889 ; 4) the two geoscientific institutions from 1888 to 1910 ; 4a) the Geological-Palaeontological Institute and Museum under the successive directorships of the geologists and palaeontologists Ernst Beyrich, Wilhelm Dames and Wilhelm Branco (Branca); 4b) the MineralogicalPetrographical Institute under the directorship of the mineralogist and petrographer Carl Klein and afterwards under the directorship of the mineralogist and petrographer Theodor Liebisch.
\end{abstract}

\section{Einleitung ${ }^{2}$}

In den vorigen Artikeln dieser Reihe (Hoppe 1998, 1999, 2000a, 2001a) wurde die Geschichte der Geowissenschaften im Museum für Naturkunde zu Berlin von seiner frühesten Vorgeschichte an dargestellt. Der letzte Artikel behandelte den ersten Zeitabschnitt des Mineralogischen Museums der Berliner Universität, das im Jahre 1810 aus der zuvor bestehenden Berliner Bergakademie hervorgegangen war, und reichte bis zum Tode des Mineralogen und Kristallographen Christian Samuel Weiss im Jahre 1856. Weiss hatte durch seine kristallographi-

\footnotetext{
1 Prof. emer. Dr. Günter Hoppe, Museum für Naturkunde, Institut für Mineralogie, Invalidenstr. 43, D-10115 Berlin, Germany. - Privat: Wilhelm-Wolff-Str. 65, D-13156 Berlin.

Erhalten Februar 2003, angenommen Juni 2003

2 Biographische Daten der im gesamten Artikel genannten Lehrkräfte und wissenschaftlichen Mitarbeiter sind in Tabelle 1 (im Anhang) zusammengestellt.
} 


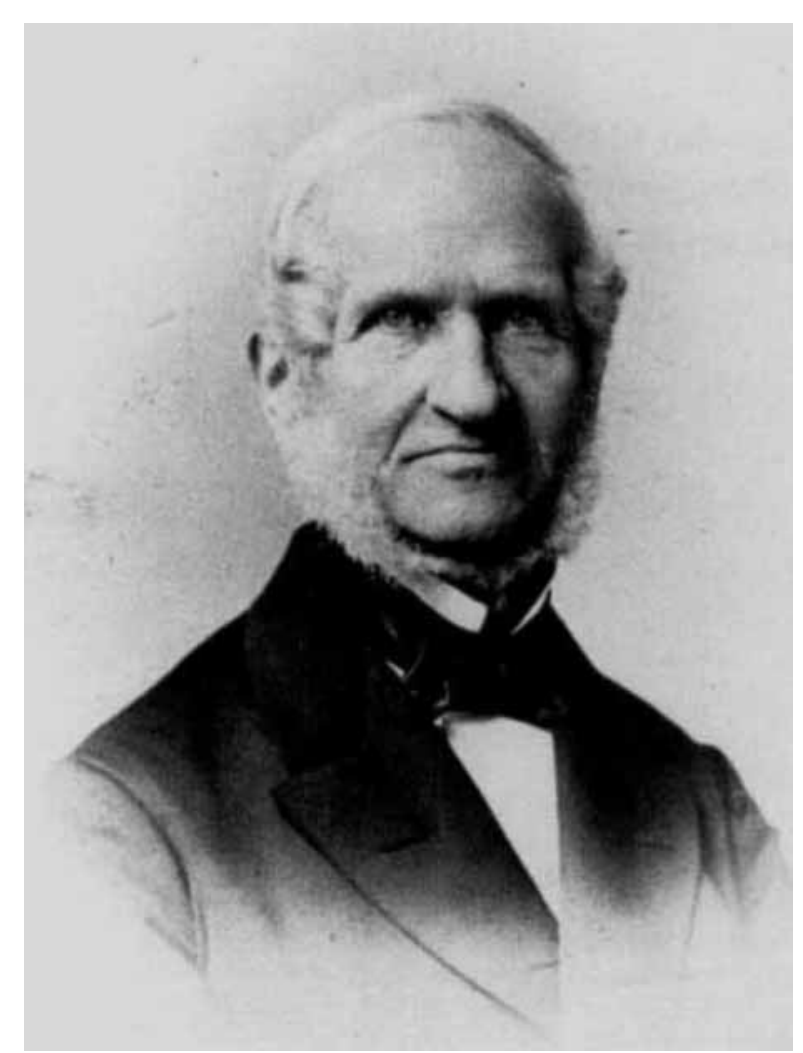

Abb. 1. Gustav Rose (1798-1873) im Alter von 75 Jahren. Fotograf: Loescher \& Petsch. - Original im Museum für Naturkunde, HHMfN-10 (Bestand: Gesellschaft Naturforschender Freunde), Sign. FM I,1.

schen Entdeckungen eine führende Position erreicht und das Mineralogische Museum der Universität Berlin zu einer angesehenen Einrichtung gemacht. Daran hatten auch seine zwei Schüler und Mitarbeiter, der Mineraloge Gustav Rose und der Paläontologe Ernst Beyrich, wesentlichen Anteil. Sie sind nun die wesentlichen Personen.

Gustav Rose (1798-1873) (Abb. 1) war seit seinem Studium an der Universität Berlin von 1816 an mit dem Mineralogischen Museum eng verbunden und war nach seiner Promotion als "Gehilfe", d. h. als wissenschaftlicher Assistent, eingestellt worden. Nach Zwischenstufen als Privatdozent und a. o. Professor erhielt er im Jahre 1839 die Stellung eines ordentlichen Professsors der Mineralogie am Mineralogischen Museum neben Weiss. Diese ungewöhnliche Berufung als zweiter ordentlicher Professor an der gleichen Einrichtung verdankte Rose der Förderung durch den Kultusminister v. Altenstein ${ }^{3}$ sowie der Fürsprache von Alexander v. Humboldt. Roses
Interessen waren auf die Erscheinung und die Eigenschaften der Minerale gerichtet. Da dieses Gebiet auch von Weiss beansprucht wurde, hatte dieser die Förderung von Rose als Zurücksetzung für sich empfunden. Die Verschlechterung der Beziehungen hatte allerdings aber schon sehr früh begonnen, als Rose an den Arbeiten des Chemikers Eilhard Mitscherlich beteiligt war, die zur Entdeckung der Isomorphie führten und die die Kristallographie von Weiss empfindlich tangierten. Trotz des gestörten Verhältnisses gelangte Rose zu wesentlichen Ergebnissen und verschaffte dem Berliner Mineralogischen $\mathrm{Mu}$ seum auch auf dem Gebiete der Speziellen Mineralogie einen bedeutenden Ruf. So strebte Rose dem Höhepunkt seiner Wirksamkeit zu, während Weiss nicht mehr solch wegweisende Leistungen wie in seinen ersten Jahrzehnten erbrachte und seine führende Position in der Entwicklung der Kristallographie allmählich an andere verlor.

Roses jüngerer Kollege Ernst Beyrich (1815-1896) war auch ein Schüler von Weiss. Er hatte sich aber für die von Weiss nur schwach vertretene Petrefaktenkunde entschieden und war erst, nachdem es Weiss gelungen war, hierfür eine Lehrstelle bewilligt zu bekommen, als Gehilfe und Dozent in das Mineralogische $\mathrm{Mu}-$ seum eingetreten. Beyrich hatte bereits einige Bestände an Versteinerungen in der Sammlung des Mineralogischen Museums vorgefunden, die zum Teil der tatkräftigen Initiative und Fürsprache A.v. Humboldts beim Kultusminister und dem König zu verdanken waren. Die Tätigkeit Beyrich war bereits durch die Verleihung des Titels eines a. o. Professors am 26.7.1846 anerkannt worden. Anders als Rose scheint Beyrich mit Weiss nicht in größere Schwierigkeiten gekommen zu sein, wohl weil dieser die Versteinerungskunde nicht wie die Mineralogie als sein Kerngebiet ansah.

\section{Das Mineralogische Museum unter dem Direk- tor Gustav Rose (1856-1873)}

\section{Das Personal}

Das wissenschaftliche Personal des Mineralogischen Museums bestand beim Tode von Christian Samuel Weiss am 1.10.1856 aus drei

\footnotetext{
${ }^{3}$ Karl Freiherr vom Stein zum Altenstein (1770-1840) war von 1817 bis 1840 preußischer Minister für geistliche, Unterrichts- und Medizinalangelegenheiten (,Kultusminister").
} 
Personen, dem o. Professor Gustav Rose, dem Gehilfen für die petrefaktologische Sammlung, a. o. Professor Ernst Beyrich, und dem Gehilfen Daniel Krull. Die Leitung des Mineralogischen Museums wurde an Gustav Rose zunächst nur interimistisch übertragen und die endgültige Entscheidung zog sich auffällig lange hin, obwohl Roses Ernennung zum ordentlicher Professor für Mineralogie an der Universität Berlin schon 1839 erfolgt war. Der Grund für diesen Zeitverzug geht aus den Akten des Ministeriums über das Mineralogische Museum, deren Überlieferung lückenhaft ist ${ }^{4}$, nicht hervor. Eine andere Quelle (GSTAB-32, Bl. 327) besagt, dass Rose auch noch im Juli 1857 als interimistischer Direktor unterzeichnete. Erst im August 1858 leitete das Ministerium seine endgültige Einsetzung als Direktor ein und beauftragte Rose, Entwürfe für die Instruktionen vorzulegen, die die Dienstaufgaben für ihn als Direktor und für den Gehilfen Beyrich festlegen sollten. Diese wurden schließlich im Oktober 1858 in Kraft gesetzt (GStAB29, Bl. 7). Dabei wurde der Instruktionsentwurf für Beyrich dahingehend geändert, dass er als Gehilfe des Direktors Rose ausdrücklich die Verantwortung für die Petrefaktensammlung übertragen erhielt ${ }^{5}$. Diese Festlegung kann als erste offizielle Anerkennung des Status der Petrefaktensammlung innerhalb des Mineralogischen Museums angesehen werden, wenn es auch bereits seit 1837 einen Katalog dieser Sammlung gab ${ }^{6}$.

\section{Die Aufhebung der Dienstwohnung}

Der ungewöhnlich lange interimistische Zustand der Leitung des Mineralogischen Museums fällt zusammen mit der Aufhebung der Dienstwohnung des Direktors, die Weiss innegehabt hatte. Es war zu erwarten gewesen, dass Rose die
Wohnung erhalten würde, da Dienstwohnungen kein privates Privileg darstellten, sondern an das Amt der Direktoren gebunden waren, jedoch sprach der Kultusminister v. Raumer ${ }^{7}$ während der Interimszeit Roses die Räume dem Herbar zu. Die Dienstwohnung befand sich, wie schon im Teil 4 dieser Artikelserie (Hoppe 2001a) dargestellt, im Ostflügel des Gebäudes der Universität. Sie war unmittelbar mit dem Mineralogischen Museum verbunden und lag in dem zur Straße Unter den Linden gelegenen Kopfteil des Ostflügels. Abgesehen von dem Verlust für Rose war es auch ein Verlust für das sehr beengte Mineralogische Museum, da sich in der Wohnung auch Teile der Sammlung des Mineralogischen Museums befanden. Deshalb befürchtete man sogar außerhalb Berlins, dass die von Weiss besonders betreute Kristallsammlung nicht mehr geschlossen erhalten bleiben würde ${ }^{8}$. Rose konnte nur erreichen, dass sich Rektor und Senat sowie die Philosophische Fakultät mit Gutachten für das Museum einsetzten, woraufhin der Minister entschied, die Wohnung zu teilen. Dem Mineralogischen Museum verblieben nun zwei Räume, die als Übungs- und Arbeitsräume für die Bergeleven deklariert wurden. Das Herbar erhielt die übrigen Räume, wie es hieß, als „vorläufige Unterbringung“ (GSTAB-32, Bl. 304). Daraufhin einigten sich am 31.7.1857 Rose (noch als interimistischer Direktor) und der Professor der Botanik, Alexander Braun, über die baulichen Maßnahmen zur Trennung der beiden Teile der Wohnung (GSTAB-32, Bl. 327).

Es kann vermutet werden, dass Roses Einsetzung als Direktor absichtlich hinausgezögert wurde, um die Dienstwohnung leichter aufheben zu können. Dafür spricht, dass A. v. Humboldt, der die Angelegenheit kannte, später das Vorgehen als „nicht ganz rechtmäßig“" verurteilt hat,

${ }^{4}$ Die Überlieferungslücke betrifft die Jahre 1850 bis 1858 , es ist der Band 8 aus der sonst bis zum Band 7 (GSTAB-26) und ab Band 9 (GSTAB-29) vollständigen Aktenreihe.

5 Die Dienststellung von Beyrich wurde als die eines zweiten Beamten des Mineralogischen Museums angesehen, wovon in der Instruktion in dieser Form noch keine Rede ist. Beyrichs Entlohnung war mit 120 jährlichen Talern nur sehr gering, was noch auf Weiss zurückging, der für ihn das Gehalt eines "Hilfsarbeiters" angesetzt hatte (ein Gehilfe erhielt normalerweise 200 Taler), weil der Umfang der Petrefaktensammlung im Vergleich zur mineralogischen Sammlung nur gering war. Beyrich erhielt diese Entlohnung für die Verwaltung der Petrefaktensammlung in gleichbleibender Höhe bis 1873. Eine Erhöhung, um die er sich bewarb, wurde 1865 vom Kultusminister abgelehnt (GStAB-29, Bl. 277-8).

6 Dieser Katalog war von dem früheren Gehilfen F. A. Quenstedt (1809-1889) angefertigt worden (siehe Hoppe 2001a).

7 Karl Otto v. Raumer (1805-1859) war von 1850 bis 1858 Kultusminister. Er verfolgte eine streng orthodoxe Politik und war ein Gegner der Bestrebungen A. v. Humboldts.

8 Aus einem Brief von Friedrich Adolph Roemer, dem Direktor der Bergschule in Clausthal (später Bergakademie), an seinen Hildesheimer Bruder Hermann vom 7.11.1857 erfährt man von den Vorwürfen gegen Rose und Beyrich. Dort heißt es: „Daß Beyrich und Rose die Weißsche Wohnung dem Mineralien Cabinette nicht gerettet haben, ist ganz unverzeihlich; ihre ganzen Schätze werden dadurch nutzlos." - Der Autor dankt Herrn Prof. Dr. W. Langer, Alfter/Bonn, für die freundliche Mitteilung des Briefes. 
wie aus einem Brief von ihm an das Kultusministerium hervorgeht ${ }^{9}$. Übrigens wurde die Dienstwohnung des Direktors des Zoologischen Museums H. Lichtenstein, die sich genau über der Wohnung von Weiss befand, nach dessen Tod im Jahre 1857 nicht eingezogen, wie zunächst zu Roses Beruhigung erklärt worden war, sondern sie wurde Lichtensteins Nachfolger zugeteilt, was zur Erbitterung Roses beigetragen hat. Dies zeigen Schriftstücke Roses noch nach Jahren. So hatte er im Entwurf zu seiner Instruktion, den er 1858 vorlegen musste, einen Passus der Einschränkung seiner Verantwortlichkeit für die Sammlung des Mineralogischen Museums im Hinblick auf seine entfernt gelegene Wohnung eingefügt (GStAB-29, Bl. 6). Das Ministerium strich diesen Passus. Hiergegen protestierte Rose und bezeichnete die Aufhebung der Dienstwohnung als eine sorglose Handlung des Ministeriums, weil die mineralogische Sammlung angesichts der hohen Kauf- und Liebhaberwerte der Minerale einer besonderen Diebstahlsgefahr ausgesetzt sei $^{10}$, was ihm aber nichts als eine barsche Belehrung und Zurechtweisung durch den Minister v. Raumer einbrachte (GStAB-29, Bl. 15) ${ }^{11}$.

Drei Jahre später, nach dem Tode des Ministers v. Raumer, hoffte Rose nochmals, sein Anliegen gegenüber dem nunmehrigen Kultusminister M. A. v. Bethmann-Hollweg ${ }^{12}$ mit größerer Aussicht auf Erfolg vorbringen zu können. Dieser zeigte sich den persönlichen Gründen von Rose gegenüber durchaus aufgeschlossen und war bereit, das Herbar in anderen, gegebenenfalls auch in gemieteten Räumen unterzubringen. Rose bemühte sich daraufhin, ein geeignetes Quartier für das Herbar zu finden, und glaubte, ein solches in der Cantianstraße am damaligen nördlichen Stadtrand gefunden zu haben. $\mathrm{Da}$ dieses aber vom Professor der Botanik Braun als zu klein und zu unzweckmäßig abgelehnt wurde (GSTAB-29, Bl. 178 vom 22.1.1862), sah Rose schließlich ein, dass die unter Minister v. Raumer geschaffene Situation nicht mehr rückgängig zu machen war, und gab weitere Bemühungen auf. Die „provisorische“ Unterbringung des Herbars in der ehemaligen Dienstwohnung von Weiss dauerte schließlich bis zum Jahre 1871. Dann wurde in diesen Räumen ein physikalisches Kabinett eingerichtet ${ }^{13}$ und das Herbar zog in ein gemietetes Privathaus.

\section{Raumsituation nach Wegfall der Dienstwohnung}

Die durch Aufhebung der Dienstwohnung des Direktors entstandene Raumsituation des Mineralogischen Museums ist in Abb. 2 dargestellt ${ }^{14}$. Zur Verfügung stand das mittlere Geschoss sowohl des östlichen Mittelflügels des Universitätsgebäudes als auch des anschließenden östlichen Seitenflügels einschließlich der zwei westlichen Zimmer des zur Straße Unter den Linden zu gelegenen Kopfbaues. Im Grundriss ist die Nutzung einiger Räume eingetragen und zwar für die Petrefaktensammlung (mit 1 bezeichnet), für die in Glasschränken aufgestellte mineralogische Schausammlung (2), für den Hörsaal (3) und für die Dienstzimmer für Rose (4) und Beyrich (5). Die übrigen umfangreichen Sammlungen waren auf die übrigen Räume nebst Galerien und Entresol (Zwischengeschoss) verteilt. Dieses Entresol befand sich über den Räumen des östlichen Seitenflügels. Es hatte nur geringe Raumhöhe

\footnotetext{
${ }_{9}$ Dieses Schreiben von A. v. Humboldt betraf die Würdigung der Leistung, die der Kustos des Herbars bei der Neuordnung der Bestände (worin sich auch viele Gaben Humboldts befanden) im Zusammenhang mit der Aufstellung in den neuen Räumen erbracht hatte (GSTAB-33, Bl. 130, vom 26.2.1859). Er erwähnte darin nebenbei, die frühere Dienstwohnung sei dadurch ,in nicht ganz gerechter Weise dem Professor der Mineralogie und Direktor des nahen Mineralien-Cabinets entzogen worden, der das Cabinet weniger pflegen kann, als er dereinst wünschte." Diese Bemerkung hatte anscheinend keine Auswirkung. Humboldt starb bald danach am 6.5.1859.

${ }_{10}$ Das Mineralogische Museum war im Jahre 1839 nächtlich beraubt worden (Hoppe 1983).

11 Den Entwurf des Ministerschreibens hatte der Regierungsrat J. Schulze (1786-1869), der „Regierungsbevollmächtigte“ des Ministeriums für die Universität Berlin, verfasst. Es stellte eine Reminiszenz an die früheren, zum Teil recht heftigen Kämpfe dar, die Schulze unter Minister v. Altenstein mehrfach mit dem vorigen Direktor des Mineralogischen Museums, C. S. Weiss, ausgefochten hatte. Damals war vorwiegend der streitbare Charakter von Weiss für derartige Reaktionen des Ministeriums verantwortlich gewesen (Hoppe 2001a). Eine solche Veranlassung hat Rose jedoch nie gegeben und konnte sich der Förderung des Ministers v. Altenstein erfreuen. Inzwischen war aber unter Kultusminister K. O. v. Raumer das allgemeine Klima für die Wissenschaften wesentlich schlechter geworden.

12 Moritz August v. Bethmann-Hollweg (1795-1877) war von 1858 bis 1862 Kultusminister.

$13 \mathrm{Im}$ Zuge der Berufung des Physikers Hermann Helmholtz (1821-1894) im Jahre 1871 musste eine vorläufige Arbeitsstätte geschaffen werden, da die vorgesehene Errichtung eines Gebäudes für das Physikalische Institut mangels der erforderlichen Mittel noch ausstand (GSTAB-34, Bl. 82).

${ }_{1+}$ Dic Abb. 2 basiert auf einer Grundrisszeichnung des Universitätsgebäudes aus dem Jahre 1819 (AHUB-3), aktualisiert durch eine Skizze aus dem Jahre 1857 (GSTAB-32, Bl. 327), unter Verwendung der Angaben von Rose (1860, S. 282). Die Eintragung des Namens ..Helmholtz" beruht auf einer undatierten Skizze (GSTAB-30, Bl. 135), die anlässlich der Berufung des Physikers H. Helmholtz angefertigt wurde.
} 


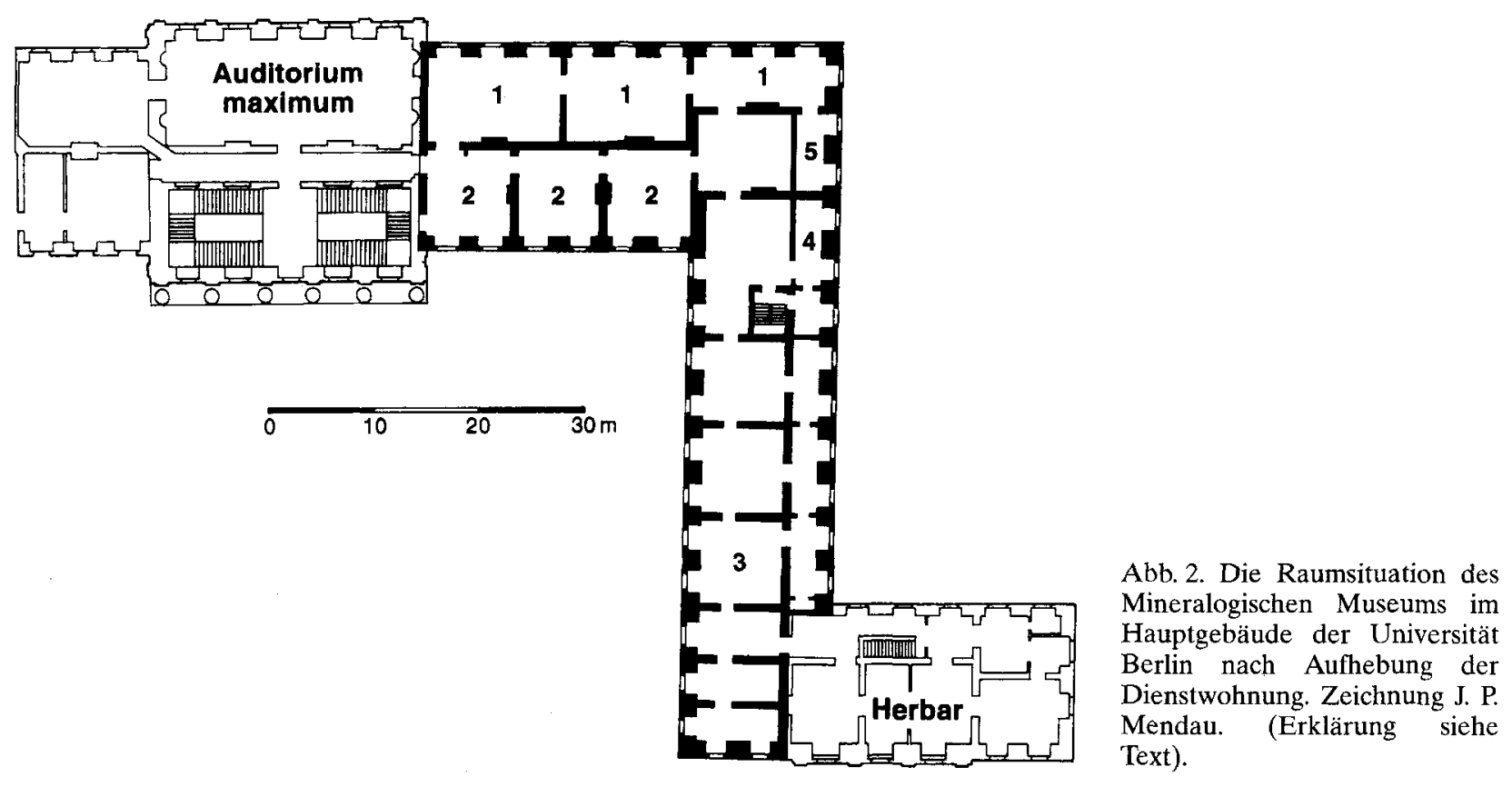

und erhielt Tageslicht durch das obere Drittel der sehr hohen Fenster des Gesamtgeschosses. Ursprünglich hatten die Räume des Entresol zu der Zeit, in der das Haus noch Prinzenpalais war, als Wohnungen von Bediensteten gedient. Nun hatte dort noch der „Aufwärter“ (Institutsgehilfe) des Mineralogischen Museums eine kleine Wohnung.

\section{Die Lehre}

Wie es sich bereits in den letzten Jahren des vorigen Direktors Weiss abzeichnete, teilten sich Rose und Beyrich in die Aufgaben der Lehre und setzten dies in gleicher Weise fort. Es war ein recht konstantes Programm, das von ihnen geboten wurde. Rose las im Wintersemester Mineralogie sechsstündig, dazu eine Stunde Kristallographie, im Sommersemester vier Stunden Mineralogie und eine sechsstündige Geognosievorlesung, von nun an mit dem Titel: „Geognosie mit besonderer Berücksichtigung des sogenannten Urgebirges und des vulkanischen Gebirges". Es dürfte sich wohl vorwiegend um eine Petrographie gehandelt haben. Ob dies mit Beyrich abgesprochen war, ist aus den Ankündigungen im Vorlesungsverzeichnis nicht zu entnehmen, denn Beyrich nannte seine vierstündige Vorlesung, die er im Sommersemester hielt, wie zuvor nur „Geognosie“" und erst nach 10 Jahren änderte er den Titel in: „Geognosie mit besonderer Berücksichtigung des sogenannten Flötzgebirges". Vier Jahre lang las Beyrich dazu noch einstündig über den geognostischen Bau der Gegend von Berlin. Im Wintersemester las Beyrich fünfstündig Versteinerungskunde. Diese Bezeichnung behielt er den gesamten Zeitraum bei, nur einmal, im Wintersemester 1866/67 hieß es im Vorlesungsverzeichnis hierfür Paläontologie. Einen Ersatz für die früher von Weiss gehaltene eingehendere Kristallographie gab es nicht, aber auch Weiss selbst hatte diese Vorlesung in seinen letzten Jahren fallengelassen.

\section{Die Bindung an die Bergbehörde}

Die im Jahre 1810 bei der Universitätsgründung eingerichtete Doppelbindung des Lehrers der Mineralogie an die Universität und an die Bergbehörde blieb analog bestehen. Auf Vorschlag der Philosophischen Fakultät der Universität wurden nun beide am Mineralogischen Museum vorhandenen Lehrkräfte auch von der Bergbehörde für die Ausbildung verpflichtet (Krusch 1904, S. XLIV). Die finanzielle Regelung wurde entsprechend übertragen. Das von der Bergbehörde früher an Weiss gezahlte jährliche Honorar von 1200 Talern wurde aufgeteilt. Neben dem Gehalt an der Universität ${ }^{15}$ erhielt Rose 500 Taler und Beyrich 700 Taler. Dafür hatten

\footnotetext{
15 Das jährliche Gehalt an der Universität von Rose als Professor der Mineralogie betrug 400 Taler und von Beyrich als Gehilfe der Petrefaktensammlung 120 Taler.

${ }_{16}$ Bergexpektanten (auch Bergbeflissene) waren Personen, die sich in Ausbildung auf die staatliche Berglaufbahn befanden. Soweit sie bereits Staatsdiener waren, wurden sie bisher Bergeleven und Bergkadetten genannt.
} 
sie dem Personenkreis der Bergexpektanten ${ }^{16}$ die Teilnahme an den Vorlesungen und Übungen kostenlos zu gestatten, ebenso auch den Zugang zu den Sammlungen. Beyrich zeigte sich für die Zusammenarbeit mit der Bergbehörde sehr aufgeschlossen, weit mehr als dies bei Weiss der Fall gewesen war. Unter ihm wurde die Ausbildung in Geologie deutlich belebt. Er führte erstmals einwöchige Exkursionen ein und erreichte es, dass die Exkursionsteilnehmer von der Bergbehörde finanziell unterstützt wurden. Die erste Exkursion hatte den Harz zum Ziel und fand zu Pfingsten 1857 statt $^{17}$.

\section{Wiederentstehen der Bergakademie}

Bei der Überführung der Ausbildung von der Bergakademie an die Universität im Jahre 1810 war von der Bergbehörde das sogenannte Bergeleveninstitut mit Bergelevenkasse geschaffen worden, das für die Koordinierung und Finanzierung der Bergelevenausbildung an der Universität zu sorgen hatte und als Unterstützungskasse der Bergeleven diente. Später wurden auch Lehrveranstaltungen technischer Art, die sich im Rahmen der Universität nicht abdecken ließen, direkt von ihr eingerichtet. Mit der fortschreitenden Spezialisierung des Berg- und Hüttenwesens machte sich jedoch eine Neuordnung und straffere Leitung der Ausbildung notwendig. Hierfür wurde im Jahre 1860 die Berliner Bergakademie erneut gegründet (GSTAB-35) ${ }^{18}$. Stationiert wurde sie im ehemaligen Gebäude der Berliner Börse in der Nähe des Berliner Doms, wo entsprechende Räume für Lehrveranstaltungen einschließlich Laboratorien eingerichtet wurden. Auf die Ausbildung in Mineralogie und Geologie hatte dies zunächst noch keine wesentlichen Auswirkungen. Es verblieb bei der bisherigen Regelung mit den beiden Professoren Rose und Beyrich, deren Vorlesungen weiterhin im Universitätsgebäude stattfanden, zumal sich die für die Ausbildung benötigten Sammlungen dort befanden. Die Bergakademie begann aber nun, eigene Sammlungen von Lehrmaterialien aufzubauen, so dass sich allmählich Änderungen zeigten $^{19}$. Diese deuteten sich auch dadurch an, dass von Privatdozenten der Universität (s. u.) zum Teil Lehrveranstaltungen angekündigt wurden, die sie in den Räumen der ehemaligen Börse abhielten.

Die Zusammenarbeit Beyrichs mit dem Bergwesen gestaltete sich auch weiterhin sehr positiv. $\mathrm{Zu}$ dem Direktor der Bergakademie, Bergrath Wilhelm Hauchecorne (1828-1900), entstand ein enges Vertrauensverhältnis, was sich darin äußert, dass Beyrich den Kultusminister am 27. 4. 1867 bat, mit Hauchecorne eine Übereinkunft über seine künftige Tätigkeit in der in Gründung stehenden preußischen Landesanstalt abschließen zu dürfen (GSTAB-36, Bl. 216): Der Minister stimmte dem zu und auch dem Antrag Beyrichs, seine gesamten, im Rahmen der Universität abzuhaltenden Vorlesungen in die Wintersemestern zu legen und die Sommersemester davon frei zu halten (GSTAB-36, B1. 226) ${ }^{20}$. Vor allem sollte Beyrich dadurch die Leitung der geologischen Kartierungsarbeiten in Preußen ermöglicht werden, die dieser als Ergebnis einer am 9. März 1867 stattgefundenen Konferenz norddeutscher Geologen, an der 13 maßgebliche Personen beteiligt waren, übernommen hatte (GSTAB-36, B1. 219) ${ }^{21}$.

\section{Weitere Lehre}

Neben Rose und Beyrich hielt, wie schon seit 1843 unter Weiss, der Chemiker und Mineraloge Karl Friedrich Rammelsberg am Mineralogischen Museum Vorlesungen über die chemischen Grundsätze der Metallurgie und die chemischen Grundlagen der Geologie. Er war am Berliner Gewerbeinstitut und an der Universität als Professor der Chemie tätig und hatte bereits 1846 bei der Bergbehörde die Errichtung eines Laboratoriums für metallurgische Chemie und Hüttenkunde durchsetzen können.

Außerdem trat der Geologe Justus Roth seit 1862 mit Vorlesungen auf, die er "Allgemeine Geologie“ oder auch nur „Geologie“ nannte und

\footnotetext{
17 Einzelheiten dazu verzeichnet Krusch 1904, S. XLV.

18 Die Erinnerung an die erste Gründung von 1770 war weitgehend in Vergessenheit geraten, so dass das Ereignis von 1860 nicht als Wiedererrichtung, sondern als Gründung galt, was erst von Krusch (1904) aufgrund eingehender Aktenstudien richtig gestellt wurde.

${ }_{19}$ Größere Auswirkungen traten erst nach Errichtung des Neubaus für die Preußische Geologische Landesanstalt und die Bergakademie im Jahre 1878 ein (siehe nächstes Kapitel).

20 Diese Regelung nahm Beyrich vom Sommersemester 1868 bis in sein letztes Lebensjahr unverändert in Anspruch.

21 Beyrich erhält danach von der Bergbehörde ein Jahresgehalt von 1500 Talern, wofür jedoch die bis dahin von der Bergbehörde gezahlten 500 Taler als Dozent und 300 Taler als Kustos der Mineraliensammlung der Bergakademie bei Beibehaltung dieser Leistungen entfallen.
} 
las ferner über Vulkane und vulkanische Erscheinungen und auch einmal über ausgewählte Kapitel aus der Geschichte der Geologie. Offenbar fügte er sich gut in das Lehrkonzept von Rose und Beyrich ein und ergänzte es in allgemein geologischer Hinsicht. $\mathrm{Zu}$ seinem Werdegang sei gesagt, dass Roth erst spät zu den Geowissenschaften kam, nachdem ihn sein ursprünglicher Apothekerberuf nicht befriedigt hatte. Da er als Apothekenbesitzer hinreichend vermögend war, um keine Anstellung anstreben $\mathrm{zu}$ müssen, konnte er sich auch auf dem Gebiet der Petrographie in geologischer und chemisch-mineralogischer Hinsicht bilden und habilitierte sich im Jahre 1861. Seit 1867 trat er als a. o. Professor auf (AHUB-1) ${ }^{22}$ und wurde, wie im nächsten Kapitel behandelt wird, 1875 im Mineralogischen Museum beamtet. Schließlich trat noch der Professor an der Landwirtschaftlichen Hochschule Albert Orth mit Vorlesungen auf und las im Jahre 1872 über Verwitterung und Bodenbildung und über die Anfertigung von geognostisch-agronomischen Karten.

Außerdem wurden seit 1867 Vorlesungen am Mineralogischen Museum auch von Privatdozenten gehalten, die am Anfang einer erstrebten akademischen Laufbahn standen und zum Teil auch zugleich Assistenten waren. Da ihre Lehrveranstaltungen meist speziellere Themen der Mineralogie oder Geologie als die Vorlesungen von Rose und Beyrich hatten, entstand eine Vielfalt der Lehre, die es bisher nicht gegeben hatte. Auf dem Gebiet der Mineralogie waren dies Adolf Remelé (in den Jahren 1867 bis 1869) mit Vorlesungen über Mineralanalyse und über chemische Mineralogie, Hugo Laspeyres (1867 bis 1870) über Petrographie und über gesteinsbildende Minerale, Alexander Sadebeck (1870 bis 1872) über bestimmende Kristallographie, über die Beziehungen zwischen Form und Inhalt der Minerale, über volkswirtschaftlich wichtige Mineralstoffe, über Geschichte und Beschaffenheit der Edelsteine, über technisch wichtige Fossilien und über die mineralogische Topographie Deutschlands, Paul v. Groth (1871 bis 1872) über Allgemeine und Spezielle Mineralogie und über Allgemeine Geognosie und Lagerstätten der Minerale, sowie Max Bauer (1873 bis 1875) über nutzbare Minerale und deren Lagerstätten, über die Elemente der Mineralogie und Geologie und fünfstündig über Mineralogie. Auf geologischpaläontologischem Gebiet waren es die Privatdozenten Albert Kunth (1870) über die Kreideformation Norddeutschlands, Karl Lossen (ab 1870 ) über die Lehre von den Gesteinen (Petrographie) und Emanuel Kayser (1872 bis 1885) über Allgemeine Geologie.

\section{Wissenschaftliche Assistenten}

Abgesehen von der Petrefaktensammlung, die selbstständig von Beyrich betreut wurde, stand dem Direktor für die Arbeit in den Sammlungen ein Assistent zur Seite. Dies war zunächst der schon unter Weiss eingetretene Student Daniel Krull, der aber im Jahre 1859 verstarb. Als seinen Nachfolger wählte Rose, zunächst als wissenschaftlichen Hilfsarbeiter, Hermann Wilhelm Vogel aus, der zuvor Assistent im chemischen Laboratorium des Berliner Gewerbeinstituts bei Professor Karl Rammelsberg war. Er hatte sich besonders der Photochemie zugewandt und erstmals auch photographische Aufnahmen am Mikroskop nach einem von ihm angegebenen Verfahren ausgeführt (Kirchheimer 1982). Rose ermöglichte es ihm, neben seinen Aufgaben als Assistent im Jahre 1863 in Göttingen mit einer Dissertation zu promovieren, die die erste wissenschaftliche Arbeit zur Photographie darstellte $^{23}$, und konnte ihn dann zum Assistenten aufrücken lassen. Vogel wurde 2 Jahre danach als Professor der Photochemie an das Berliner Gewerbeinstitut berufen, an dem er schon ab 1864 Vorlesungen gehalten hatte. Ihm folgte im März 1865 der Mineraloge Alexander Sadebeck, der in Breslau studiert hatte. Dieser blieb bis 1872 und folgte dann einem Ruf als Professor der Mineralogie und Geologie nach Kiel, von wo aus er nach dem Tode von Rose den Katalog der mineralogischen Schausammlung des Mineralogischen Museums Berlin herausgab (Rose \& Sadebeck 1874). Nach seinem Weggang trat Max Hermann Bauer ein, der in Tübingen promoviert hatte und danach Privatdozent in Göttingen gewesen war. Er wurde auch in Berlin Privatdozent, folgte aber bereits 1875 dem Ruf nach Königsberg als Professor der Mineralogie (anschließend in Marburg). Einen zusätzlichen $\mathrm{Ge}$ hilfen gab es ab 1867 für die Petrefaktensammlung. Es war Albert Kunth, der 1863 mit einer

\footnotetext{
22 Asen (1955) gibt für die Berufung von Roth zum a. o. Professor das Jahr 1869 an.

23 Mit dieser Publikation (Vogel 1873) begann H. W. Vogel seine intensive Publikationstätigkeit über photochemische und photographische sowie spektralanalytische Themen.
} 
geologischen Dissertation in Berlin promoviert hatte und 1870 als Privatdozent auftrat. Er verstarb am 22.1.1871 an einer Kriegsverwundung $^{24}$. An seine Stelle als Assistent trat danach Wilhelm Dames, der im Mineralogischen Museum eine lange Karriere vor sich hatte, wie in den folgenden Kapiteln gezeigt wird.

\section{Die Entwicklung der Sammlungen}

Der Sammlungsbestand des Mineralogischen Museums geht auf das Mineralienkabinett der preußischen Berg- und Hüttenverwaltung und der Bergakademie zurück, das bei der Universitätsgründung im Jahre 1810 insgesamt übernommen worden war (Hoppe 1999, 2001a). Nach Rose (1860) besaß die Sammlung folgende Abteilungen: 1.) die systematisch-mineralogische Sammlung, 2.) die Sammlung größerer in Glasschränken aufgestellter, ebenfalls systematisch geordneter Stücke (sogenannte Prachtsammlung), 3.) die Kristallsammlung, 4.) die Meteoriten, 5.) die systematisch-geognostische Sammlung und 6.) die geographische Sammlung oder die geognostischen Sammlungen einzelner Länder. Man erkennt hieraus, dass ihre Einteilung noch im wesentlichen die gleiche ist, wie die der Bergakademie, die von D. L. G. Karsten nach den von Abraham Gottlob Werner aufgestellten Prinzipien geordnet worden war (Hoppe 1999, S. 13).

Obwohl die Ausbildungsfunktion der ehemaligen Bergakademie auf die Universität übertragen worden war, stand der Etat des Berg- und Hüttenwesens für Sammlungskäufe nicht mehr zur Verfügung. Von da an war die Erweiterung der Sammlungsbestände neben der eigenen Sammeltätigkeit auf den Etat der Universität, auch gegebenenfalls auf Sondermittel des Dispositionsfonds des Königs, worauf Alexander v. Humboldt als Kammerherr des Königs großen Einfluss hatte, und auf Schenkungen angewiesen. Die Bestände waren so erheblich angewachsen und die ursprünglich reichlich bemessenen Raumreserven dadurch weitgehend aufgebraucht ${ }^{25}$.
Dennoch wurden die Sammlungsbestände weiter vervollständigt, wenn auch in geringerem Umfang, da Zuschüsse aus zentralen Fonds nach dem Tod des großen Fürsprechers A. v. Humboldt $(\dagger 1859$ ) weit schwieriger zu erhalten waren. So gelang es zum Beispiel zunächst nicht, die Sammlung fossiler Tier- und Pflanzenreste des Lithographenschiefers aus dem Nachlass des Arztes Hugo Redenbacher in Hof, die $4000 \mathrm{Ta}-$ ler kosten sollte, zu erwerben, obwohl sich der Kultusminister 1864, gestützt auf ein Gutachten von Beyrich, beim Finanzminister eindringlich um die Mittel bemühte (GSTAB-29, Bl.250). Immerhin ist den Akten zu entnehmen, dass $\mathrm{Zu}$ schüsse zu kleineren Käufen gewährt wurden, so 400 Taler für den Ankauf eines ungewöhnlich großen Topaskristalls von Nertschinsk im Ural (GSTAB-29, Bl. 116). Der gleiche Betrag wurde genehmigt für eine Auswahl der Unterharzer Erzminerale aus der Sammlung des verstorbenen Bernburger Oberbergrats J. C. L. Zincken, die dessen Schwiegersohn Karl Rammelsberg angeboten hatte (GSTAB-29, Bl. 195). Auch ein Pterodactylus-Fund von Eichstätt konnte erstanden werden, sowie schließlich doch die Redenbachersche Sammlung, jedoch auf zwei Raten auf 1866 und 67 aufgeteilt (GSTAB-30, Bl. 34). Der Kauf einer Bernsteinsammlung von 6000 Stück mit vielen Inklusen des verstorbenen Sanitätsrates Dr. Carl Berendt wurde noch von Rose eingeleitet, aber erst 1873 nach seinem Tode mit einem Kaufpreis von 4500 Mark abgeschlossen (GSTAB-31, Bl. 3).

\section{Aussicht auf einen Museumsneubau}

Die Raumnot im Universitätsgebäude war durch Ausweitung der meisten Lehrfächer und durch die überfüllten Museen der Mineralogie und Zoologie allmählich sehr groß geworden. Gegen Ende der Lebenszeit Roses verdichtete sich aber die Hoffnung auf die Lösung der Raumprobleme der Universität durch Errichtung eines Neubaus für die naturkundlichen Museen. Sogleich entstand in den Museen aber auch die Sorge um die

\footnotetext{
${ }^{24}$ Kunth hatte bereits den Krieg von 1866 mitgemacht und die Cholera danach überstanden. Jedoch erlitt er am Beginn des deutsch-französischen Krieges 1870/71 bei dem verlustreichen Angriff auf die Spicherner Höhen am 6. August 1870 eine Verwundung am Fuß, die nicht sogleich hinreichend versorgt wurde. Nach langem Krankenlager in Rüdesheim wurde er im Barackenlazarett auf dem Tempelhofer Feld in Berlin operiert und verstarb dort am Lazarettfieber (Hohn 1952).

${ }_{25}$ Um innere Reserven nutzbar zu machen, war zum Beispiel ein auf vier Tischen aufgestelltes großes Reliefmodell der Schweizer Alpen an der Wand aufgehängt worden. Man erfährt dies aus den Akten allerdings nur deshalb, weil zur Veräußerung der Tische eine Genehmigung beim Ministerium eingeholt werden musste (GSTAB-29, BI. 199). - Das Reliefmodell stammte noch aus der Naturalienkammer des Berliner Schlosses, für die es um 1805 von dem Schweizer Modellbauer Müller erworben worden war. Frau Dr. M. Wyder, Zürich, wird für die freundliche Mitteilung gedankt.
} 
Mitsprache bei der Planung eines solchen Baues. Da die Bedürfnisse „dem Vernehmen nach“ zwar von Rektor und Senat dem Ministerium vorgetragen worden waren, aber ohne die Direktoren der zwei naturkundlichen Museen hinzuzuziehen, traten die beiden Direktoren, der Zoologe Professor Wilhelm Peters (1815-1883) und sein mineralogischer Kollege Rose, mit einem gemeinsamen ausführlichen Schreiben an den Kultusminister heran (GSTAB-30, B1. 248, vom 10. 5. 1873). Hierin stellten sie nach Ausführungen über Entstehung, Bedeutung und Wert der beiden Museen deren räumlichen Bedürfnisse dar und leiteten ihren Anspruch, gehört zu werden, davon ab, dass ihre beiden Museen im Gegensatz zu den Kunstmuseen im Ministerium nicht durch einen speziellen sachverständigen Rat vertreten wurden, und dass sie deshalb glaubten, selbst die Belange der Museen vertreten zu müssen. Sie legten dabei besonderen Wert darauf, dass der Zuschnitt der beiden Museen von Anfang erheblich groß gewesen ist, da sie nicht nur als bloße Universitätsmuseen, sondern für allgemeine Nutzung bestimmt waren, und dass daher ihr Quartier im Universitätsgebäude bei deren Gründung im Jahre 1810 unter besonderer Berücksichtigung des künftigen Raumbedarf bemessen worden war. Sie verwiesen schließlich auf die erheblichen Größen des neuerbauten Museums für Zoologie und Mineralogie in Wien und des in Aufbau befindlichen in London. - Der Eindruck, den dieses Schreiben bei dem Kultusminister Falk ${ }^{26}$ erzeugt hat, lässt sich jedoch leicht aus der lakonischen Antwort, es sei zur Kenntnis genommen (GSTAB-30, Bl. 260, vom 4. 7. 1873), entnehmen.

\section{Würdigung von Gustav Rose}

Kurz nach dem letztgenannten, gemeinsamen Vorstoß beim Minister starb Gustav Rose am 15. 7. 1873 im Alter von 75 Jahren. Er war dem Mineralogischen Museum der Universität Berlin vom Beginn seines Studiums eng verbunden und hat ihm von seiner Anstellung als Gehilfe im Jahre 1822 an 51 Berufsjahre angehört, die letzten 18 Jahre als sein Direktor. In dieser langen Zeit hat er wissenschaftlich bedeutende Leistungen erbracht, von denen bereits im 4 . Teil dieser Artikelserie (Hoppe 2001b) die frühen Arbeiten Roses behandelt wurden, darunter die ergebnis- reichen Studien im Zusammenhang mit Alexander v. Humboldts russischer Forschungsreise (Rose 1837/42, Hoppe \& Suckow 2003). Als seine nachhaltigste Leistung muss man sein ,kristallochemisches Mineralsystem“ (Rose 1852) bezeichnen. Bis in seine letzten Jahre hinein konnte er seine Aktivität fortsetzen. Ein Drittel seiner zahlreichen Publikationen brachte er heraus, nachdem er im Alter von 58 Jahren Direktor des Mineralogischen Museums geworden war, darunter so bedeutende, wie die Abhandlung über die Polymorphie des $\mathrm{CaCO}_{3}$ (Rose 1857/9), seine Meteoritensystematik an Hand der Berliner Meteoritenbestände (Rose 1863) und seine posthum erschienene große Diamantabhandlung (Rose 1876). Roses Hauptgebiet war die Spezielle Mineralogie. Er strebte bei seinen Arbeiten an Mineralen und Mineralgruppen eine Synthese der auf exakten Untersuchungen und Messungen beruhenden chemischen, physikalischen und kristallographischen Standpunkte an.

Seine Publikationen zeigen, dass er die damals neuesten Methoden schnell aufgriff und anwandte. Dazu gehörte vor allem die Anwendung des Mikroskopes, dessen Nutzen er durch seinen Kollegen bei der russischen Reise Alexander v. Humboldts, Christian Gottfried Ehrenberg (1795-1876), für die Untersuchung von Stäuben kennengelernt hatte. Dies erweiterte er zur mikroskopischen Untersuchung dünngeschliffener Minerale und Gesteine, die auf seine Anregung hin von dem Berliner Privatgelehrten Dr. phil. Adolph Oschatz nach 1850 hergestellt wurden (GSTAB-37) (Rose 1856, Groth 1926, S. 191). Auch das Verfahren des sogenannten Selbstdruckes zur Abbildung der geätzten Oberfläche opaker Minerale wandte Rose bei einem Eisenmeteoriten an (Rose 1851). Er konnte dies jedoch ganz erheblich verbessern, obwohl die direkte Mikroskopie von reflektierenden Oberflächen noch nicht möglich war, indem er mittels Hausenblasen gefertigte, durchsichtige Abdrucke der Oberfläche mit dem normalen Durchlichtmikroskop untersuchte. Bald danach konnte er die Hilfe seines Assistenten $\mathrm{H}$. Vogel nutzen, der mit einer neuen Vorrichtung erste photographische Aufnahmen am Mikroskop anfertigte (Vogel 1862, Rose 1862). Allerdings verwandte Rose die erhaltenen Mikrophotographien noch nicht direkt zum Druck, sondern zeichnete sie um. Alles das setzte Rose für seine große Meteoritenabhandlung

\footnotetext{
26 Adalbert Falk (1827-1900), Kultusminister von 1872 bis 1879, enger Mitarbeiter von Bismarck bei dessen Bestrebungen zur Trennung von Kirche und Staat.
} 
(Rose 1863) ein, die auf dem Studium aller Objekte der Meteoritensammlung des Mineralogischen Museums basierte. Sie ist grundlegend geworden durch die Systematik der Meteorite und durch Aufstellung von Begriffen, die sich bis heute in der Meteoritenkunde erhalten haben, wie zum Beispiel der Name Chondrite für Steinmeteorite mit typischen kugeligen Strukturen.

Roses bescheidenes Wesen verschaffte ihm viele Freundschaften. Bereits in der Studienzeit war die Freundschaft mit dem Chemiker Eilhard Mitscherlich (1794-1863) entstanden, als dieser bei den Arbeiten, die zur Entdeckung der Isomorphie führten, kristallographische Hilfe brauchte und Rose sie ihm ganz uneigennützig gewährte. Diese Freundschaft hielt das ganze Leben, auch als Mitscherlich seine Interessen später auf geologisch-mineralogische Phänomene, wie Vulkane, ausdehnte. Roses Nachruf auf Mitscherlich ist das Dokument dieser Freundschaft (Rose 1864). Das gestörte Verhältnis zu seinem Lehrer und späterem Kollegen Weiss, das in
4. Teil dieser Artikelserie besprochen ist, trübt das Bild von Roses Charakter nicht und geht ganz zu Lasten von Weiss, der argwöhnte, Rose wolle ihn verdrängen. Es war zweifellos Roses Langmut zu verdanken, dass es nicht zu einem wirklichen Bruch gekommen ist. Schließlich ist zum Verhältnis Roses zu Alexander v. Humboldt noch zu ergänzen, dass Rose bis in die letzten Lebenstage Humboldts geduldige Zuarbeit für dessen großes Werk Kosmos geleistet hat, was aus den letzten Textseiten und dem letzten Zitat des unvollendeten 5. Bandes dieses Werkes hervorgeht. Die zahlreichen Stimmen von Schülern und Fachgenossen sind voller Hochachtung vor Roses Person und seiner Leistung, als Beispiel wird auf den Nachruf seines Schülers und Schwiegersohns Gerhard vom Rath hingewiesen (v. Rath 1873). Ein besonders ehrenvolles Denkmal hat ihm Paul Groth, der sich als sein Schüler bekannte, an zahlreichen Stellen seiner „Entwicklungsgeschichte der mineralogischen Wissenschaften“ (Groth 1926) gesetzt ${ }^{27}$.

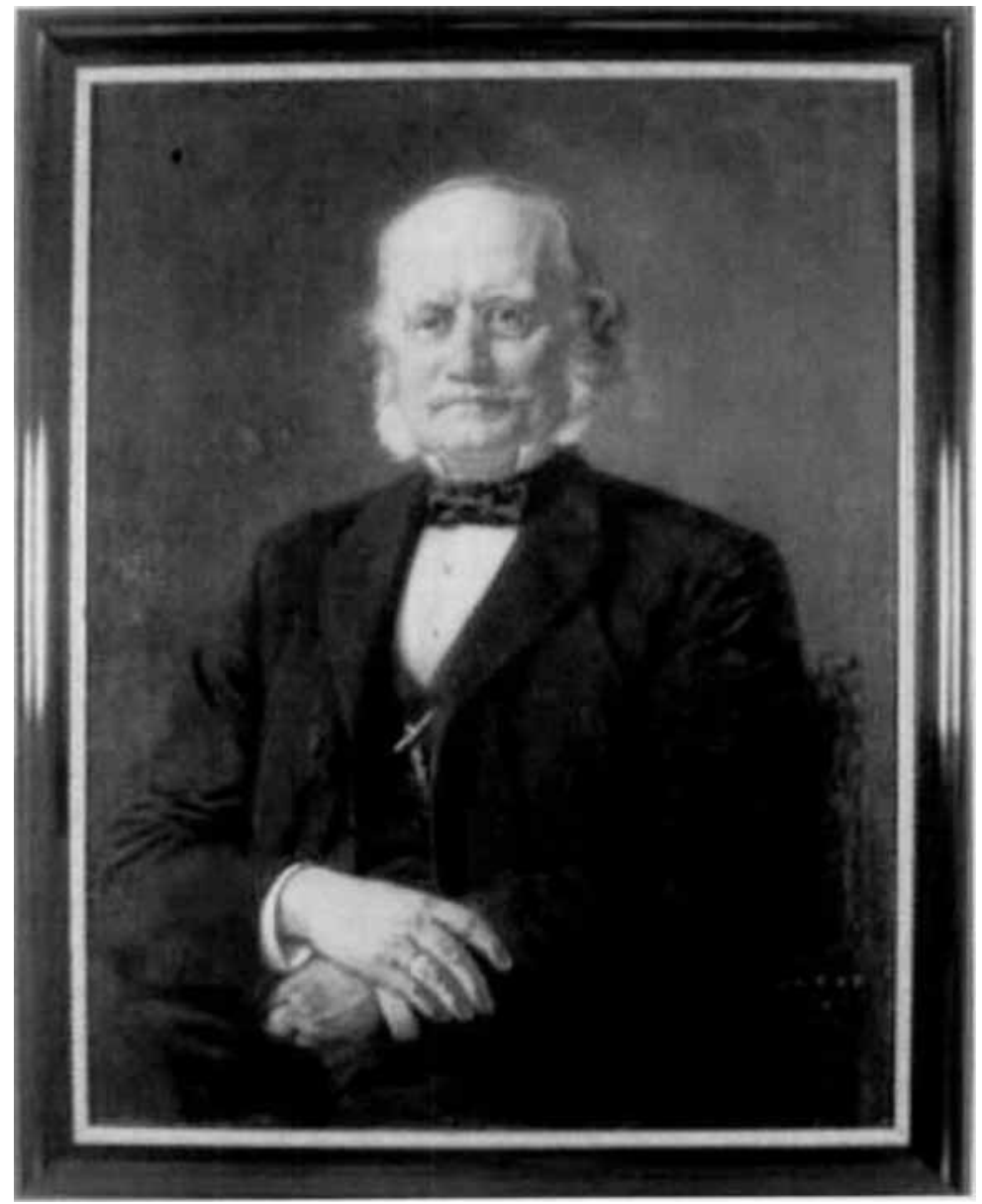

Abb. 3. Ernst Beyrich (1815-1896). Original im Museum für Naturkunde, HHMfN-8, Sign. B-VII/ 4.

\footnotetext{
27 Leider ist der handschriftliche Nachlass von Gustav Rose beim Brand des Bonner Mineralogischen Institutes im 2. Weltkrieg, wohin das Material durch den Schwiegersohn Roses, den Bonner Professor der Mineralogie Gerhard vom Rath (1830-1888), gekommen war, vernichtet worden.
} 
Das Mineralogische Museum unter den Direktoren Ernst Beyrich und Martin Websky bis zur Teilung in zwei Institutionen (1873 bis 1888)

\section{Leitung und Struktur}

Die Leitung des Mineralogischen Museums wurde nach dem Tode von Gustav Rose dem bisherigen 2. Direktor, Ernst Beyrich (Abb. 3), übertragen (GSTAB-30, B1. 261). Damit erhielt erstmals der Vertreter der paläontologischen Richtung die Leitung der Institution, die aber weiterhin den Namen Mineralogisches Museum behielt. Zum Nachfolger von Rose als Mineralogen wurde Martin Websky berufen, der seit 1868 als a. o. Professor an der Universität Breslau tätig war und sich dort unter dem Mineralogen und Geologen Ferdinand Roemer mineralogisch und kristallographisch betätigt hatte (Völkel 2002). Auf Bitten Roemers hatte er als unbeamteter Privatdozent bzw. a. o. Professor ehrenamtlich während mehrerer Jahre (1867-72) für das Breslauer Institut eine systematische Mineralsammlung aufgebaut (GSTAB-51). Seine Berufung als o. Professor der Mineralogie nach Berlin erfolgte am 15. 4. 1874. Zwei Monate danach entschloss sich das Ministerium, den beiden Professoren, Beyrich und Websky, gemeinsam die Leitung des Mineralogischen Museums zu übertragen. Beyrich als 1. Direktor war für die Petrefakten-Sammlung und für die allgemeine Geschäftsführung zuständig, Websky als 2. Direktor für die mineralogischen Sammlungen. Außerdem sollte die Stelle eines „dritten Beamten “ für die petrographische Sammlung geschaffen werden (GSTAB-31, Bl. 101). Beyrich drängte darauf, dass die Petrefakten-Sammlung, die bisher gegenüber den übrigen Sammlungen des Mineralogischen Museums sehr zurückstand, im kommenden Etat wesentlich größere Mittel erhielt (GSTAB-31, B1. 126, 151), während Websky seine Vorstellungen über finanzielle Notwendigkeiten vorwiegend von solchen Vorhaben ableitete, die die Gefahr der Vertauschung der mineralogischen Sammlungsstücke bei dem bevorstehenden Transport der Sammlung durch Unterbringung der Stücke in hinreichend großen Pappkästchen ${ }^{28}$ und durch Anbringung von Aufklebern vermindern sollten. Hierfür waren wegen der sehr großen Anzahl der Stücke nicht unerhebliche Gelder erforderlich (GSTAB31, Bl. 128). Das Ministerium setzte die neue Struktur des Museums am 30.11.1874 in Kraft und legte fest, dass Justus Roth als „dritter Be- amter" die Leitung der petrographischen Sammlung, die bisher zu den von Websky zu verwaltenden Sammlungen gehörte, erhalten soll (GSTAB31, B1. 137), was dann im April 1875 vollzogen wurde. Roth war bisher nur mit Lehraufgaben als a. o. Professor betraut gewesen und hatte hierfür seine mit großer Sorgfalt angelegte Privatsammlung zu Demonstrationen benutzt (Liebisch 1893, S. 5). Als Verwalter einer staatlichen Sammlung durfte er nun keine private Sammlung der gleichen Art besitzen. Er gab sie deshalb, wie er dem Ministerium versicherte, sogleich an die Universität Königsberg ab (GSTAB-31, B1. 209) und baute eine neue Lehrsammlung auf.

\section{Beziehung zur Geologischen Landesanstalt}

Zur Tätigkeit von Beyrich ist zu ergänzen, dass er seine enge Zusammenarbeit mit der Bergakademie und darüber hinaus mit der preußischen Bergbehörde noch weiter festigte. Mit Billigung des Kultusministeriums nahm er das Amt des 2. Direktors der 1873 gegründeten preußischen Geologischen Landesanstalt an, in das er am 2. Juli 1875 eingesetzt wurde. Erster Direktor wurde der Direktor der Bergakademie Berlin, Oberbergrat Wilhelm Hauchecorne, mit dem Beyrich schon länger eng zusammengearbeitet hatte (GSTAB-35).

\section{Neubauplanung}

Mit vorigem war die Errichtung des Gebäudes für die preußische Geologische Landesanstalt und Bergakademie auf dem aufgelassenen Gelände der königlichen Eisengießerei am damaligen nördlichen Stadtrand von Berlin ursächlich verbunden und damit auch die Planungen für den Neubau des Gebäudes der naturkundlichen Museen der Universität, das ebenfalls auf diesem Baugelände entstehen sollte. Während der Bau des erstgenannten Gebäudes im Jahre 1875 begonnen und 1878 beendet wurde, zog sich die Projektierung des Museums infolge langwieriger Auseinandersetzungen mit den Vorstellungen des Architekten sehr lange hin, so dass der Bau erst 1883 begonnen und 1889 beendet wurde. In der gesamten Zeit beteiligten sich die Direktoren des Mineralogischen Museums an Beratungen und Diskussionen, worauf aber zunächst nicht eingegangen wird, da hierfür das nächst folgende Kapitel vorgesehen ist.

\footnotetext{
${ }^{28}$ Die meisten Stücke lagen bis dahin auf weit kleineren Pappkästchen oder zum Teil sogar lose in den Schubladen.
} 


\section{Lehre}

Die Lehre am Mineralogischen Museum wurde getragen von dem Geologen und Paläontologen Beyrich, der wie zuvor nur in den Wintersemestern las, dem neuberufenen Mineralogen Martin Websky und dem nun am Museum angestellten Geologen Justus Roth. Wesentliche Änderungen des Vorlesungsprofils ergaben sich nur dadurch, dass Websky die von Rose immer nur kurz vorgetragene Kristallographie als Hauptvorlesung behandelte und sie jeweils im Sommersemester, die Mineralogievorlesung im Wintersemester vortrug, außerdem noch kleinere Vorlesungen zur Lagerstättenkunde, über Edelsteine und Kristallzeichnen hielt. Beyrich behielt die Titel seiner Vorlesungen immer noch wie zuvor bei und las: "Geognosie mit besonderer Berücksichtigung des sogenannten Flötzgebirges" und "Versteinerungskunde", wovon er nur höchst selten abwich. Die Vorlesungen von Roth deckten das Zwischengebiet ab. Er hielt regelmäßig die von Websky nicht vorgetragene Vorlesung „Petrographie“ und seine „Allgemeine und chemische Geologie" ergänzte das Programm von Beyrich. Außerdem hielt der o. Professor der Chemie Karl Friedrich Rammelsberg, der nicht zum Lehrkörper des Mineralogischen Museums gehörte, auch in diesem Zeitabschnitt wieder eine Vorlesung über die chemischen Grundlagen der Geologie, allerdings nur noch bis 1879 , da er dann, im 66. Lebensjahr stehend, sein Betätigungsgebiet einschränkte ${ }^{29}$. Er kündigte zwar ab 1883 eine Vorlesung zur Einleitung in die Kristallographie an, richtete sie aber ausdrücklich an Chemiker.

\section{Weitere Lehre}

Wie auch schon zuvor traten eine Reihe von Privatdozenten als Vortragende auf. Einige davon hatten eine Stellung an der Bergakademie oder an der Geologischen Landesanstalt und kündigten ihre Vorlesungen, die sie in den Wintersemestern an der Bergakademie hielten, auch in der Universität an. Dazu gehörten der Geologe Karl Lossen, der weiterhin über Petrographie vortrug (seit 1880 auch mit mikroskopischen Demonstrationen), auch der Geologe Emanuel Kayser, der bis 1885 über Allgemeine Geologie und zuweilen auch über deutsche Devon Bildungen und über die geologische Entwicklungsgeschichte las und ferner der Mineraloge Hugo Bücking, der 1879 und 1880 über die mikroskopische Physiographie der petrographisch wichtigen Mineralien las. Auch der Paläontologe und Geologe Wilhelm Branco $^{30}$, der von 1881 bis 1887 als Privatdozent auftrat, war seit 1882 an der Geologischen Landesanstalt tätig. Er hielt regelmäßig paläontologische Übungen sowie 1886 auch Vorlesungen über Allgemeine Geologie, bevor er Lehrstuhlangebote, zunächst in Königsberg und dann anderwärts, annahm. Er kam später, wie noch behandelt wird, zurück. Ferner trat noch der Geologe an der Geologischen Landesanstalt Felix Wahnschaffe als Privatdozent auf und hielt von 1886 an Vorlesungen über die Geologie des norddeutschen Flachlandes und über Bodenuntersuchungen. In diese Reihe gehört schließlich noch der Geologe Gottlieb Berendt, der 1875 als Landesgeologe an die Geologische Landesanstalt kam und im gleichen Jahr a. o. Professor an der Universität wurde, jedoch an der Universität keine Vorlesung ankündigte.

\section{Assistenten der paläontologischen Richtung}

Im paläontologischen Teil des Mineralogischen Museums stand dem Direktor Beyrich als Assistent Wilhelm Dames zur Seite, der bereits im Jahre 1871 eingetreten war und von da an ohne Unterbrechung am Mineralogischen Museum und später an der Nachfolgeinstitution tätig war. Er habilitierte sich und trat ab 1874 auch als Privatdozent auf. Wie im mineralogischen Teil des Museums wurde 1875 auch hier die Assistentenstelle in eine Kustodenstelle umgewandelt, die Dames bekam. Seine Vorlesungen betrafen die Geologie der norddeutschen Tiefebene, wozu er auch Exkursionen durchführte, besonders aber las er über fossile Wirbeltiere und über Leitfossilien, daneben auch über fossile Fische und über fossile Crustaceen. Er ergänzte dadurch die paläontologische Lehre ganz wesentlich, zumal er auch in den Sommersemestern las, in denen Beyrich regelmäßig pausierte. Ferner las er von $1887 / 88$ an auch über die erratischen Blöcke (Geschiebe) der norddeutschen Ebene. Zu seiner weiteren Tätigkeit, auch als Nachfolger von Beyrich, wird später berichtet. Neben dem Kustos Dames gab es erst ab 1884 noch einen weiteren Helfer, Ernst Koken, zunächst als Hilfs-

\footnotetext{
29 Im gleichen Jahr verkaufte er auch seine private Mineralsammlung an das Mineralogische Museum (s. unten).

30 Wilhelm Branco änderte ab Januar 1907 seinen Namen in Branca.
} 
assistenten. Er promovierte im gleichen Jahr und nach seiner Habilitation wurde er 1887 Privatdozent, und rückte 1888 auf eine neugeschaffene Assistentenstelle auf. Weiteres über ihn an späteren Stellen.

\section{Assistenten der mineralogischen Richtung}

Die am mineralogischen Teil des Mineralogischen Museums vorhandene Assistentenstelle war anfangs mit Max Bauer besetzt, der noch unter Rose eingetreten war. Er habilitierte sich 1873 und hielt Vorlesungen über die nutzbaren Minerale und deren Lagerstätten und eine Einführung in die Mineralogie, mit denen er die Lücke, die der Tod Roses gerissen hatte, bis zum Antritt von Websky überbrückte. Im Jahre 1875 folgte er der Berufung nach Königsberg. Websky bemühte sich daraufhin, an seiner Stelle Theodor Liebisch zu bekommen, der in Breslau, wo er sein Schüler gewesen war, 1874 promoviert hatte und vor kurzem nach Bonn gegangen war. Er kam sogleich und Websky übertrug ihm Arbeiten in der Sammlung, die der Vorbereitung zum späteren Umzug dienten (Liebisch 1910). Auch er habilitierte sich und las von 1878 bis 1879 eine Einführung in die Mineralogie, ferner über geometrische und physikalische Kristallographie, über die mikroskopische Physiographie der Minerale und über Messen und Zeichnen der Kristalle. Obwohl die Assistentenstelle bereits 1875 in die Stelle eines Kustoden umgewandelt wurde (GSTAB-31, Bl. 176) und also unbefristet sowie höher besoldet war, blieb er aber nur bis 1880 und folgte einem Ruf nach Breslau und danach an mehrere weitere Universitäten, um später nach Berlin zurückzukehren. Websky entschied sich dann für den bereits seit 1877 in Berlin als Privatdozenten tätigen Mineralogen Andreas Arzruni, der als Kustos eingestellt wurde. Er stammte aus Armenien und war zuvor bereits Assistent in Straßburg gewesen. Seine Vorlesungen behandelten die Kristallographie und Kristallchemie sowie die Mineralogie der Salze. Auch er blieb nicht lange in Berlin, sondern nahm 1883 einen Ruf nach Breslau an, von wo er aber bald danach zur Technischen Hochschule Aachen wechselte und dort bis zu seinem Tode als o. Professor der Mineralogie tätig war. Ihm folgte 1883 der in Göttingen promovierte Mineraloge August Tenne, der das Kustosamt bis zu seinem Tode im Jahre 1901 ausübte. Er habilitierte sich 1886 und hielt als Privatdozent Vorlesungen über gesteinsbildende Minerale. Websky gelang es 1886 wegen der dringenden Arbeiten vor dem Bezug des neuen
Hauses einen Hilfsassistenten, den Mineralogen Ludwig Henniges einzustellen, der bis zu Webskys Tod blieb. - Außerdem ist zu erwähnen, dass der seit 1885 als Privatdozent der physikalischen Chemie auftretende Andreas Fock von 1886 an Lehrveranstaltungen über Kristallographie ankündigte, die sich aber wohl vorwiegend an Chemiker richteten.

\section{Raumsituation}

Die höchst angespannte Raumsituation erleichterte sich 1879 ein wenig dadurch, dass die Räume der ehemals verloren gegangenen Dienstwohnung von Weiss durch den Auszug des Physikalischen Kabinetts in den Neubau für das Physikalische Institut am Reichstagsufer frei wurden und nun wieder bezogen werden durften. Dadurch konnten dringend benötigte Studentenarbeitsplätze geschaffen werden, auch fanden die Reflexionsgoniometer zur Kristallvermessung, deren Anschaffung Websky im Zusammenhang mit seiner Berufung durchsetzen konnte (GSTAB-39, B1. 76), eine geeignete Aufstellung. Auch die paläontologische Sammlung profitierte davon. Allerdings gelang es Beyrich nicht, weitere durch den Auszug der Physik freigewordene Räume im Keller zu erhalten.

\section{Entwicklung der Sammlungen}

Gegenüber der früheren Einteilung der Sammlungen war nur eine geringe Veränderung eingetreten. Es gab nun die Abteilungen: 1.) systematischmineralogische Sammlung, 2.) eine dazugehörige Schausammlung in größeren Exemplaren, 3.) Sammlung geschliffener Steine und Gebirgsarten, 4.) Meteoriten, 5.) systematisch-geognostische Sammlung, 6.) geographische Sammlung oder die geognostischen Sammlungen einzelner Länder, 7.) paläontologische Sammlung (Guttstadt 1886). Trotz bestehender Überfüllung der Räume schränkte man die Sammeltätigkeit und Käufe für die Sammlungen nicht ein und nahm die zunehmende Unübersichtlichkeit angesichts des in Aussicht stehenden neuen Quartiers in Kauf. Die folgenden kurz gefassten Darstellungen beruhen vor allem auf den Akten, die das Kultusministerium über das Mineralogische Museum geführt hat und berücksichtigen vor allem größere Sammlungsbeschaffungen. Daneben gab es aber zahlreiche, meist kleinere Beschaffungen durch eigene Aufsammlungen, Käufe aus dem Etat des Museums und Schenkungen, die sich nur zu einem kleinen Teil in den Ministeriumsakten niedergeschlagen 
haben, aber anderen Quellen zu entnehmen sind, wie den Jahresberichten ${ }^{31}$, den Berichten anlässlich des 100jährigen Universitätsjubiläums (Lenz 1910, darin Branca $1910^{32}$ und Liebisch 1910) und dem detaillierten Bericht von W. O. Dietrich (1960), der den überlieferten Bestand der paläontologischen Sammlung bevorzugt für die Beschaffungen zur Zeit Beyrichs dargestellt hat, ohne allerdings die hier benutzten Akten gekannt zu haben.

\section{Paläontologische Sammlung}

Unter Beyrich konnte die paläontologische Sammlung erheblich stärker als die mineralogische Sammlung ausgebaut werden. Es beginnt mit der im Jahre 1874 eingeleiteten Erwerbung einer Petrefaktensammlung, die Dr. v. Fischer, München, in Bayern und Österreich zusammengetragen hat. Sie wurde für $15000 \mathrm{fl}(25714,30$ Mark) in zwei Raten im November 1875 übernommen (GSTAB-31, B1.255), allerdings mussten daraus Stücke für Königsberg abgezweigt werden (GSTAB-38, Bl. 22).Dann folgte das nicht bei Dietrich (1960) erwähnte Vermächtnis von Otto Brandt vom 28.7.1874, das die Schenkung einer geologisch-paläontologischen Regionalsammlung des Gebietes um Vlotho an der Weser im Wert von 6-800 Mark darstellte (GSTAB-38, Bl. 106).

Im Jahre 1876 wurde die Sammlung „mikroskopischer Formen", das Lebenswerk des Professors Dr. Christian Gottfried Ehrenberg (17951876), für 30000 Mark gekauft. Hierbei wurde als besondere Vergünstigung am 26.5.1876 bewilligt, den Kaufbetrag mit Rücksicht auf den Gesundheitszustand in seiner Wohnung zu zahlen (GSTAB-38, Bl.60). Dies war genau einen Monat vor seinem Tode. Der berühmte mikropaläontologische Teil davon kam nach Dietrich (1960) allerdings erst 1907 in das Geologisch-paläontologische Institut und Museum. Dieser Teil ist deshalb so bedeutend, weil er die zahlreichen Originale von Mikroorganismen enthält, die Ehrenberg beschrieben hat. Die nächste große Erwerbung war im Jahr darauf der Ankauf der Petrefaktensammlung J. Th. van Brinckhorst, Maastricht, der nach einem Gutachten Beyrichs
(GSTAB-38, Bl. 246) vom 17. 5. 1878 zum halben Angebotspreis für $15000 \mathrm{fr}$ vollzogen werden konnte (GSTAB-39, Bl. 1).

Das Kultusministerium zeigte sich in dieser Zeit auch bereit, Forschungsreisen von Wissenschaftlern dadurch zu unterstützen, dass die von ihnen geschaffenen Aufsammlungen von Gesteinen und Versteinerungen für das Mineralogische Museum aufgekauft wurden ${ }^{33}$. Im Falle des Afrikaforschers Dr. Georg Schweinfurth (1836-1925) wurde dies 1878 für die Sammlung aus der ägyptischen Wüste für einen Betrag von 2000 Mark bereits zuvor in Aussicht gestellt (GSTAB-38, Bl. 164) und nach der Reise aufgrund von „Attesten“ des Paläontologen Dames und des Mineralogen Liebisch ausgezahlt (GSTAB-39, Bl. 62). Dagegen wurde die große asiatische Forschungsreise des Geographen Dr. Ferdinand Frh. v. Richthofen (1833-1905), speziell seine Erforschung Chinas in den Jahren 1868 bis 1872 , erst lange danach gefördert, indem die von ihm 1879 angebotene Belegsammlung zu seinem großen Reisewerk, das er von 1877 an herausbrachte, für die geforderten 20000 Mark (GSTAB-39, B1. 98) gekauft wurde. Nach einem Gutachten der Akademie der Wissenschaften kam ihr ein Wert von 32000 Mark zu (GSTAB39, Bl. 90). Die Genehmigung erfolgte, nachdem "Atteste" von den beiden Kustoden Dames und Liebisch über das Material vorgelegt worden waren (GSTAB-39, Bl. 98).

Im Jahre 1879 schien sich die Möglichkeit einer großen Erwerbung von Säugetier-Versteinerungen aus der Pampas-Formation von Südamerika anzukündigen. Nach Besichtigung des Materials in Italien empfahl Beyrich den Ankauf und veranschlagte einen Preis von 30-40000 Lire (GSTAB-39, Bl. 79). Das Angebot zerschlug sich jedoch durch anderweitigen Verkauf. Im Jahre 1884 gab es dann von Sanjago Roth ein erneutes Angebot einer ähnlichen Sammlung mit einer Forderung von 25000 Mark. Nun wurde Dames nach Genua gesandt. Aufgrund seines Gutachtens nebst Beschreibung der Sammlung setzte Beyrich den Preis auf 15000 Mark herab und beantragte im Februar 1885 die Mittel dazu (GSTAB-39, Bl. 295), jedoch kam auch dieser Kauf nicht zustande.

\footnotetext{
31 Diese Jahresberichte erschienen seit 1888 in der Zeitschrift „Chronik der Königlichen Friedrich Wilhelms-Universität zu Berlin“"

${ }_{32}$ Für den hier zunächst zu behandelnden Zeitraum sind die Angaben von Branca wenig aussagekräftig, da, wie Branca versichert (1910, S. 337), die nötigen Unterlagen oft „nicht mehr zu beschaffen“ waren.

${ }_{33}$ Dadurch gelangten solche Vorgänge in die Ministeriumsakten, was bei den zahlreichen unentgeltlichen Übergaben von Aufsammlungen nicht der Fall war.
} 
Die vorhandene Bernsteinsammlung konnte im Jahre 1887 bedeutend durch den Kauf der Sammlung Künow, Königsberg, für 15000 Mark vermehrt werden (GSTAB-40, Bl. 117).

\section{Kauf des „Urvogels“}

Der Kauf des „Urvogel“-Exemplars Archaeopteryx lithographica im Jahre 1880 bildete den absoluten Höhepunkt der Erwerbungen. Zu dem hohen wissenschaftlichen Wert als einzigartiges Bindeglied zwischen den Reptilien und Vögeln kommt noch die außerordentliche Seltenheit der Funde hinzu. Das hier zu besprechende Fundstück stammt von 1877 und ist das zweite Exemplar und übertrifft das erste an Aussagekraft bedeutend. Angesichts des hohen Wertes des Stückes erscheint es berechtigt, die Geschichte seiner Erwerbung etwas ausführlicher darzustellen ${ }^{34}$.

\section{Erstes Urvogel-Angebot}

Der erste Kontakt entstand durch die private Gesellschaft in Frankfurt a. M. mit dem anspruchsvollen Namen „Freies Deutsches Hochstift für Wissenschaften, Künste und allgemeine Bildung“, deren Vorsitzender im Jahre 1877 eine direkte Eingabe an Kaiser Wilhelm I., König von PreuBen, richtete. In ihr wurde darüber informiert, dass der erste Aufsehen erregende Fund eines Urvogels von 1861 sofort vom Britischen Museum für 15000 Mark gekauft worden war und so der deutschen Wissenschaft, obwohl er von deutschem Boden bei Eichstätt in Bayern stammt, nicht direkt zur Verfügung steht, sondern 1863 von Professor Richard Owen in England beschrieben wurde. Zum jetzigen, zweiten Fund hätte der Besitzer, Ernst Haeberlein in Pappenheim, bereits Kaufangebote bekommen, so vom Münchener Museum für 15000 Gulden (etwa 26000 Mark). Dies hätte Haeberlein jedoch zurückgewiesen, da er durch weitere Präparation die Schwanzfedern freigelegt hatte und der Fund dadurch weit vollständiger als der erste wurde, weshalb er den Preis auf 36000 Mark erhöht hätte. Auch für diesen Preis läge bereits das Interesse des Yale College in New Haven (Connecticut) vor und von Kennern würde vermutet, dass aus England und USA durchaus 100000 Mark geboten werden könnten. Deshalb hätte die oben genannte Gesellschaft, obwohl sie kein Vermögen besitzt, mit dem Eigentümer einen rechtskräftig gewordenen Kaufvertrag abgeschlossen, der das genannte Fundstück vorläufig für Deutschland sichert. Da die Aussichten, den Kaufpreis durch eine Spendensammlung aufzubringen, aber nur gering wären, gipfelte das Schreiben in einem Appell an den Kaiser, dieses Fundstück von unschätzbarem Wert zu Händen des Deutschen Reiches zu erwerben.

\section{Ablehnung des ersten Urvogel-Angebotes}

Die Frankfurter Gesellschaft war der Regierung in Berlin nicht unbekannt, da deren frühere Initiative zur Rettung und Erwerbung von Goethes Vaterhaus vom Kaiser finanziell unterstützt worden war, wodurch die Gesellschaft das Haus kaufen sowie ihren Sitz 1862 darin nehmen konnte. Die erneute Initiative veranlasste die Regierung in Berlin, sich der Seriosität der Gesellschaft und vor allem ihres „Obmanns" zu versichern und neben fachlichen Gutachten auch die Stellungnahme des Frankfurter Polizeipräsidenten Hergenhahn einzuholen. Der „Obmann“ (Vorsitzende) der Gesellschaft war Dr. Otto Volger genannt Senckenberg (1822-1897), der sich in Göttingen nach Studium und Promotion als Privatdozent auf dem Gebiet der Mineralogie, Geologie und Paläontologie betätigt hatte und nach mehreren Stationen schließlich 1856 Professor am Senckenberg-Institut in Frankfurt am Main geworden war. Im Jahre 1859 gründete er obige Gesellschaft, in der er seit 1860 Obmann war, und betätigte sich seitdem als Privatmann. In Hergenhahns und weiteren Gutachten wurde das Anliegen der Gesellschaft, den Fund dem Vaterland zu erhalten, um dessen in Aussicht stehenden Verkauf in ein ausländisches Museum zu verhindern, positiv beurteilt. Der Vorsitzende erhielt dagegen eine weniger günstige Einschätzung. Ihm wurden durch dubiose Geschäfte entstandene Schulden nachgesagt. Außerdem wurde berichtet, dass er sich vertraglich verpflichtet hatte, für die Stadt Frankfurt durch Ausbau von Brunnen die Trinkwasserversorgung der Stadt zu gewährleisten, was aber durch den Konkurs seines Unternehmens gescheitert war. Er war es, der den bis zum 23.2.1878 befristeten Kaufvertrag der Gesellschaft mit dem Besitzer des Urvogels, Ernst Häberlein, zum Kaufpreis von 36000 Mark zustandegebracht hatte, bei dessen unerfülltem Ablauf das Exemplar an Häberlein zurückfallen musste. Diese ermittelten Umstände

\footnotetext{
${ }^{34}$ Hierfür wurden vorwiegend die Akten des Kultusministeriums der Jahre 1877/78 und 1880/81 benutzt (GSTAB-38, B1 124-218 und GSTAB-39, B1. 111-208, jeweils mit Unterbrechungen).
} 
bewogen den preußischen Kultusminister A. Falk, die Ablehnung zu empfehlen, die der Kaiser und König daraufhin am 28.1.1878 vollzog.

\section{Endgültiger Kauf des Urvogels}

Zwei Jahre ruhte nun die Angelegenheit, danach änderte sich die Situation. Haeberlein, der Besitzer des Urvogels, legte am 16.3.1880 direkt, ohne Vermittlung durch die Frankfurter Gesellschaft, ein neues Angebot vor. Es betraf den Verkauf des Archaeopteryx-Exemplars zusammen mit einer Sammlung weiterer, zum Teil in Rahmen gefasster Versteinerungen aus dem Lithographenschiefer zu dem Gesamtpreis von 26000 Mark. Nach Besichtigung und Gutachten durch Beyrich zeigte sich das Kultusministerium bereit, die Mittel zu beschaffen und den Kauf zustande zu bringen. Nun aber erwies sich das Finanzministerium als entschiedener Gegner des Ankaufes, da man dort die vorigen Ablehnungsgründe nicht für ausgeräumt ansah. Unterdessen griff unter Vermittlung von Dames der Berliner Industrielle Dr. Werner Siemens (1816-1892) ein und ließ Beyrich am 5.4.1880 wissen, daß er bereit wäre, das Archaeopteryx-Exemplar für das Museum für Naturkunde dadurch zu sichern; dass er den Kauf (ohne die Beigaben) zunächst vollziehen und dem Ministerium eine Frist eines Jahres für die Aufbringung des Kaufpreises anbieten würde. Der Kultusminister R. v. Puttkamer $^{34 a}$ nahm dieses Angebot an, vermochte zwar den Finanzminister noch nicht zu überzeugen, konnte aber den Betrag von 6000 Mark für die Beigaben zum Archaeopteryx-Exemplar flüssig machen, wodurch Häberlein zunächst befriedigt wurde und abwartete. Aber auch mit einer Petition der Teilnehmer der Jahresversammlung der Deutschen Geologischen Gesellschaft vom 14. 8. 1880 mit 39 Unterschriften, in der auf die epochemachende Bedeutung des ArchaeopteryxFundes hingewiesen wurde, gelang dem Kultusminister der Durchbruch noch nicht. Erst als Virchow in einer Rede am 15.12.1880 im Abgeordnetenhaus ebenfalls die hohe Bedeutung des Archaeopteryx herausstellte und seine Stellung in der Entwicklung der Wirbeltiere als ein wissenschaftliches Problem ersten Ranges einschätzte, gab dies dem Kultusminister den Rückhalt, um am 29.12.1880 an den Finanzminister mit der Erklärung heranzutreten, „dass die Staatsregierung sich diesem Ankauf schlechterdings nicht entziehen kann, ohne schwere und meines unvorgreiflichen Erachtens wohlbegründete Vorwürfe wegen Vernachlässigung der deutschen wissenschaftlichen Interessen auf sich zu ziehen", woraufhin der Finanzminister einlenkte. Allerdings musste Siemens selbst dann noch gestatten, dass die Bezahlung des Kaufpreises auf zwei Jahresraten gestreckt wurde. Das kostbare Stück wurde dann vom Kustos a. o. Professor Wilhelm Dames nach weiterer Präparation eingehend untersucht und in einer grundlegenden Monographie umfassend dargestellt (Dames 1884) ${ }^{35}$.

\section{Dublettenabgabe}

Schon bei früheren Anlässen war vom Kultusministerium die Abgabe sogenannter Dubletten aus den Sammlungsbeständen verlangt worden. Dieses Thema entstand neu, als der frühere Kustos der mineralogischen Abteilung, Liebisch, nachdem er nach Greifswald berufen worden war, sich 1883 mit der Bitte an das Kultusministerium wandte, für das dortige wenig gut bestückte Mineralogische Institut, Leitfossilien und typische Gesteinsarten aus Berlin zu erhalten (GSTAB39, Bl. 241). Dem Antrag wurde statt gegeben und anscheinend war dies der Anstoß zum Start einer größeren Aktion des Ministeriums im Jahre 1884. Die paläontologische Abteilung des Mineralogischen Museums erhielt die Aufgabe, die Sammlung systematisch auf abgebbare Dubletten zu überprüfen. Dafür durfte der gerade promovierte Ernst Koken als Hilfsassistenten eingestellt werden. Dieser erarbeitete ein 16seitiges „Verzeichnis der gegenwärtig in der paläontologischen Abteilung des Mineralogischen Museums befindlichen Doubletten“ (GSTAB-40, B1.2), das vom Kultusministerium vervielfältigt und an eine groBe Zahl von Schulen versandt wurde. AnschlieBend wurden die von 34 Lehranstalten gewünschten Fossilien, meist zwischen 60 bis 150 Stück, verschickt, worüber Beyrich am 31.3.1886 berichtete. Koken, der das Unternehmen im wesentlichen bewältigt hatte, erhielt eine Remuneration von 500 Mark (GSTAB-40, Bl. 61).

\footnotetext{
34 a Robert v. Puttkamer (1828-1900) war von 1879 bis 1881 preußischer Kultusminister.

35 Die von Dames in seiner Publikation gegebene Darstellung der Erwerbungsgeschichte konnte durch Benutzung der Ministeriumsakten wesentlich ergänzt werden. - Dames erwähnt übrigens seine Rolle als Vermittler des Eingreifens von Siemens nicht.
} 


\section{Die mineralogischen Sammlungen}

Im Jahre 1876 beliefen sich die Bestände der von Websky verwalteten Sammlungen des Mineralogischen Museums auf 900 mittelgroße und 200 ungewöhnlich große Stücke in der Schausammlung, in der Hauptsammlung auf etwa 75000 Stücke in 1400 Schubkästen und in der geographisch geordneten petrographischen Sammlung auf etwa 40000 Stücke in 1500 Schubkästen (Liebisch 1910, S. 313). Letztere Sammlung, die geographisch geordnet war, wurde Roth übertragen und bildete einen Grundstock für den Aufbau der von ihm beabsichtigten petrographischgeologischen Lehrsammlung.

Eine bedeutende Schenkung für die mineralogische Sammlung gab es im Jahre 1878. Der geographisch-geologische Forschungsreisende Dr. Wilhelm Reiss (1838-1908) übergab seine in den Anden Kolumbiens und Ecuadors aufgesammelten vulkanischen Gesteine. Dies war so umfangreich, dass dafür neun Schränke angeschafft werden mussten (GSTAB-38, Bl. 252). Weitere Erwerbungen waren Käufe, so ein Teilstück des Meteoriten von Rittersgrün für 1000 Mark (GSTAB-38, B1.95) und Mineralkäufe im Jahre 1878 bei Mineralhandlungen zur Vervollständigung der oryktognostischen Sammlung, wofür Websky 3000 Mark genehmigt bekam (GSTAB38, B1. 236). Eine sehr wertvolle Erwerbung war die Mineralsammlung von Karl Rammelsberg, die aus 1168 Stück bestand und 1879 für 4500 Mark gekauft wurde (GSTAB-39, Bl. 69). Ihr besonderer Wert beruhte darauf, dass sie die Originale zu den überaus zahlreichen Mineralanalysen dieses bedeutenden Mineralchemikers enthielt. Websky erhielt 1880 nochmals 4000 Mark für Mineralkäufe (GSTAB-39, B1.114, 117) und 1886 konnte ein Meteorit, Santa Fé, New Mexico, für 1000 Mark angeschafft werden (GSTAB40, Bl. 82).

Außerdem ist die Beschaffung von großen Mengen von Pappkästchen zu erwähnen, die Websky sowohl für die Neuordnung als auch für die Transportsicherung der Sammlung brauchte. Aus seinem detaillierten Antrag aus dem Jahre 1885 geht hervor, dass seit 187547100 Stück in 22[!] verschiedenen Größen angeschafft wurden und nun noch weitere 42600 Stück für 2440 Mark notwendig waren (GSTAB-39, Bl.313).
Hieraus ist zwar ein Schluss auf die BestandsgröBe der Sammlung möglich, aber wahrscheinlich liegt der wahre Bestand noch weit höher, da auch die bereits in großer Zahl vorhandenen kleinen Pappkästchen, auf denen bisher viele Stücke aufgelegt waren, für kleine Stücke weiter verwendet wurden. Als Ordnungsprinzipien verwandte Websky an erster Stelle die Mineralart in systematischer Reihenfolge, an zweiter Stelle innerhalb der Mineralart die Fundorte in geographischer Ordnung ${ }^{36}$.

\section{Tod von Websky, Würdigung}

Vom Ende des Jahres 1886 an begann die Reihe einiger erheblicher Veränderungen für das Mineralogische Museum der Universität. Die erste Veränderung war der Tod des Direktors der mineralogischen Abteilung, Martin Websky, der im Alter von 62 Jahren am 27. 11. 1886 verstarb.

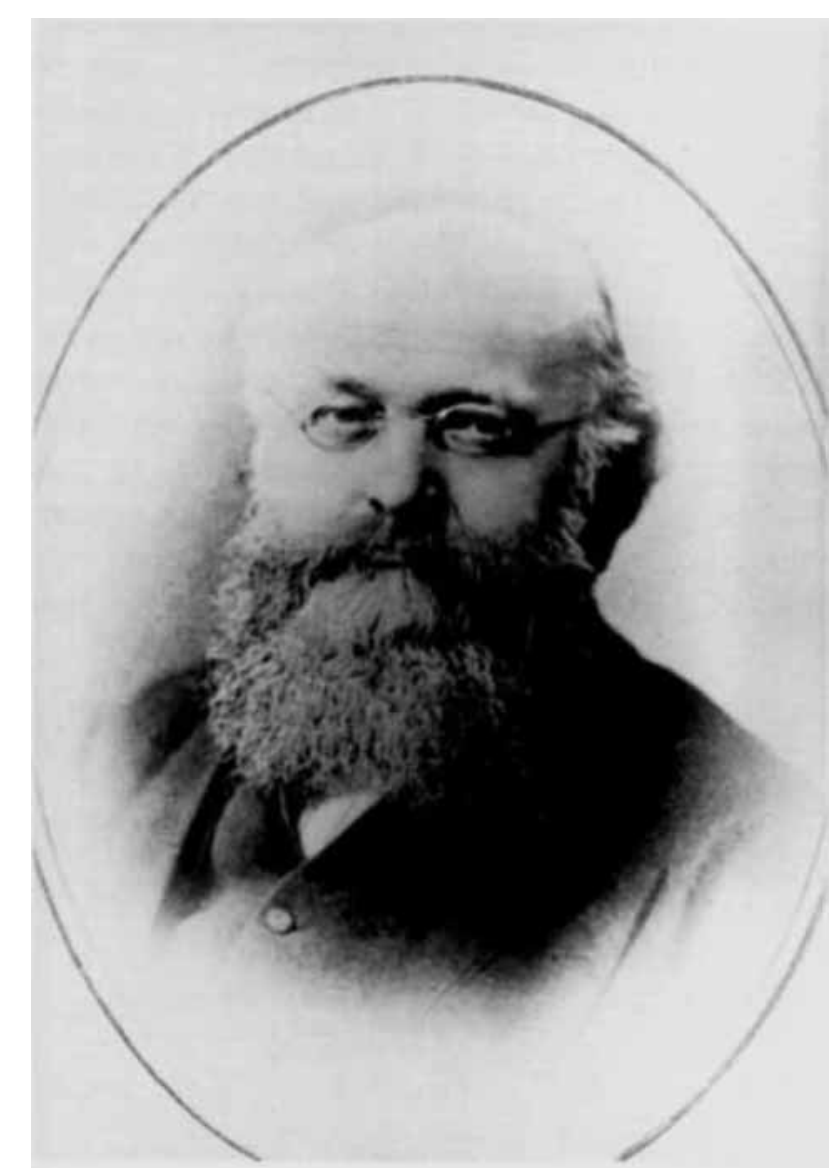

Abb. 4. Martin Websky (1824-1886). - Original im Museum für Naturkunde. HHMfN-9 (Bestand: Mineralogisches Museum).

\footnotetext{
${ }^{36}$ Diese Ordnung der Mineralsammlung konnte allerdings erst im Neubau praktisch wirksam werden und hat sich dort so bewährt, dass sie von allen Nachfolgern Webskys beibehalten wurde. - Sie hat sich zum Beispiel auch bei der Ausarbeitung der 1. Auflage der Mineralogischen Tabellen von 1941 durch den Kustos Hugo Strunz als sehr nützlich erwiesen (persönliche Mitteilung von Herrn Prof. Dr. Hugo Strunz).
} 
Martin Websky (Abb. 4) war 13 Jahre lang der 2. Direktor des Mineralogischen Museums gewesen. Nach dem Urteil von Groth $(1926$, S. 163) war er „der wohl seit Breithaupt [ $\dagger 1873]$ hervorragendste praktische Mineraloge". Von ihm stammt eine systematische Erfassung der spezifischen Gewichte der Minerale. Zahlreiche davon hat er umfassender untersucht. Bereits frühzeitig hat er Gesteinsdünnschliffe, die er von Oschatz erhielt (Völkel 2002, S. 82), polarisationsmikroskopisch untersucht und trat damit in die Nachfolge von G. Rose. Am wichtigsten ist aber, dass er es zur bedeutenden Erweiterung der kristallographischen Kenntnis der Minerale gebracht hat, vor allem dadurch, dass er Verbesserungen des Goniometers einführte (,Webskyscher Spalt"u. a.), wodurch er schmalste Flächen noch mit Sicherheit vermessen konnte und dem Problem der scheinbar unregulären Kristallflächen, von ihm Vizinalflächen genannt, näher kam (Websky 1879). Überhaupt war er ein Meister der rechnenden und zeichnenden Kristallographie, wie seine Vorlesung, deren Manuskript erhalten geblieben ist (AHUB-4), und der erste Teil seines Lehrbuchs (Websky 1887) ${ }^{37}$ beweisen. Er zeigte sich hierin in der von Weiss begründeten und von Rose messend verweiterten Tradition und deklarierte sein Buch als dritten Band von G. Roses Elemente der Kristallographie (Rose 1833). Websky erbrachte aber noch eine für die Berliner Sammlungen nicht hoch genug einzuschätzende Leistung, die darin bestand, dass er die Transportsicherung des Sammlungmaterials gegen Vertauschung begonnen und zugleich den Grundstock für eine gründliche Neuordnung nach dem Muster der von ihm

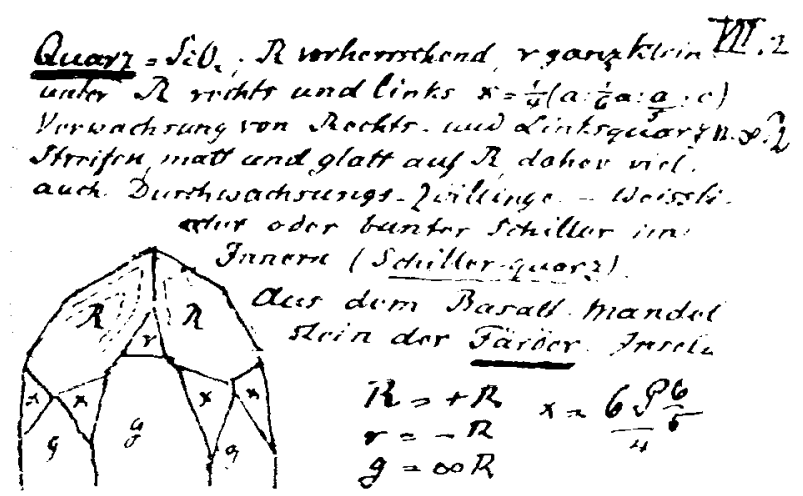

Abb. 5. Quarz aus Basaltmandelstein von den Färöer-Inseln. Sammlungsetikett mit Kristallzeichnung von der Hand von M. Websky. Größe $3,5 \times 5,5 \mathrm{~cm}$. - Original im Museum für Naturkunde, Mineralsammlung. in Breslau geschaffenen systematischen Mineralsammlung gelegt hat. Hierfür hat er den größten Teil seiner Zeit in Berlin geopfert und wohl, wie es Nachrufe hervorheben (z. B. Bauer 1887), seine Gesundheit angesichts der ungünstigen Bedingungen in den unheizbaren Sammlungsräumen gefährdet. Websky untersuchte dabei auch viele Mineralstufen genauer, wie aus zahlreichen, von ihm angefertigten Etiketten und Aufklebern hervorgeht (Abb. 5). Wegen der erheblichen Größe der Sammlung konnte er trotz großer Anstrengung die Neuordnung bei weitem nicht zu Ende führen, das ist erst von seinen Nachfolgern erreicht worden.

\section{Carl Klein als Nachfolger von Websky}

Durch die Berufung des Mineralogen und Petrographen Carl Klein am 4.3.1887 (GSTAB-40, Bl. 114) kam es im Mineralogischen Museum zu erheblichen Veränderungen. Klein hatte mehrere Universitäten als Student und als Hochschullehrer kennen gelernt, zuletzt Göttingen. Dort hatte er ein mineralogisch-petrographisches Institut aufgebaut und war besonders an der Untersuchung von Gesteinen mit den Mitteln der Polarisationsmikroskopie interessiert. Seine Ansichten waren gefestigt, und er strebte bei seiner Berufung an, den von ihm zu übernehmenden Teil des Mineralogischen Museums nach seinen Vorstellungen einzurichten. Er erklärte auch, dass die räumlichen Gegebenheiten des entstehenden Gebäudes besser für ein in zwei als in drei Teile geteiltes Mineralogisches Museum geeignet sei. Dies bewog das Ministerium die zurzeit vorhandene personelle Situation entsprechend zu ändern und den davon besonders betroffenen Justus Roth, der im 69. Lebensjahr stand, von der Leitung der petrographischen Sammlung als 3. Beamten ab 1.4.1887 zu entbinden und ihn, wie es hieß, auf seinen Wunsch, im Gegenzug dazu zum o. Professor zu ernennen, wobei ihm aber ausdrücklich die ungehinderte Benutzung der petrographischen Sammlung, die wieder an die Mineralogie zurückfiel, zugesichert wurde (GSTAB-41, Bd. 1, Bl. 236).

Bei der Beantragung der Mittel beim Ministerium verhielt sich Klein nicht zurückhaltend und führte zur Begründung an, dass die apparative Ausstattung des Mineralogischen Museums höchst unvollkommen wäre und hinter allen anderen

\footnotetext{
${ }^{37}$ Das Buch wurde von August Tenne, dem Kustos unter Websky, herausgegeben und mit einem Nachruf (S. 5-6) versehen. Der zweite Teil ist nicht erschienen.
} 
deutschen Universitäten zurückstünde, wobei er sogar zum Ausdruck brachte: „Das Museum stand lange Jahre in dem Rufe, dass es nur aufnehmen, aber nichts zu wissenschaftlicher Bearbeitung vorbereiten könne, vielfach konnte man auch die Gegenstände überhaupt nicht wieder finden. Die Übelstände sind in der Literatur gebührend getadelt worden und allen Forschern sind dieselben bekannt.“ (GSTAB-42, Bl. 82, vom 20. 5. 1887).

\section{Teilung des Mineralogischen Museums in zwei Abteilungen des Museums für Naturkunde}

Die Berufungsverhandlungen von Klein überschnitten sich im Kultusministerium mit der Vorbereitung anderer Beschlüsse, die am 7.5.1887, noch vor Fertigstellung des neuen Gebäudes, von Kultusminister v. Gossler ${ }^{38}$ verkündet wurden. Es handelte sich um die Bildung der Institution Museum für Naturkunde der Universität Berlin durch Zusammenlegung des Zoologischen und des Mineralogischen Museums, die zugleich in drei Abteilungen gegliedert wurde. So entstanden folgende drei Abteilungen des Museums für Naturkunde: 1.) die Geologisch-paläontologische Abteilung unter dem o. Professor Geh. Bergrat Dr. Ernst Beyrich, 2.) die Mineralogischpetrographische Abteilung unter dem o. Professor Dr. Carl Klein und 3.) die Zoologische Abteilung, kommissarisch geleitet von dem o. Professor Dr. Karl August Möbius (1825-1908), der sich zunächst noch in Kiel befand (GSTAB-40, Bl. 145$)^{39}$. Am 25.5.1887 wurde weiterhin noch die Ernennung von Beyrich als dienstältestem Direktor zum Verwaltungsdirektor des Museums für Naturkunde verfügt. Er sollte für die allgemeinen, nicht den Abteilungsdirektoren zukommenden Angelegenheiten des bald zu beziehenden Museums für Naturkunde zuständig sein (GSTAB-40, B1. 153). Dieses Amt übte Beyrich bis zu seinem Tode aus.

\section{Selbstständigkeit der Abteilungen und neue Bezeichnungen}

Nach recht kurzer Zeit, am 16.2.1888, beantragten die drei Direktoren, die mit dem Abteilungsstatus unzufrieden waren, ihren Einrichtungen Selbstständigkeit zu gewähren. Das Ministerium ging am 2. 5. 1888 darauf ein (GSTAB-42, Bl. 207) und die Bezeichnungen wurden geändert in 1.) Geologisch-paläontologische Sammlung nebst In- stitut, 2.) Mineralogisch-petrographische Sammlung nebst Institut sowie - unter gleichzeitiger Aufteilung - 3.) Zoologische Sammlung und 4.) Zoologisches Institut. Alle Einrichtungen durften nun am 30.5. 1888 ihre künftigen personellen und finanziellen Bedürfnisse vortragen. Aber während die finanziellen Vorstellungen recht großzügig bewilligt wurden, stießen die personellen Forderungen bereits beim Kultusministerium und noch mehr beim Finanzministerium auf Unverständnis, so dass beiden geowissenschaftlichen Institutionen nur eine Erhöhung um je einen Assistenten (gegenüber jeweils beantragten zusätzlichen $2 \mathrm{Ku}$ stoden und 2 Assistenten) für 1888 gewährt wurde (GSTAB-40, Bl. 160 vom 28.6.1887). Ein weiterer Vorstoß beim Finanzministerium erfolgte 1888 (GSTAB-40, Bl. 239 vom 22.6.1888), was aber nur für die Mineralogie zu nochmaliger Zubilligung einer Assistentenstelle im Jahr 1889 führte.

Bald danach, noch 1888 , begann der Umzug in das neue Gebäude und das Einräumen in das dort vorhandene, speziell den Gegebenheiten angepasste neue Mobiliar. Bevor jedoch hierauf und auf die weitere Entwicklung der nun zwei geowissenschaftlichen Einrichtungen weiter eingegangen wird, folgt der Einschub des folgenden Kapitels.

\section{Projektierung und Erbauung des Museums fiir Naturkunde}

\section{Benutzte Quellen}

Die etwa 10 Jahre währende Vorbereitungs- und Projektierungszeit sowie die anschließende fünfjährige Bauzeit des Museums für Naturkunde hat sich in den Akten des Ministeriums für geistliche, Erziehungs- und Medizinalangelegenheiten (Kultusministerium), die in dieser Zeit über die geowissenschaftlichen Institutionen (GSTAB-30, $31,38-40)$ geführt wurden, nur gering niedergeschlagen, da darüber eine besondere Akte geführt wurde. Sie trägt die Bezeichnung „Über den Bau des Hauses für die Sammlungen der hiesigen Universität auf dem Grundstück der Kgl. Eisengießerei zu Berlin“ (GSTAB-43) und umfasst in sechs Bänden die Jahre 1873 bis 1889. Auf Einzelnachweise aus dieser Akte wird meist verzichtet. Eine weitere wichtige Grundlage lieferte der eingehende Artikel von I. Jahn (1989), der auf einer für die Jahre 1876 bis 1891 parallel

\footnotetext{
${ }^{38}$ Gustav v. Gossler (1838-1902) war von 1881 bis 1891 preußischer Kultusminister.

39 Die Berufung von K. A. Möbius als o. Professor der Zoologie erfolgte am 31.3. 1888.
} 
geführten Akte des Ministeriums für öffentliche Arbeiten basiert und besonders die museologischen und zoologischen Aspekte betont. Ferner stand die von den Architekten stammende Gebäudebeschreibung zur Verfügung (Tiede \& Kleinwächter 1889), die jedoch auf das Planungsgeschehen vor dem Baubeginn im Jahre 1883 nicht näher eingeht. Die folgende Darstellung behandelt bevorzugt die geowissenschaftlichen Aspekte.

\section{Bauplatzwahl und Ensemblebildung}

Die Dringlichkeit der Behebung des Platzbedarfs der Universität führte nach 1871 zu dem Entschluss, für die im Gebäude der Universität untergebrachten und unter großer Platznot leidenden naturkundlichen Museen ein eigenes Gebäude zu errichten. Als Baustelle standen freie oder freiwerdende Stellen zur Diskussion, unter anderem das von der Panke durchflossene Gelände der im Jahre 1804 gegründeten, aber inzwischen unrentabel gewordenen Königlichen Eisengießerei in der Invalidenstraße vor dem Neuen Tore (Abb. 6), oder das Kasernengrundstück des 2. Garderegimentes nahe dem nördlichen Ende der Friedrichstraße. Diese und andere Stellen kamen aber auch für weitere anstehende öffentliche Bauvorhaben, wie für die Erweiterung der Charité, für das Gewerbeinstitut, für die Geologische Landesanstalt nebst Bergakademie und für das Landwirtschaftliche Lehrinstitut, in Frage. Rektor und Senat der Universität hielten das Gelände der Eisengießerei wegen der großen, eine halbe Stunde Fußweg betragenden Entfernung für ungeeignet und legten deshalb am 1.11. 1873 dem preußischen König, Kaiser Wilhelm I., eine Eingabe vor, die von zahlreichen Personen mit Ausnahme der Museumsdirektoren unterzeichnet war. Es gab sogar in der Universitätsleitung den Gedanken, für das Zoologische Museum einen Neubau hinter dem Universitätsgebäude, das damals noch nicht die Hinterflügel hatte, zu errichten und das Mineralogische Museum in dessen Räume, einschließlich der zoologischen Dienstwohnung, zu verlegen. Gegen diese kleinliche Haltung wandte sich der Pathologe und Anatom der Universität, Rudolf Virchow (1821-1902), der sich im preußischen Abgeordnetenhaus als Vertreter der Liberalen Fortschrittspartei für die Belange der Volksbildung und Wissenschaftsförderung einsetzte, in Reden vom 23. 1. 1874 und 13.3. 1875 mit dem Hinweis auf die Verhältnisse in London, wo die entsprechende Entfernung zum dortigen Museum weit größer ist. Er stellte auch klar, dass die Bestände der Berliner naturkundlichen Universitätssammlungen längst über die unmittelbaren $\mathrm{Be}$ dürfnisse der Universität hinausgingen, so dass sie in höherem Maße eigentliche Landessammlungen geworden wären, ,Zentralanstalten, in denen der Gelehrte überhaupt alles dasjenige Material finden soll, was Deutschland leisten kann". Die Einwendungen der Universitätsleitung hatten keine Wirkung und die Entscheidung, für welche Institutionen Gebäude auf dem Bauplatz in der Invalidenstraße errichtet werden sollen, fiel bereits mit einer Kabinettsorder vom 15.4.1874. Es war das Ensemble von drei Institutionen mit Ausbildungsund zugleich Museumsfunktionen, die Geologische Landesanstalt mit Bergakademie, das Landwirtschaftliche Lehrinstitut und die naturkundlichen Einrichtungen der Universität alias Museum für Naturkunde.

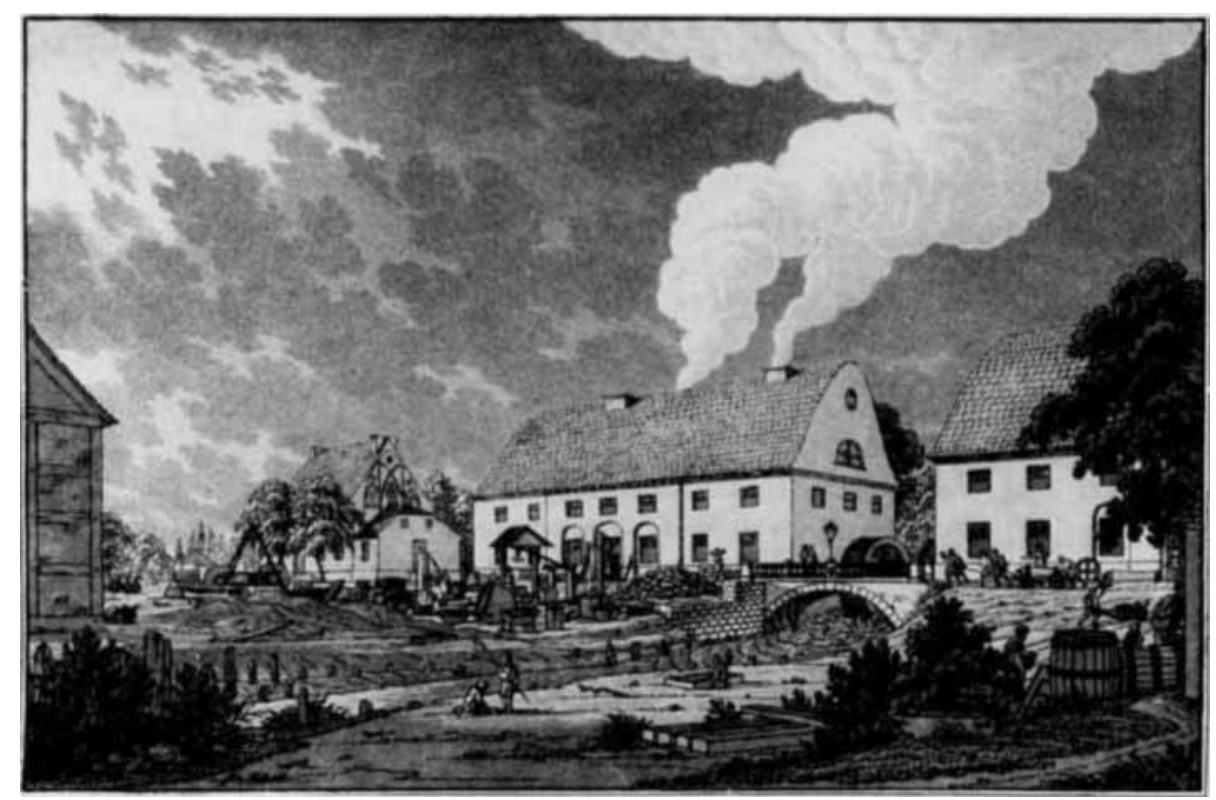

Abb, 6. Die königliche Eisengießerei vor dem Neuen Tore von Berlin, zwischen 1805 und 1810. Aquatintaradierung. Original im Stadtmuseum Berlin, Inventarsigel: VII 59/1242 W, Fotografie Stadtmuseum Berlin. 


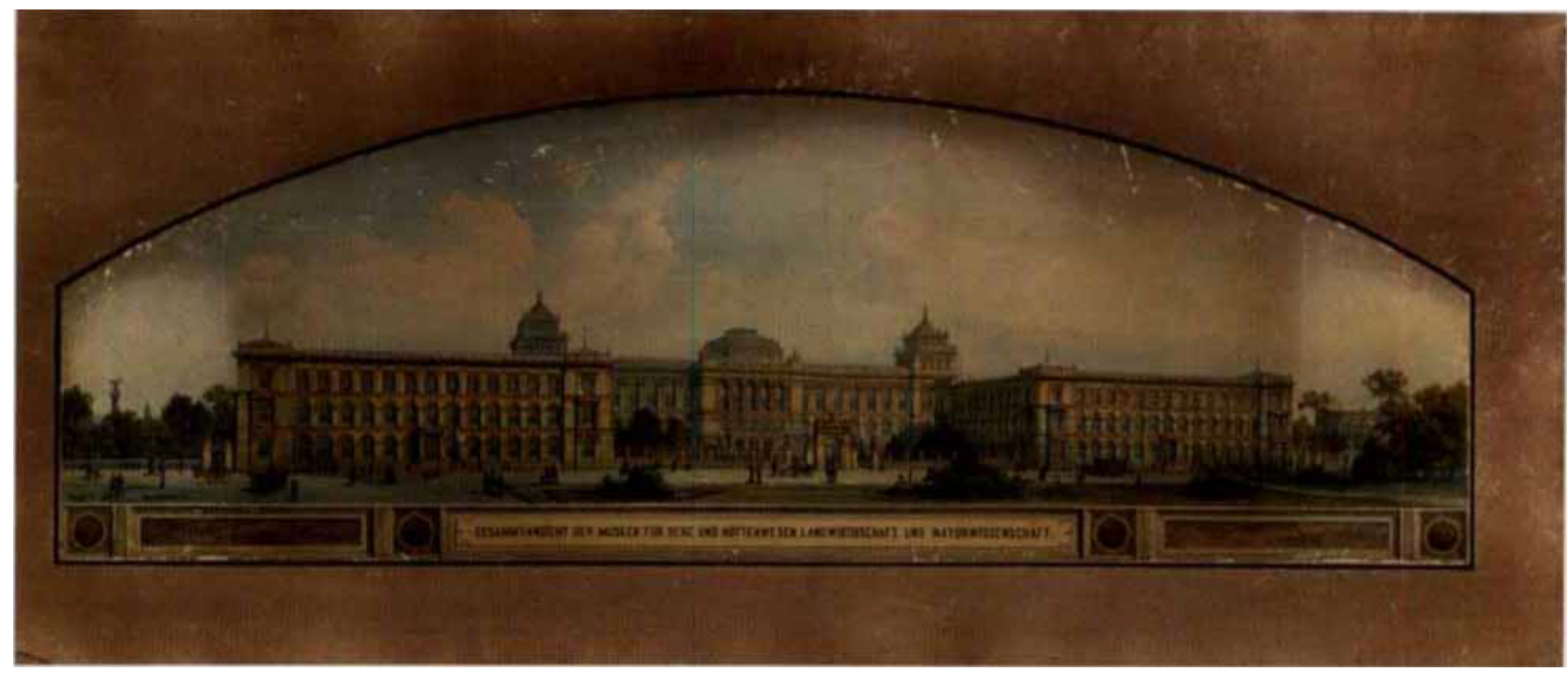

Abb. 7. Geplante Ansicht des gesamten Bauensembles auf dem Gelände der ehemaligen Eisengießerei von 1877, in der Mitte das Museum für Naturkunde nach dem 1. Entwurf. - Zeichnung des Architekten, Bauinspektor Tiede, signiert: Aug. Tiede inv. 75. G. Lapieng px. 77. - Original in Privatbesitz.

\section{Erster Entwurf}

Für das Bauensemble entwickelte der Bauinspektor der Ministerial-Baukommission August Tiede (1834-1911) einen gemeinsamen Plan. Danach erhielt das Universitätsmuseum die bevorzugte Stelle in der Mitte einer symmetrischen Anordnung. Eine Ansichtszeichnung aus dem Jahre 1877 (Abb. 7) zeigt in der Mitte das Universitätsmuseum, das links und rechts flankiert wird von den zwei Bauten der Geologischen Landesanstalt mit Bergakademie (westlich, das heutige Verkehrsministerium) und des Landwirtschaftlichen Lehrinstituts (östlich, die heutige Landwirtschaftliche Fakultät der Humboldt-Universität). Die flankierenden Bauten befanden sich bereits seit 1875 bzw. 1876 im Bau und erhielten beide im Innern einen Museumssaal mit Glasdach. Für das Universitätsmuseum war eine Frontlänge vorgesehen, die größer als der Zwischenraum zwischen den beiden anderen Gebäuden war, weshalb es weit von der Straße zurückgesetzt angeordnet war und beiderseits hinter die beiden Nachbargebäude reichte.

\section{Kritik am ersten Entwurf}

Der Baubeginn für das Gebäude der naturkundlichen Museen der Universität zog sich bis 1883 hin, obwohl Tiede dazu bereits am 1.8.1875 eine Denkschrift und einen ersten konkreten Plan vorlegte, der mit der Gesamtansicht des Ensembles korrespondiert (Abb. 8). Als Muster für die Saalgestaltung waren die Säle von Bibliotheksbauten verwendet. Das untere Geschoss war für die geowissenschaftlichen und die oberen Geschosse für die zoologischen Sammlungen vorgesehen und der hintere Saal sollte die zootomische Sammlung aufnehmen. In der einsetzenden Diskussion stellten die beiden geowissenschaftlichen Direktoren, Beyrich und Websky, ihre Vorstellungen über die Zuordnung der Räume auf die Sammlungsteile dar und mahnten auch die Einrichtung von Dienstwohnungen an. Weit intensiver beteiligte sich der Direktor des Zoologischen Museums, Professor Wilhelm Peters. Er hatte schon 1873, zusammen mit seinem mineralogischen Kollegen Gustav Rose, kurz vor dessen Tod, die Einbeziehung der naturkundlichen Fachleute in die Erarbeitung von Neubauplänen angemahnt (GSTAB-30, Bl. 248, siehe S. 11). Seine nun am 23.8.1875 vorgelegte Stellungnahme stellte auf 29 Seiten die Bedürfnisse des Zoologischen Museums und die Einrichtung der Säle ausführlich dar, was Tiede auf 33 Seiten erwiderte. Mit ähnlicher Intensität setzten sich weitere gegenseitige Stellungnahmen fort, an denen dann auch die Direktoren des Mineralogischen Museums teilnahmen, wodurch sich eine Unvereinbarkeit der Vorstellungen offenbarte. Tiede wurde danach auf eine Studienreise zum Kennenlernen von Museumsbauten nach Belgien, Holland, London und Paris gesandt (später auch noch nach München, Stuttgart, Karlsruhe und Frankfurt a.M.). Auch seine danach am 13.3. 1876 vom Kultusministerium den $\mathrm{Mu}-$ seumsdirektoren offiziell zur Begutachtung gestellten Pläne (GSTAB-38, Bl. 30) und die Stellungnahmen zeigten keine hinreichende Annäherung der Standpunkte. Hierbei kamen, wie 


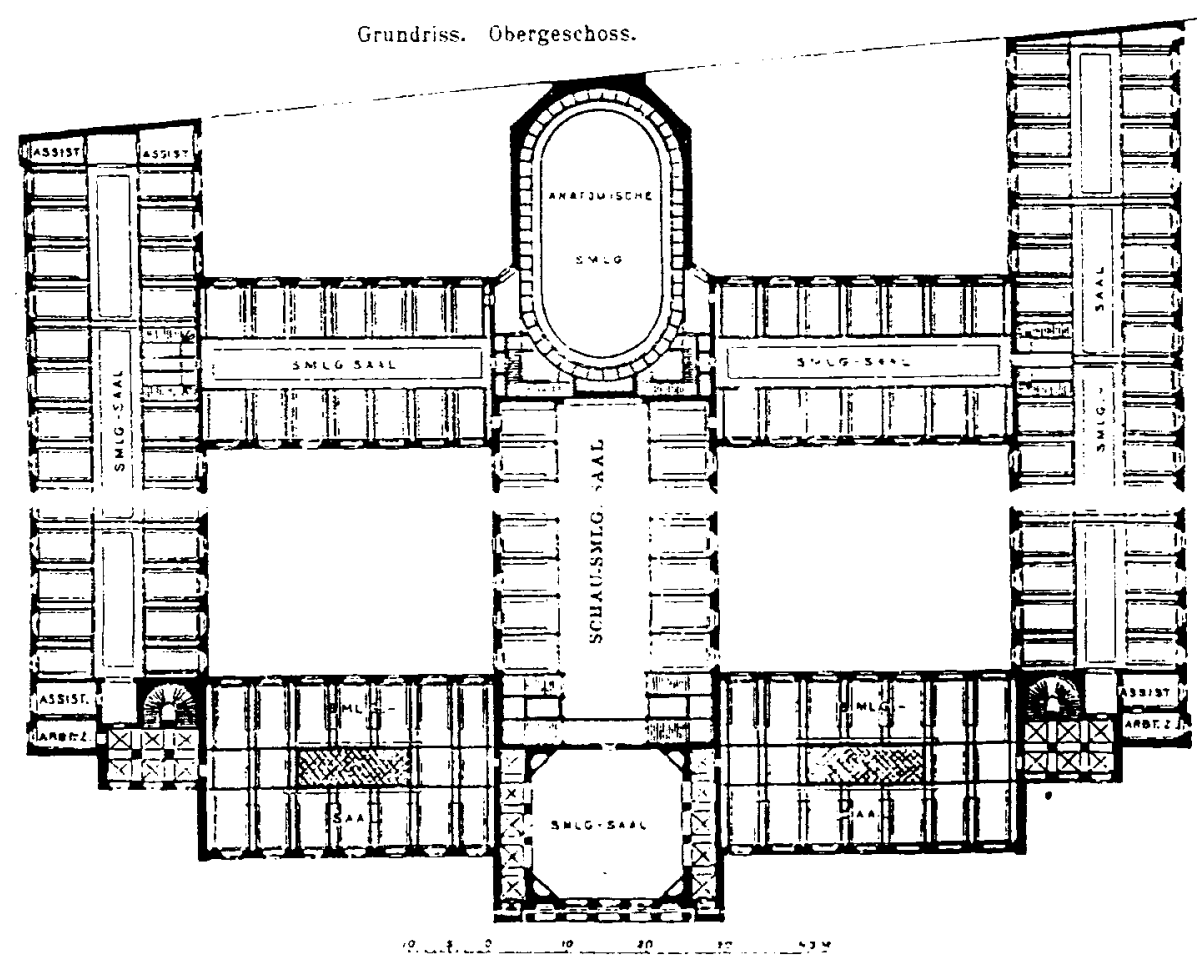

Abb. 8. Grundriss des $\mathrm{Mu}-$ seums für Naturkunde nach dem nicht ausgeführten 1. Entwurf von 1875 . - Reproduziert aus: Tiede 1899, S. 57.
Jahn (1989) urteilt, „grundlegende und nahezu zeitlose Probleme über die Zusammenarbeit von Architekten und Museologen" zu Tage. Den Architekten ging es in erster Linie wohl um die Schaffung möglichst eindrucksvoller Gebäude, für die es in Berlin bereits Vorbilder monumentaler Museumsbauten gab (Altes Museum, erbaut $1825-1830$ und Nationalgalerie, erbaut 1863-1871) oder sich in Planung befanden. Von den naturwissenschaftlichen Museumsdirektoren musste erst durchgesetzt werden, dass die spezifischen Bedürfnisse der naturkundlichen Sammlungen an die Gestaltung und Einrichtung der Räume anerkannt und hinreichend berücksichtigt wurden. Dies betraf in besonderem Maße die zoologischen Sammlungen wegen der Vielgestaltigkeit ihrer Objekte und der verschiedenen Notwendigkeiten der Wartung, war aber durchaus auch ein allgemeines Problem. Auch hielt Peters die Höhe der Säle von 21/2 Metern für angemessen, während Tiede ausdrücklich auf außerordentlich hohen und großen Sälen bestand. Ferner ging es um die sachgerechte Ausstattung mit Mobiliar, dessen Beschaffenheit und Aufstellung die ungehinderte wissenschaftliche Bearbeitung der darin untergebrachten Objekte zu gewährleisten hat. Außerdem bemühte sich Peters, für die Zoologie einen größeren Anteil des Gebäudes als die Geowissenschaften zu erhalten. Zwar hatte der Architekt bereits das Verhältnis zu Gunsten der Zoologie auf den Wert von 1,8 zu 1 gegenüber der Situation im
Universitätsgebäude heraufgesetzt. Aber Peters betonte, dass dies nicht ausreicht, zumal in den von Tiede besuchten Museen in Leiden, London, Paris oder Stuttgart das Verhältnis wie $6 \mathrm{zu} 1$ bis $9 \mathrm{zu} 1$ betragen würde. Auch von Seiten der Königlich Technischen Baudeputation wurde am 13.6.1877 erhebliche Kritik zu zahlreichen Punkten der Baupläne geäußert, die zum Teil aber auch auf die nur ,mäßige“ Größe des Bauplatzes zurückgingen.

\section{Endphase der Planung}

Erst die Bildung einer „Kommission von Naturhistorikern und Bautechnikern" brachte 1878 einen Durchbruch. Vor allem wurde eine stärkere Trennung der Geowissenschaften von der Zoologie durch Änderung des Grundrisses und Zuteilung eigener Gebäudeteile durchgesetzt. Durch die Beanspruchung Tiedes für die zwei Nachbarbauten zog sich aber die Entscheidung und die Erarbeitung der Form des endgültigen Grundrisses noch hinaus. Schließlich wurden im Jahre 1879 zur Erleichterung der Entscheidung auf dem Baugelände Versuchsbauten zur Auswahl von drei verschiedenen Saalmodellen errichtet. Nach den jahrelangen Auseinandersetzungen, die sogar so weit gingen, dass das Kultusministerium Peters wegen beleidigender Äußerungen gegen Tiede rügen musste, bahnte sich schließlich ein Kompromiss an, dem Peters zustimmte. Tiedes zweiter Entwurf wurde nach weiteren 


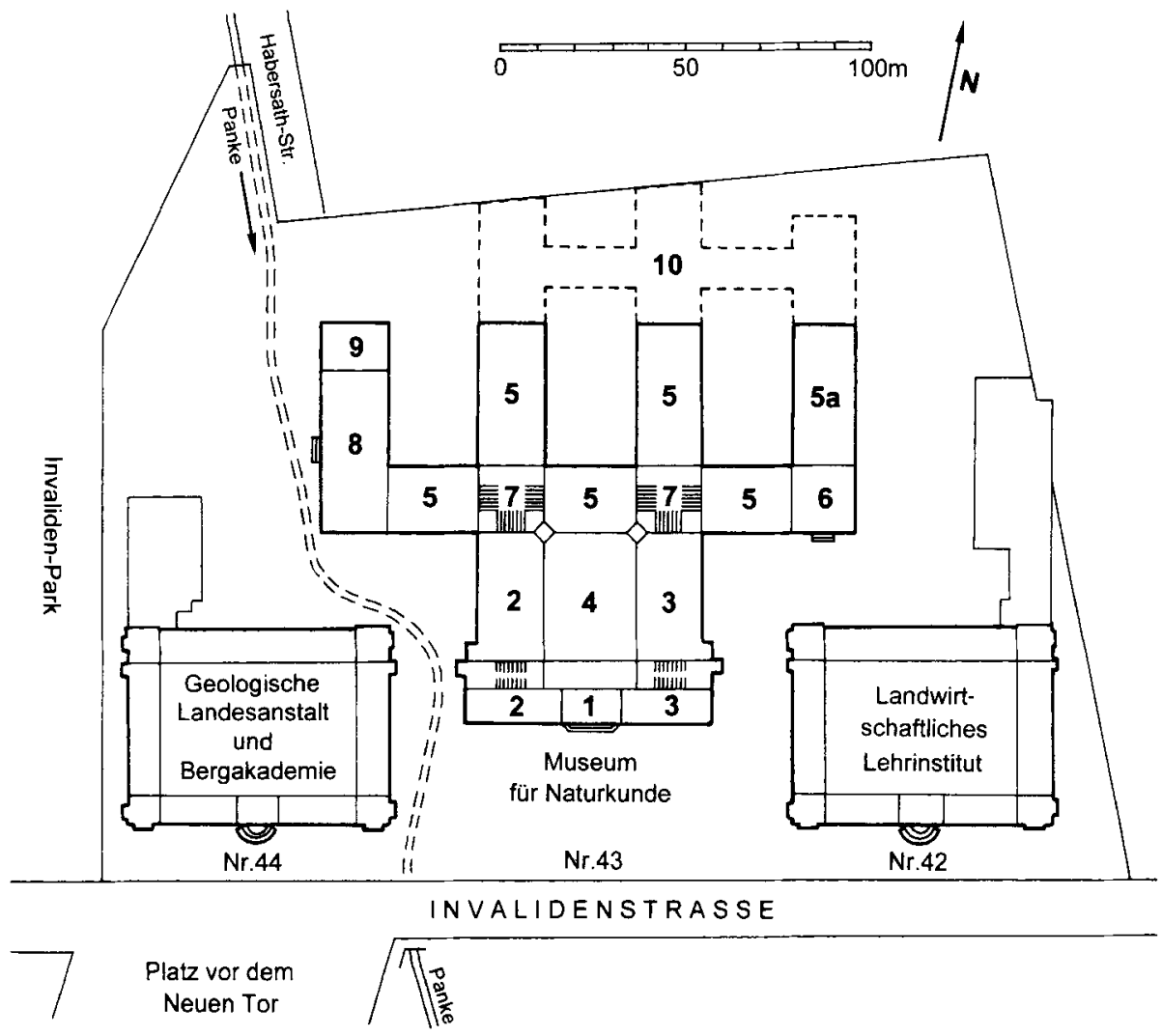

Abb. 9. Das Bauensemble auf dem Gelände der ehemaligen Eisengießerei nach dem ab 1883 ausgeführten 3. Grundrissentwurf des Museums für Naturkunde, ergänzt durch die bis 1888 eingerichtete Nutzung (nebst gravierenden späteren Veränderungen). Zeichnung $\mathrm{J}$. P. Mendau.

Legende: 1 Vestibül, 2 Mineralogisch-Petrographisches Institut und Museum, 3 Geologisch-Paläontologisches Institut und Museum, 4 Lichthof (der heutige Sauriersaal), 5 Zoologisches Museum (5a Ruine des 2. Weltkrieges), 6 Verwaltung des Museums für Naturkunde, 7 Haupttreppenhäuser, 8 Zoologisches Institut, 9 DienstWohnhaus des Direktors des Zoologischen Institutes, $10 \mathrm{Er}-$ weiterungsbau von 1914/16 für das Zoologische Museum.
Gutachten staatlicher Stellen nur noch in geringerem Maße geändert. Beyrich und Websky hatten sich leichter mit Tiede geeinigt und auch damit abgefunden, dass ihnen trotz mehrmaliger Anträge keine Dienstwohnungen im Gebäude zugebilligt wurden.

Nach dem dritten Entwurf wurde der Baubeginn auf April 1883 festgesetzt und die Leitung dem Regierungsbaumeister Kleinwächter übertragen. Der nun gültige Grundriss (Abb. 9) sah für die geowissenschaftlichen Sammlungen einen $65 \mathrm{~m}$ breiten, quadratischen Vorderbau mit überdachtem Lichthof vor, der dem 140 Meter breiten Trakt der zoologischen Sammlung vorgesetzt ist und in den Zwischenraum zwischen den Nachbarbauten hineinragt. Bei den enormen Raumgrößen und -höhen war es geblieben, da davon ausgegangen war, dass sämtliche Sammlungsteile für das Publikum zugänglich sein sollten, wenn auch bereits erste Gedanken, dies zu ändern, aufgekommen waren (Jahn 1989). Die im zweiten Entwurf vorgesehene gemeinschaft- liche monumentale Haupttreppenanlage entfiel, aber es gab dennoch zwei großartige Treppenhäuser im zoologischen Trakt sowie zwei etwas bescheidenere im Vorderbau. Es blieb auch bei einer Reihe weiterer Mängel, die die Baudeputation bereits im Gutachten vom 13.6. 1877 aufgelistet hatte und die sich zum Teil in der Folge sehr störend auswirkten ${ }^{40}$.

\section{Baubeginn und nachträgliche Änderungen}

Durch den Tod des Zoologen Peters am 20.4. 1883 und die Forderungen seines Nachfolgers, des Zoologen Franz Schulze (18401921), musste der Baubeginn nochmals um ein halbes Jahr verschoben werden, da letzterer es durchsetzen konnte, dass für ihn ein von der zoologischen Sammlung getrenntes Zoologisches Institut und ein geräumiges Wohnhaus als seine Dienstwohnung im westlichen Flügel des zoologischen Traktes des Museumsbaus eingerichtet wurden, was erhebliche nachträgliche Ände-

\footnotetext{
40 Von den wohl sämtlich mit Recht monierten Punkten wird hier nur folgendes erwähnt. Die beiden seitlichen Ausstellungssäle im Erdgeschoss und der Lichthof hatten durch die große Nähe der Nachbargebäude und die sich durchkreuzende Bauweise des Museums nur ungenügenden Zugang von Tageslicht. Dies wurde zwar durch die 1890 eingerichtete elektrische Beleuchtung verbessert, aber sehr spärlich. Ausreichende Beleuchtung erhielt der Mineralsaal zum Beispiel erst nach 9 Jahrzehnten. Eine weitere Unzulänglichkeit war die zu tiefe Einsenkung des Gebäudes, wodurch das Kellergeschoss bis unter das Niveau der Kanalisation reichte. Die damit verbundenen Gefahren und Nachteile wurden sogar erst nach 10 Jahrzehnten durch Einbau einer Hebeanlage behoben.
} 
rungen mit sich brachte, da unter anderem ein zusätzliches Treppenhaus eingebaut werden musste $^{41}$.

Weitere Veränderungen in der Nutzung des Baues setzte der Zoologe Karl Mocbius (1826-1908) durch, der am 2.5.1887 zunächst als kommissarischer Direktor des zoologischen Museums eingesetzt und am 31.3.1888 berufen wurde. Er hatte zuvor als Direktor des Zoologischen Museums der Universität Kiel bereits im Jahre 1884 seine Ansichten über den Bau und die Einrichtung eines Museums publiziert und sich für eine wichtige museologische Neuerung eingesetzt, und zwar für die Trennung der für das Publikum zugänglichen ..Schausammlung“ von den "Hauptsammlungen“. Letztere sollten als wissenschaftliches Arbeitsmaterial in den Obergeschossen „magazinartig“, das heißt gedrängter und nicht öffentlich zugänglich, untergebracht werden, was nun auch in Berlin eingerichtet wurde (Jahn 1989, S. 290). Auch die Ausstellung konnte davon profitieren, da sie nun stärker auf das Publikum abgestimmt werden konnte, was besonders in der zoologischen Schausammlung ausgenutzt wurde. Aber auch die geowissenschaftlichen Direktoren schlossen sich diesem Modus $a^{42}$. Größere bauliche Veränderungen zum Vorteil der Hauptsammlungen waren allerdings nicht mehr möglich, da der Bau schon viel zu weit fortgeschritten war. Die riesigen Saalhöhen der Obergeschosse waren nun nicht nur unnötig, sondern auch nachteilig, da bei geringeren Raumhöhen der umbaute Raum mehr Stellflächen für das wissenschaftliche Material ergeben hätte ${ }^{43}$.

\section{Bezeichnung des Museums und Figurenschmuck der Vorderfront}

Nach diesen Änderungen schritt die Fertigstellung des Baues voran. Am 12.5.1886 fragte die Ministerial-Baukommission angesichts der bevorstehenden Abrüstung des Vorderbaues (Abb. 10) an, ob als Inschrift die Worte „Museum für Naturkunde" angebracht werden sollen. Dies setzte eine Diskussion in Gang (GSTAB-43, Bd. 4, Juni/Juli 1886). Erwogen wurden unter anderem: „Museum für Thier- und Gesteinskunde“, „Museum für beschreibende Naturwissenschaft", „Museum für Naturwissenschaft", „Institut für Mineralogie und Zoologie" und vom Dekan der Philosophischen Fakultät vorgeschlagen „Studio mineralogiae et zoologiae dicatum ${ }^{\text {444 }}$. Schließlich kam es zur Einigung auf „Museum für Naturkunde". Als dann die Fertigstellung der Fassade des Vorderbaues im Jahre 1887 näher rückte, musste auch über die Ausschmückung mit plastischen Bildwerken entschieden werden. Für die Standbilder wurde an Personen wie Charles Darwin gedacht. Den Ausschlag gab der Kultusminister G. v. Goßler, der der Meinung war, dass es ..genug eigene berühmte Leute" gäbe, und entschied, dass Standbilder von Leopold von Buch und von Johannes Müller aufgestellt werden sollen (GSTAB-43, Bd. 5, 3. 5. 1887). Sie wurden von dem Berliner Bildhauer Richard Ohmann (1850-1910) aus schlesischem Sandstein geschaffen und seitlich über dem Portal postiert. Die dargestellten Personen waren bedeutende Vertreter ihres Faches, die sich auch um die Sammlungen des Hauses verdient gemacht haben, und repräsentieren deshalb die Bestimmung des $\mathrm{Mu}-$ seums für die Geowissenschaften und die Zoologie hervorragend. Außer den Statuen wurden

\footnotetext{
${ }^{41}$ Dieser Flügel war bisher für die Unterbringung der zootomischen Sammlung vorgesehen, die auf die früheren Anatomen Karl Jasmund Rudolphi $(1771-1832)$ und Johannes Müller (1801-1858) zurückging und beim Bezug des Neubaus mit der zoologischen Sammlung vereinigt werden soltte. Noch befand sich die zootomische Sammlung jedoch im Anatomischen Institut und der damalige Anatom Karl Bogislav Reichert (1811-1883) verweigerte die Herausgabe, die aber von seinem Nachfolger, dem Anatom Wilhelm v. Waldeyer-Hartz (1836-1921). im Jahre 1888 gestattet wurde, so dass sie dann im Ostflügel des zoologischen Traktes untergebracht werden musste (AHUB-6).

42 Aus dieser Zeit stammt die bis heute intern gebrauchte Bezeichnung ...Magazin" für den Saal im 1. Obergeschoss, in dem die systematisch aufgestellte mineralogische wissenschaftliche Hauptsammlung untergebracht ist.

${ }_{43}$ Realisiert wurde dies aber im Erweiterungsbau. der wegen erneut eingetretener Raumnot notwendig wurde und in den Jahren 1914/16 mit geringeren Geschosshöhen, aber einem Geschoss mehr, an der rückwärtigen Front des Museumsgebäudes erbaut wurde. - Bereits 1899 war zwar ein Erweiterungsbau für das Zoologische Museum neben dem nach Berlin-Dahlem verlagerten Botanischen Garten der Universität vorgesehen gewesen, aber nicht zustandegekommen. Auch andere Projekte scheiterten an den Zeitumständen. Dies betrifft sowohl das Projekt, das gesamte Museum für Naturkunde nach 1930 auf ein größeres Gelände in Berlin-Dahlem zu verlegen und drei getrennte Neubauten für die Museen der Mineralogie, der Paläontologie und der Zoologie zu errichten, als auch die wiederholten Bestrebungen, den östlichen Flügel des Zoologischen Museums, der im 2. Weltkrieg durch Fliegerbombentreffer zerstört wurde, wieder aufzubauen. Nach fast 5 Jahrzehnten ist dieser Flügel noch immer eine Ruine aus stehengebliebenen Außenmauern.

${ }_{+4}$ Die Diskussion über die Namensgebung offenbart deren Problematik. - Die Situation wiederholte sich, als bei Änderungen der Universitätsstruktur erneut über den Gebäudenamen nachgedacht werden musste, sowohl nach der sog. 3 . Hochschulreform der DDR im Jahre 1968 als auch nach der Wiedervereinigung der beiden deutschen Staaten.
} 
Porträtmedaillons von dem Bildhauer Gerhard Janensch geschaffen, die in großer Höhe unter der Hausinschrift zwischen den Säulen angebracht wurden. Sie stellen den um die Förderung der Naturwissenschaften hochverdienten Alexander v. Humboldt (1769-1859), den Mineralogen und Kristallographen Christian Samuel Weiss (1780-1856) und den Mikrobiologen und Mikropaläontologen Christian Gottfried Ehrenberg (1795-1876) dar ${ }^{45}$. Im Innern des Museums wurde auch für Schmuck gesorgt, der u. a. sich an den gusseisernen Säulen, Treppenhausträgern und vor allem den Geländern zeigt und der darauf Bezug nimmt, dass das Museum auf dem ehemaligen Gelände der königlichen Eisengießerei steht, die unter anderem durch ihren Eisenkunstguss bekannt war.

\section{Der Vorderbau für die geowissenschaftlichen In-} stitutionen

Die beiden geowissenschaftlichen Einrichtungen erhielten das Vordergebäude. In seinem westlichen Vorder- und Seitenflügel wurde die Mineralogisch-petrographische Sammlung nebst Institut, im östlichen die Geologisch-paläontologische Sammlung nebst Institut untergebracht. Im Erdgeschoss lagen jeweils ein großer und ein kleiner Ausstellungssaal, im ersten Geschoss die wissen- schaftlichen Hauptsammlungen sowie in der Mitte des Vorderflügels über dem Vestibül der mineralogische Hörsaal. Im zweiten Geschoss lagen die Räume der beiden Institute mit Arbeits-, Untersuchungs- und Laborräumen, auch Seminarräume für Studenten und kleinere Hörsäle. In der Mitte des Vorderflügels über dem mineralogischen Hörsaal lagen Räume für die petrographische Sammlung, die ursprünglich die dritte Abteilung des ursprünglichen Mineralogischen Museums gebildet hatte, aber inzwischen wieder der Mineralogie zugeordnet worden war. Insgesamt gesehen, hatten die beiden geowissenschaftlichen Institutionen jeweils etwa die Hälfte des Vordergebäudes erhalten ${ }^{46}$. Der Lichthof wurde allerdings zunächst vom Zoologischen Museum für die Aufstellung der Skelette großer Wale genutzt.

\section{Eröffnung des Museums für Naturkunde}

Der Umzug der Institutionen begann im Jahre 1888 , bereits vor der endgültigen Beendigung der Bauarbeiten, und war 1889 abgeschlossen. Wegen des großen Umfanges der Sammlungsbestände und des geringen Personals nahm die Einrichtung erhebliche Zeit in Anspruch. Am 2. 12. 1889 fand dann im Beisein von Kaiser und König Wilhelm II. die feierliche Einweihung des

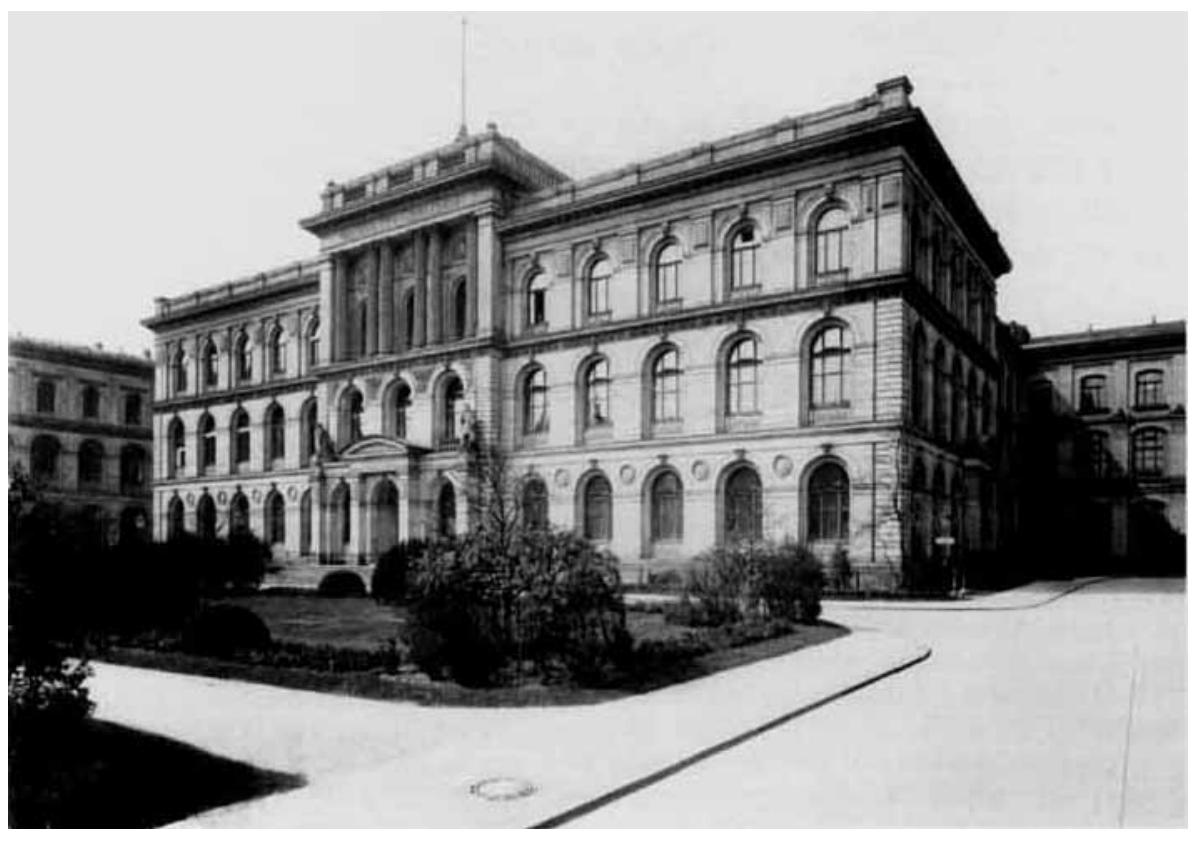

Abb. 10. Der Vorderbau des Museums für Naturkunde, Sitz der beiden geowissenschaftlichen Institutionen. - Original im Museum für Naturkunde, HHMfN-7 (Bestand: Zoologisches Museum), Sign.: B III/ 596.

\footnotetext{
45 Auch diese Personen haben sich um die Förderung der im Museum für Naturkunde vertretenen Wissenschaften und die damit verbundenen Sammlungen verdient gemacht, wie es an entsprechenden Stellen der vorliegenden Artikelreihe dargelegt ist.

46 Mit der petrographischen Sammlung war auch der Saal, in dem sie aufgestellt war, der Mineralogie zugefallen. Er befand sich genau in der Mitte des Vorderhauses im 2. Obergeschoss.
} 
Museums statt, bei der der Kultusminister G. v. Gossler die Festrede hielt ${ }^{47}$. $\mathrm{Zu}$ diesem Zeitpunkt waren die Ausstellungsräume noch nicht überall fertig geworden, was besonders den mineralogischen Sammlungssaal betraf, in den noch eine große Schenkung, die während des Einzugs eingetroffen war, eingearbeitet werden musste ${ }^{48}$. Die Eröffnung für die Öffentlichkeit konnte erst im Jahre 1890 erfolgen und dann auch anfangs nur wenige Stunden pro Woche.

\section{Zeitgenössische Stimmen}

Das neue Gebäude wurde eine große Bereicherung für die darin untergebrachten Institutionen, die sich darin ausbreiten, ihre Schätze übersichtlich ordnen und diese auch angemessen präsentieren konnten. Das Museum wirkte verstärkt als Anreiz, um private Sammlungen dorthin zu schenken oder zum Kauf anzubieten, wenn auch sogleich beim Ministerium die Sorge aufkam, dass der geschaffene Raum bald wieder überfült würde. Es sei auch darauf hingewiesen, dass sich durch die entstandenen Bauten eine enge Nachbarschaft der geowissenschaftlichen Einrichtungen des Museums für Naturkunde mit der PreuBischen Geologischen Landesanstalt ergab, die für lange Zeit sehr nützlich und befruchtend gewirkt hat ${ }^{49}$. Andererseits gab das Gebäude auch Anlass zu erheblicher Kritik. Auf manches, was von seiten der Baukommission und der naturkundlichen Fachleute kam, ist schon hingewiesen. Auch auswärtige Fachleute kritisierten das Gebäude heftig, wie der Breslauer Ferdinand Roemer, der in Briefen an seinen Bruder in Hildesheim das Museumsgebäude scheußlich nennt, ohne allerdings nähere Gründe zu nennen, und meint: „der Baumeister, so wie die Professoren, welche sich dessen Anordnungen haben gefallen lassen, müssen in den Anklagezustand versetzt werden“ (Helms 1997, S. 301). Für die Stadt stellte das Museum eine große Bereicherung dar, allein schon durch seine Architektur, allerdings entwickelte sich der Besuch durch die Bevölkerung nur allmählich. In späteren Folgejahren wurde das Museum für Naturkunde aber zu einem Besuchermagneten.

\section{Die zwei geowissenschaftlichen Institutionen im Museum für Naturkunde}

Die Entwicklung der beiden Institutionen, die aus dem bei der Gründung der Universität Berlin im Jahre 1810 geschaffenen Mineralogischen Museum hervorgegangen sind, wird in diesem Artikel noch bis zum Jahre des 100jährigen Bestehens der Universität Berlin weiter verfolgt. Es waren die Geologisch-paläontologische Sammlung nebst Institut unter dem Direktor Beyrich und die Mineralogisch-petrographische Sammlung nebst Institut unter dem Direktor Klein. Über sie wird nun in den beiden folgenden Kapiteln getrennt berichtet. Die Kapitelüberschriften entsprechen den erst im Jahre 1901 eingeführten Namen der Institutionen.

\section{Geologisch-paläontologisches Institut und Sammlung 1888 bis 1910}

\section{Die Abfolge der Direktoren}

Anders als in der mineralogisch petrographischen Schwestereinrichtung war in der GeologiePaläontologie der Einzug in das neue Gebäude nicht mit einem Wechsel des Direktorats verbunden. Im Gegenteil war der Direktor Beyrich, der 1890 bereits seinen 75. Geburtstag beging, als dienstältester Direktor sogar noch mit der Funk-

\footnotetext{
47 Minister Gustav v. Goßler (vgl. Anm. 38) geht in seiner Rede auch auf die Vorgeschichte der naturkundlichen Universitätssammlungen ein, wenn auch äußerst kurz (abgedruckt in „Die Post“, Dienstag, 3. Dez. 1889, HHMfN-7, Sign.: S II, Sammlg. Zeitungsausschnitte). Da er aber dabei einem für den Umgang mit der Geschichte des Museums kennzeichnenden kapitalen Irrtum aufsitzt, muss darauf eingegangen werden. In der Rede heißt es nach einleitenden Worten über die Wertschätzung der Wissenschaft durch den Kaiser und König: ..Hundert Jahre sind verflossen, seitdem Preußens großer Staatsmann Freiherr von Haugnitz den ersten Grund zu den Sammlungen legte", ohne dies näher zu belegen. Gemeint ist Christian August Heinrich Kurt Graf von Haugwitz (1752-1832), der in seiner Zeit als preußischer Kabinettsminister 1792-1804 und 1805/6 mit außenpolitischen Angelegenheiten befasst war und von dem keine Aktivitäten in Hinblick naturkundlicher Sammlungen bekannt sind. Dagegen war es aus dem Kreise der damaligen Staatsmänner der hochverdiente preußische Bergbauminister, Friedrich Anton Freiherr von Heinitz (1725-1802), der sich in mannigfacher Weise der Sammlung der preußischen Berg- und Hüttenbehörde und der Bergakademie angenommen hat und ihr entschiedener Förderer gewesen ist, wie im 2 . Teil dieser Artikelserie dargestellt (Hoppe 1999, 2003).

t8 Es war die Schenkung der Sammlung Carl Rumpff/Erzherzog Stephan (s. S. 36).

49 Die guten und lebhaft genutzten nachbarlichen Beziehungen wurden von den Nachfolgeinstitutionen der Geologischen Landesanstalt jedoch von den 60iger Jahren des vorigen Jahrhunderts an aus Geheimhaltungshysterie allmählich eingeschränkt und schließlich praktisch abgebrochen. - Das Gebäude wurde inzwischen einer anderen Nutzung überführt (Bundesministerium für Verkehr).
} 
tion des Verwaltungsdirektors des Museums für Naturkunde betraut worden, obwohl er doch bereits durch die Nebentätigkeit als 2. Direktor der Preußischen Geologischen Landesanstalt und Bergakademie zusätzlich belastet war. Nach 6 Jahren starb Beyrich am 9.7.1896. Der eintretende Wechsel im Direktorat wurde dadurch gemildert, dass zunächst der bisherige Kustos, Professor Wilhelm Dames, als Nachfolger eingesetzt wurde. Dames war seit 1871 unter Beyrich in der Institution tätig und hatte seit längeren Jahren auch erhebliche Teile der Aufgaben des Direktors übernehmen müssen, ohne allerdings von Beyrich freie Hand zu bekommen. Jedoch dauerte die Periode von Dames als Direktor nur zwei Jahre, da er am 22.12.1898 im Alter von 55 Jahren verstarb. Nun wurde ein Auswärtiger als Nachfolger berufen. Die Wahl fiel auf den Geologen und Paläontologen Wilhelm Branco ${ }^{50}$, der am 11. 4. 1899 berufen wurde und sein Amt bis 1917 innehatte. Der nun folgende Bericht behandelt zunächst die Zeit unter Beyrich und Dames.

\section{Lehre unter Beyrich und Dames}

Wie schon seit zwei Jahrzehnten hielt Beyrich seine Vorlesungen nur in den Wintersemestern. Es waren zwei vierstündige Vorlesungen. Die eine lautete wie schon immer: „Geognosie unter besonderer Berücksichtigung des sogenannten Flötzgebirges", bei der anderen hatte er sich nun auf „Ausgewählte Abschnitte aus der Versteinerungskunde" festgelegt. Im Jahre 1893 hält er aber nicht mehr beide, sondern nur die erstgenannte und 1894 hielt er die letzte Vorlesung. Weit beweglicher und vielseitiger in seinen Vorlesungen zeigte sich Wilhelm Dames, der bereits seit 1874, zunächst als Privatdozent, tätig war und 1891 zum o. Professor ernannt wurde. Er las meist mehrstündig über die Leitfossilien der Flötzformationen, über die Paläontologie der Wirbeltiere, der Säugetiere und der Wirbellosen, über fossile Crustaceen, über die erratischen Blöcke (Geschiebe) der norddeutschen Ebene, über die Geologie der norddeutschen Tiefebene, über allgemeine und historische Geologie, und schließlich auch über den Ursprung und das Alter des Menschengeschlechtes. Weiterhin sind die Vorlesungen des o. Professors Justus Roth zu verzeichnen. Seine zwei Hauptvorlesungen betrafen die allgemeine und chemische Geologie und die Petrographie. Daneben las er auch über Bau, Wirkungsweise und Verteilung der Vulkane. Ferner traten wie bisher auch Lehrkräfte der Bergakademie im Vorlesungsverzeichnis der Universität auf, so der Privatdozent Felix Wahnschaffe in den Wintersemestern mit zwei Vorlesungen über allgemeine Geologie und über die Geologie des Quartärs unter besonderer Berücksichtigung des norddeutschen Flachlandes, sowie daneben mit Übungen in physikalischer und chemischer Bodenuntersuchung. In diese Kategorie von Vortragenden gehört auch Professor Karl August Lossen, der regelmäßig wie seit längerem bis zu seinem Tod im Jahre 1893 die Lehre der Gebirgsarten vortrug (Kayser 1893). Auch von den Kustoden und Assistenten Beyrichs traten einige als Vortragende auf, wie im folgenden gezeigt wird.

\section{Die Mitarbeiter unter Beyrich und Dames}

Als Mitarbeiter standen dem Direktor Beyrich ein Kustos und ein Assistent sowie zeitweilig ein oder zwei Hilfsassistenten zur Seite. Kustos war zunächst bis 1891 Dames, der aber im gleichen Jahr zum o. Professor ernannt wurde, weil Beyrich wegen seiner Belastungen dringend eines Stellvertreters bedurfte. Sein Nachfolger als Kustos wurde Otto Jaekel, der zuvor Assistent in Straßburg gewesen war. Er habilitierte sich 1890 in Berlin, war zunächst für das Jahr 1891 Hilfsassistent und wurde danach zum Kustos ernannt, als welcher ihm am 13.9.1895 der Professorentitel verliehen wurde. Er las über die Entwicklung der Tierwelt aufgrund der Paläontologie, über die Geologie Deutschlands, über die Descendenzlehre und den Darwinismus aufgrund der Paläontologie und über die Stammesgeschichte der Echinodermen. Da er auch unter Branca bis 1906 Kustos blieb, wird auf ihn später nochmals eingegangen (s. S. 33). Als weiteren Helfer hatte Beyrich seit 1884 noch Ernst Koken als Hilfsassistenten bei sich, der 1888, kurz vor Einzug in das neue Gebäude, zum Assistenten aufrücken konnte und seit diesem Jahr auch als Privatdozent auftrat. Er las über Gebirgsbildung, über fossile Pflanzen, über die Geologie Nordwestdeutschlands, über die Geologie Deutschlands und über die Entwicklung der Tierwelt nach den Resultaten der Paläontologie. Koken nahm dann 1891 eine Berufung als Professor nach Königsberg an. Im Jahre 1890 war Georg Lieder für

50 Branco änderte im Januar 1907 seinen Namen in Branca. 
einige Monate Hilfsassistent. Ihm folgte Karl Futterer, der 1891 als Assistent eingestellt wurde. Nach seiner Habilitation trat er als Privatdozent auf und las von 1893 an über die Geologie Afrikas, besonders der deutschen Kolonien, über die Bildungsgeschichte der Meere bzw. allgemeine Meereskunde, über Goldlagerstätten in Afrika und über die Stammesgeschichte der Cephalopoden. Futterer blieb bis 1895 und folgte dann einem Ruf als Professor nach Karlsruhe. Ihn ersetzte 1895 Johannes Böhm als Assistent, der 1901 zur Geologischen Landesanstalt ging. Ein 2. Assistent konnte erstmals nach Beyrichs Tod unter Dames eingestellt werden, es war $a b$ 1897 Emil Philippi, über den im Direktorat Branca (s. u.) berichtet wird.

\section{Wiirdigung von Ernst Beyrich}

Als Ernst Beyrich am 9.7.1896 verstarb, war er fast 81 Jahre alt. Mit den geowissenschaftlichen Institutionen der Berliner Universität war er 55 Jahre ununterbrochen verbunden. Wie dargestellt, hat sich Beyrich gegenüber den Wünschen der preußischen Berg- und Hüttenverwaltung stets bereitwillig und aufgeschlossen verhalten. In ihm erfüllte sich das, was man ehemals von Christian Samuel Weiss erhofft hatte, als die Bergakademieausbildung an die in Gründung befindliche Universität übertragen wurde, was aber von ihm nicht zu erhalten war. Als Schüler von Weiss holte sich Beyrich seine ihm mehr zusagende Ausrichtung auf die Geologie und Paläontologie an der Universität in Bonn sowie bei der Arbeit an den Goniatiten des rheinischen Schiefergebirges. Hiermit promovierte er 1837 bei Weiss und ging auf eine zweijährige Forschungsreise mit dem Berliner Geologen Julius Ewald (1811-1891), seinem lebenslangen Freund. Er festigte sich dabei in seiner Arbeitsrichtung und vermochte es 1840 . Weiss dazu zu bewegen, beim Kultusministerium die Einrichtung des Lehrfaches Petrefaktenkunde am Mineralogischen Museum zu erwirken. Kurz nach seiner Anstellung als „Gehilfe“ für die Petrefaktensammlung und nach seiner Habilitation im Jahre 1841 nahm er die Nebentätigkeit für das Berg- und Hüttenwesen auf, indem er den Auftrag zur geologischen Bereisung Schlesiens annahm. Zugleich war es auch der Start zu den Kartierungsarbeiten, einer der großen Aufgabe seines Lebens, deren Höhepunkt er in seinen späten Lebensjahren erreichte, als er schließlich eine große Anzahl kartierender Geologen leiten konnte. Mit dem 13 Jahre jüngeren Wilhelm
Hauchecorne, dem Leiter der 1860 erneuerten Bergakademie entwickelte er eine enge Freundschaft, die die Basis bildete, um zusammen mit Hauchecorne die Leitung der 1873 errichteten Geologischen Landesanstalt zu übernehmen. Das Organisationstalent Hauchecornes wurde in glücklicher Weise durch Beyrichs wissenschaftliche Fähigkeiten ergänzt. Beyrich konnte dazu unter anderem die Verwendung der Fossilien als stratigraphisch nutzbare ökologische Anzeichen und Zeitmarken sowie die genauere Gliederung des Tertiärs nebst Aufstellung des Oligozäns einbringen. Hervorzuheben ist auch Beyrichs beständiger Einsatz für die Vermehrung und Dokumentation der bedeutenden Sammlungsbestände sowohl in der Sammlung der Geologischen Landesanstalt als auch, wie von W. O. Dietrich (1960) detailliert belegt, im Museum für Naturkunde. Nicht $\mathrm{zu}$ vergessen ist der aktive und nachhaltige Einsatz in der 1848 von ihm mitgegründeten Deutschen Geologischen Gesellschaft. All dies bestätigen Nachrufe und biographische Darstellungen zeitgenössischer und späterer Autoren sowohl aus der Sicht der Universität (u. a. Dames 1899, Koken 1901, Helms 1997) als auch aus der Sicht der Geologischen Landesanstalt (Hauchecorne 1896, Carlé 1988). Hierbei kommen auch manche menschliche Schwächen $\mathrm{zu}$ Tage, wie Beyrichs oft erbarmungslose Kritik gegenüber den Kartierern, was zu unnötigen Verärgerungen geführt hat (Carlé, S. 75), oder sein schroffes und ungerechtes Verhalten gegenüber seinem Kustos und Neffen Dames, der darunter offenbar sehr litt (nach Briefen von Ferdinand Roemer, Helms, S. 301), ferner auch sein geringes Redetalent und die Lässigkeit der losen Aneinanderreihung des Stoffes in den Vorlesungen (Koken, S. 38), was aber den Lehrerfolg anscheinend nicht beeinträchtigt hat.

\section{Würdigung von Wilhelm Dames}

Die Amtszeit von Wilhelm Dames (Abb.11) als Nachfolger Beyrichs und als Direktor war nur kurz. Zwei Jahre nach dem Tode Beyrichs verstarb er im Alter von 55 Jahren. Dennoch hat er eine Würdigung verdient, da vor allem er es war, der es Beyrich ermöglichte, seine aufwändige und verantwortliche Doppeltätigkeit an der Universität und im Bergwesen auf Dauer hin auszuüben, da er ihm ein zuverlässiger und befähigter Vertreter war. Besonders wichtig war dabei seine vielseitige Vorlesungstätigkeit, mit der er das Vorlesungsprogramm nicht nur wesentlich 


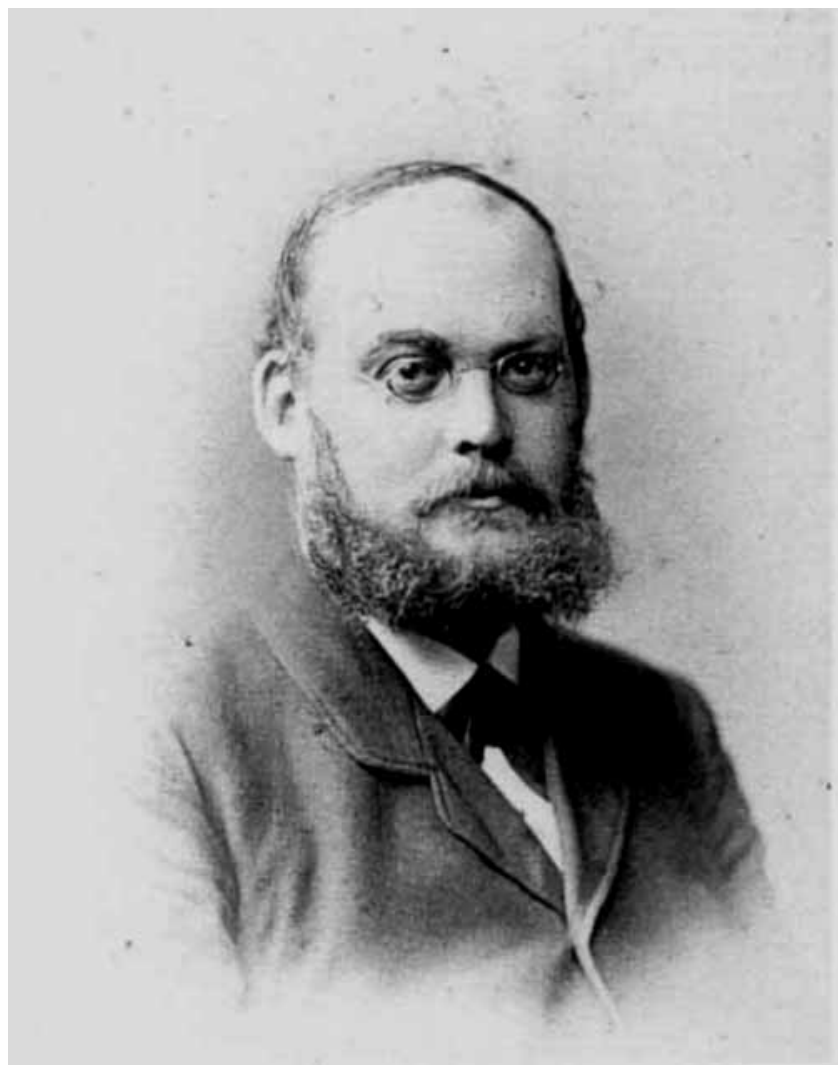

Abb. 11. Wilhelm Dames (1843-1898). - Original im Museum für Naturkunde, HHMfN-8 (Bestand: Paläontologisches Museum), Sign. B I/67.

bereichert, sondern auch die von Beyrich nie geschlossene Lücke der Sommersemester ausgefüllt hat. Dames war zugleich ein verantwortungsbewusster Kustos und hat diese Funktion 16 Jahre lang neben seiner lebhaften Lehrtätigkeit ausgeübt. Es gelang ihm, beides mit Forschungsarbeiten zu verbinden. Auch hier war er vielseitig in seinen vorwiegend paläontologischen Arbeiten über Wirbellose, paläozoische Fossilien und später über fossile Säugetiere und Reptilien (Koken 1899). Einen Höhepunkt stellt seine groBe Arbeit über den Urvogel Archaeopteryx dar (Dames 1884), in der er alle Aspekte dieses seltenen Fossils erschöpfend behandelt hat. Andererseits war er einer der ersten, der die Torellsche Theorie der Inlandvereisung vertreten hat, auch in einer 1890 gehaltenen Vorlesung. Von Quenstedt (1957) wird auf die Fähigkeit von Dames hingewiesen, noch die in späteren Zeiten immer mehr auseinanderlaufenden Tätigkeitsfelder des Kustos, des Hochschullehrers und Forschers sowie des Redakteurs einer wissenschaftlichen Zeitschrift in sich zu vereinen.

\section{Direktor Wilhelm Branca $\left(\right.$ Branco) ${ }^{51}$}

Nach dem Tod von Dames übernahm Otto Jaekel für ein Vierteljahr die Geschäftsführung. Die Berufung von Wilhelm Branca (Abb. 12) erfolgte dann am 14.4. 1899 (GSTAB-46, Bl. 201). Branca war in Berlin kein Unbekannter, hatte er doch bereits 1881 und von 1882 bis 1887 als Privatdozent gewirkt. Dennoch brachte sein Eintritt als Direktor einen deutlichen Einschnitt. Branca hatte für einen Wissenschaftler einen ungewöhnlichen Lebenslauf hinter sich, da er zunächst Offizier war, dann Landwirt, und erst danach im Alter von 32 Jahren ein Geologiestudium abschließen konnte. Er war dann als Assistent an etlichen Universitäten tätig, habilitierte sich 1881 in Berlin, war von 1882 bis 1887 als Landesgeologe an der Preußischen Geologischen Landesanstalt und daneben als Privatdozent an der Berliner Universität tätig, hatte dann nacheinander Lehrstühle an mehreren Universitäten inne, zuletzt an der Landwirtschaftlichen Hochschule Hohenheim bei Stuttgart, von wo aus er der Berufung an die Universität Berlin folgte. Brancas erste Publikation betraf erloschene Vulkane in Mittelitalien (Branca 1877), danach arbeitete er paläontologisch, vorwiegend über Cephalopoden, auch über Fische, ging dann aber, als er von 1890 bis 1895 in Tübingen war, zur Erforschung der Vulkane der schwäbischen Alb über (Branca 1894), worin er erfolgreich war und im Jahre 1895 vom König Württembergs durch die Verleihung des Adelstitels geehrt wurde. Anschließend versuchte er dann, zusammen mit dem Stuttgarter Eberhard Fraas (1862-1915), das Nördlinger Ries als zusammengefallene vulkanologische Aufwölbung zu deuten (Branca \& Fraas 1901). Diese Hypothese, die er vehement verteidigte, wurde noch von Pompeckj (1928) als hohe Leistung Brancas gefeiert. Auch H. Reck (1929) würdigte seinen Lehrer begeistert. In Berlin widmete er sich der möglichst allseitigen Entwicklung des Institutes und der Sammlung. Schließlich kam ihm die "Vorarbeit" der Ausbeutung der Tendaguru-Saurierfundstätte durch seinen Stuttgarter Freund Eberhard Fraas im Jahre 1907 sehr entgegen und er führte die Ausgrabung zum Nutzen des an Wirbeltiermaterial noch unterentwickeltem Berliner Museums von 1909 bis 1913 mit Elan und Durchsetzungskraft in großartigem Stil von Berlin aus weiter. Sein beweglicher Geist führte ihn unter anderem auch noch zu

\footnotetext{
${ }^{51}$ Bereits von hier ab wird die ab 1907 von Branco gebrauchte Namensform Branca verwendet.
} 


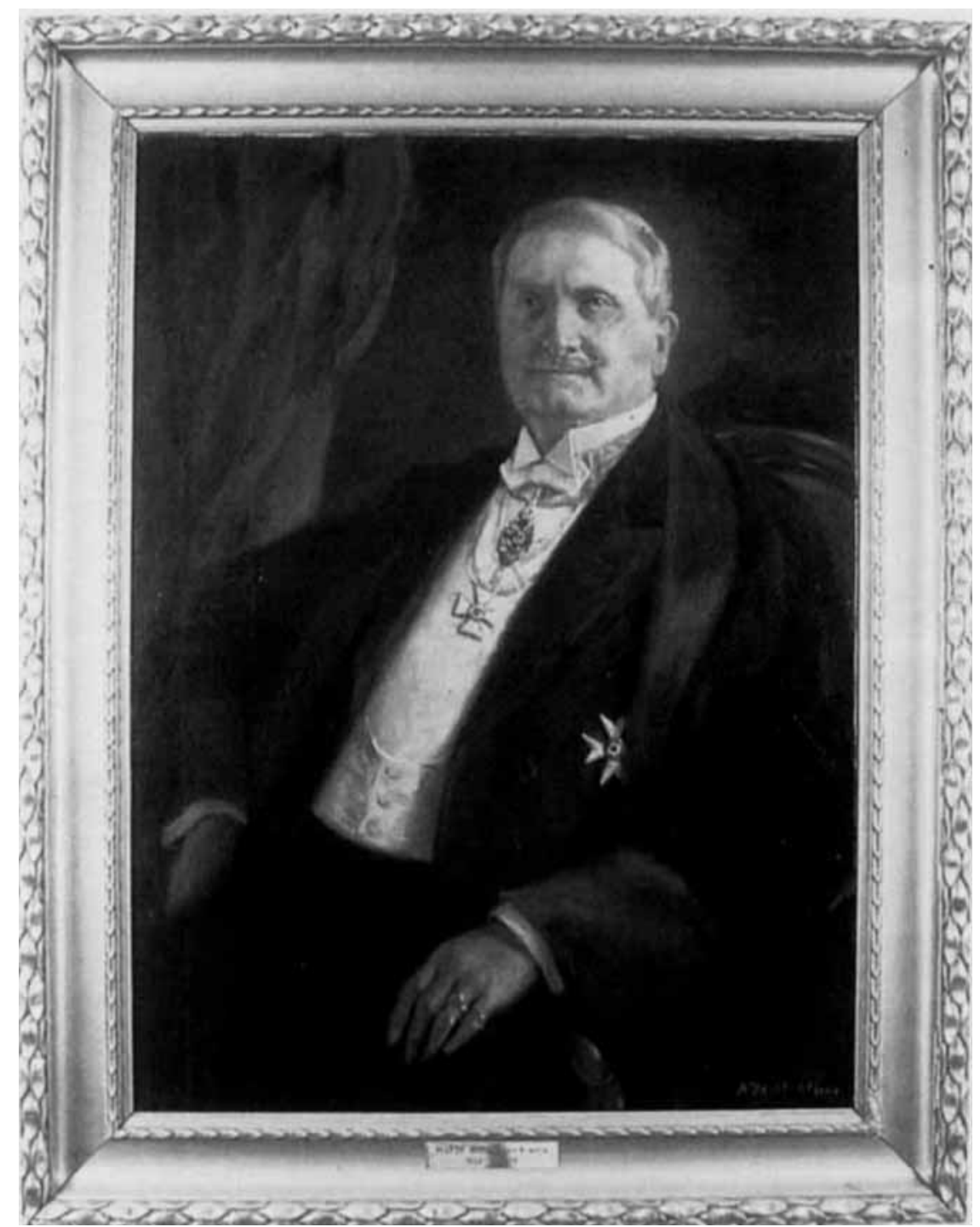

Abb. 12. Wilhelm v. Branca (1844-1928). Gemälde von Alexander Desclabissac. - Original im Museum für Naturkunde, HHMfN8 (Bestand: Paläontologisches Museum), Sign.: B VII/1. den Fragen des fossilen Menschen, womit er sich bis $\mathrm{zu}$ seiner Emeritierung im Jahre 1917 beschäftigte.

\section{Lehre}

Branca hielt regelmäßig zwei Hauptvorlesungen, eine vierstündige Geologie im Wintersemester und eine fünfstündige Paläontologie im Sommersemester. In den ersten vier Anfangsjahren war er allerdings noch nicht so festgelegt, aber das ist nur scheinbar, da er den Stoff der späteren Vorlesungen in Teile zerlegt und anders auf die Semester verteilt vortrug. Im Jahre 1901 definierte er eine Vorlesung auch genauer: „Geologie als Entwicklungsgeschichte der Erde und der Lebewelt" und er hielt 1907 auch einmal eine zusätzliche Vorlesung über fossile Säugetiere. Wie unter Beyrich und Dames traten neben Branca wieder Dozenten der Bergakademie mit Vorlesungen auf. An erster Stelle ist Felix Wahn- schaffe zu nennen, der weiterhin über allgemeine Geologie und über die Geologie des Quartärs Norddeutschlands las. Vom Jahre 1901 an wurde das Angebotsspektrum von einem neuen Dozenten der Bergakademie durch ein neues Fach erweitert. Es war der Landesgeologe und Professor Henry Potonié, dem an der Universität die Facultas docendi für Paläophytologie erteilt worden war. Seine Vorlesung wurde im Vorlesungsverzeichnis als „Paläobotanik für Botaniker und Geologen" angekündigt, später statt dessen „Ausgewählte Kapitel aus der Paläobotanik“, auBerdem las er mehrmals auch noch über die Entstehung der Steinkohle und der brennbaren Fossilien. Zu erwähnen ist auch, dass der spätere Direktor ab 1932, der Geotektoniker Friedrich Stille, als er seit 1900 Geologe der Preußischen Geologischen Landesanstalt war, unter Branca seit 1904 als Privatdozent auftrat, bis er 1908 an die Technische Hochschule Hannover berufen wurde. Seine Vorlesungen betrafen die Physio- 
graphie des mittleren und nordwestlichen Deutschlands, Grundwasser und Quellen, das geologische Bild Mitteleuropas und die Paläogeographie. Der von Asen (1955) als Geologe verzeichnete Gastprofessor von der HarvardUniversität, Massachusetts, William Morris Davis, trat nur im Rahmen der Geographie im Jahre 1908 mit Vorlesungen auf. Schließlich hielten auch einige habilitierte Assistenten Brancas Vorlesungen auf, wie aus folgendem hervorgeht.

\section{Kustoden unter Branca}

An Mitarbeiterstellen standen Branca bei seinem Eintritt ein Kustos, zwei Assistenten und ein Hilfsassistent zur Verfügung. Die Kustosstelle war besetzt mit Otto Jaekel, der bereits 1892 unter Beyrich eingetreten war und 1895 den Professorentitel erhalten hatte. Er hatte bereits unter Beyrich ein recht breites Vorlesungsspektrum vorgetragen, das er auch unter Branca fortsetzte, anfangs zwei Vorlesungen, was er von 1902 an auf eine Vorlesung reduzierte. Meist las er über Teilgebiete der Paläontologie, über die Stammesgeschichte der Echinodermen, über die Entstehung der Wirbeltiere, über die Descendenzlehre und anderes. Im Januar 1904 wurde er zum a. o. Professor ernannt (GSTAB-41, Bd. 3, Bl. 203). Auch dieser Titel war wie der vorige mit keinerlei Mitteln versehen ${ }^{52}$ und Jaekel blieb auf der Kustosstelle. Als Jaekel im April 1906 das Kultusministerium um einen halbjährigen Urlaub zum Abschluss einiger wissenschaftlichen Arbeiten bat, sah Branca in der von ihm verlangten Stellungnahme eine Möglichkeit, sich zur Unvereinbarkeit der gleichzeitigen Wahrnehmung einer Kustos- und Lehrtätigkeit zu äußern und bittet das Ministerium, Jaekel ein anderwärts freiwerdendes Extraordinariat zu erteilen, damit die Berliner Kustosstelle frei wird und ein Kustos angestellt werden kann, „der seinen Schwerpunkt, wie es sich gehört, in den Arbeiten für das Museum findet." Außerdem teilt Branca im gleichen Schreiben mit, dass er bei der Anstellung von Werner Janensch als Assistent im Jahre 1901 von diesem verlangt habe, sich nicht zu habilitieren (GSTAB-47, Bl. 268), offenbar da er ihn zum späteren Kustos ausersehen hatte. Im Herbst 1906 ging Jaekel schließlich als o. Professor nach Greifswald und Branca konnte die Kustosstelle mit Janensch besetzen, der sich in dieser Position bewährte. Zwar wurde auch er im Jahre 1909 „,beurlaubt“, aber aus einem Anlass, der der Aufgabe eines Kustos entsprach. Es war die Leitung der Tendaguru-Ausgrabungen im deutschen Schutzgebiet Ostafrika (dem heutigen Tansania), die die großartigen Saurierfunde erbrachte. Janensch blieb Kustos bis zu seiner Entpflichtung im Jahre 1950 im Alter von 72 Jahren.

\section{Assistenten Brancas}

Die Tätigkeit der Assistenten ist wegen der anfangs zwei und später drei Assistentenstellen und der zusätzlichen Hilfsassistenten sowie der meist nur kurzen Dienstzeiten nicht leicht zu übersehen. In der folgenden Zusammenstellung werden die Tätigkeitsjahre in Klammern mit dem Zusatz „A“ für Assistent und „HA“ für Hilfsassistent angegeben.

Bereits vor Brancas Berufung war Johannes Böhm (A 1895-1901) eingetreten und ging danach in die Berliner Bergakademie und Geologische Landesanstalt, und ebenso auch Emil Philippi (A 1897-1900). Letzterer habilitierte sich danach, wurde aber erst 1904 nach seiner Teilnahme an der deutschen Südpolarexpedition als Privatdozent wirksam und nahm 1906 einen Ruf nach Jena an. Er las über die Geologie der deutschen Mittelgebirge, über die Geologie der Alpen, über das Klima der Vorwelt und über Sedimentbildungen der Gegenwart, besonders am Boden der Tiefsee. Die folgenden wurden von Branca eingestellt. Der erste war Friedrich Solger (HA 1899, A 1900-1903), der anschließend eine Stelle im Berliner Märkischen Museum annahm, sich aber habilitierte und als Privatdozent auftrat. Er las ab 1908 über die Geologie Brandenburgs, über die Methoden der Geologie und über das organische Leben als gelogischer Faktor. Er erhielt 1909 eine Professur in China und wurde später, nach japanischer Kriegsgefangenschaft, wieder im Geologisch-paläontologischen Institut tätig. Es folgte Georg Brandes (HA 1900, A 1901-02), der 1902 schwer erkrankte und 1906 verstarb. Danach ist Walther v. Knebel (HA 1901, 1906) zu nennen, der sich 1907 habilitierte. Seine drei für das Wintersemester 1907/8 angekündigten Vorlesungen über die Paläontologie der Crustazeen, über Quellen- und Höhlenkunde und über die Geologie der atlantischen

\footnotetext{
52 Jaekel musste bei der Ernennung sogar schriftlich bestätigen, dass er keine geldlichen Forderungen von diesem Titel ableiten darf.
} 
Inseln fanden nicht statt, da er 1907 während einer von der Akademie der Wissenschaften finanzierten Island-Exkursion ertrank. Als nächster ist der bereits genannte Werner Janensch (A 1901-1906) zu erwähnen, der anschließend, wie schon dargestellt, zum Kustos aufrückte. Es folgen dann Egon Kirschstein (HA 1902-5, A 1905-06), der 1907 ein Jahr Urlaub erhielt, um an der Forschungsexpedition des Herzogs Adolf Friedrich zu Mecklenburg nach Ost- und Zentralafrika teilnehmen zu können, was Branca unterstützte (GSTAB-48, Bl. 34), sowie Ernst Stromer v. Reichenbach, der nur wenige Monate des Jahres 1903 Hilfsassistent war. Als nächster ist Hermann Stremme (A 1903-1908) zu nennen, der sich anschließend habilitierte und als Privatdozent Vorlesungen über fossile Säugetiere bzw. Wirbeltiere hielt, auch Exkursionen führte. Er ging 1914, einem Ruf folgend, nach Danzig. Edwin Hennig (A 1906-1917). der besonders lange Zeit Assistent war, erhielt 1909 Urlaub zur Teilnahme an der Ostafrika-Expedition, und war dann bis 1911 aktiv an der Leitung der Tendaguru-Ausgrabungen beteiligt ${ }^{52 a}$. Er habilitierte sich danach und ging 1917 nach Tühingen. Nur relativ kurze Zeit blieben Rudolf Hermann (HA 1906, A 1907), Wilhelm Kronecker (HA 1908, A 1909-1911) und Hugo Schwarz (A 1909). Letzterer und Johannes (Hans) v. Staff (A 1909-1911) waren als Vertreter für die nach Ostafrika beurlaubten Janensch und Hennig eingestellt worden. Von ihnen blieb v. Staff etwas länger, habilitierte sich 1909 und hielt im Jahre 1910 Vorlesungen über Grundwasser und Quellen sowie über die Paläontologie der Foraminiferen. Er blieb bis 1914 als Privatdozent und ging als Regierungsgeologe nach Südwestafrika, wo er 1915 starb (Hennig 1915). Als letzter vor dem Jahre 1910 wurde Hans Reck angestellt (HA 1909, A 1910-14), der sich unter Branca sowohl auf paläontologischem als auch auf vulkanologischem Gebiet entwickelte. Vor seiner Anstellung war er 1908 auf Island, wo er das Schicksal der verschollenen Expedition W. v. Knebels aufzuklären versuchte.

\section{Entwicklung der Sammlungen unter Beyrich, Dames und Branca}

Die folgenden Ausführungen über die Entwicklung der Sammlungen beziehen sich vorwiegend auf größere Erwerbungen und Schenkungen, über die Unterlagen in den Akten des Kultusministeriums vorliegen. Zur Vervollständigung der Sammlungen haben aber auch die eigenen Aufsammlungen, Schenkungen und kleinere Käufe erheblich beigetragen, worüber jedoch hauptsächlich auf die Jahresberichte verwiesen werden muss, die ab 1889 in der Zeitschrift „Chronik der königl. Friedrich-Wilhelms-Universität zu Berlin" erschienen sind, auch auf den Bericht von Branca (1910) und auf die Zusammenstellung von Dietrich (1965).

Nachdem die bereits genannten Versuche zur Erwerbung von Sammlungen fossiler Wirbeltierreste der Pampasformation Argentiniens von 1879 und 1884/5 gescheitert waren, traf im Februar 1889 wiederum ein Angebot zum Kauf einer neu zusammen gebrachten Sammlung von dem Besitzer Sanjago Roth in Zürich, für 40000 Mark ein (GSTAB-40, Bl. 281). Der Kauf wurde vom Kultusministerium befürwortet, jedoch vom Finanzministerium im Mai 1889 abgelehnt, da in letzter Zeit schon sehr viel gekauft worden sei und „die ins Feld geführte Notwendigkeit, I ücken zu schließen, nicht dahin führen dürfe, dass die neu hergestellten Räume bald wieder unzureichend werden" (GSTAB-44, B1. 8). Auch ein nochmaliger Vorstoß stimmte den Finanzminister nicht um, dies gelang erst im Oktober 1890 durch Gutachten, die von der Akademie der Wissenschaften und von dem Paläontologen Hermann Roemer in Hildesheim stammten. Darüber war aber viel Zeit vergangen und auch diese Sammlung war inzwischen verkauft. Sanjago Roth brachte schließlich 1891 nochmals eine kleinere Sammlung zusammen, deren Kauf Beyrich beantragte (GSTAB-44, Bl. 248, vom 28. 7. 1891). In den Ministeriumsakten findet sich jedoch kein Hinweis über einen Erfolg. Vermutlich ist auch dieser Kaufversuch gescheitert, wofür spricht, dass Branca 10 Jahre später seinen großen Antrag auf Beschaffung von Wirbeltierfossilien damit begründete, dass Beyrich hierfür nichts getan habe (s. u.), auch Dietrich (1965) erwähnt nichts davon.

Eine sehr wertvolle und umfangreiche Schenkung gab es nach dem am 11.12.1891 erfolgten Tode des bedeutenden Berliner Geologen und Paläontologen Julius Ewald (1811-1891), des Herausgebers der gesammelten Schriften Leopold v. Buchs (Ewald u. a. 1867/85). Die Witwe

\footnotetext{
52a Die Beurlaubung von Hennig ist von Branca (1910) für das Jahr 1908 abgegeben, jedoch erfolgte sie gleichzeitig mit der von Janensch im Jahre 1909. Herrn Gerhard Maier. Calgary, Canada, wird für die freundliche Mitteilung seiner detaillierten Überprüfung gedankt.
} 
übergab seine hinterlassene Sammlung (GSTAB44, Bl. 315). Ewald war seit seinem Studium mit dem Museum eng verbunden gewesen und hatte seine Sammlung bei Kartierungsarbeiten und auf Reisen in Europa geschaffen. Sie war besonders dadurch wertvoll, da sie von vielen Lokalitäten vollständige Aufsammlungen der Versteinerungen enthielt.

Im Januar 1894 konnte ein wertvolles Einzelstück aus Sondermitteln des Kaisers erworben werden (Dietrich 1965, S. 273), ein Plesiosaurus aus Holzmaden, der 9000 Mark kostete (GSTAB-45, Bl. 179). Bei dem Besuch des Kaisers Wilhelm II. aus Anlass der Schenkung der Mineralsammlung aus dem Nachlass von E. v. Knobelsdorff (s. S. 39) konnte Dames dieses Objekt als Plesiosaurus Guilelmi Imperatoris präsentieren, welches Ereignis auch den Weg in die Presse fand ${ }^{53}$.

Als entscheidenden Schritt erreichte es Branca im Jahre 1901, dass ihm zur Vervollständigung der paläontologischen Sammlung als sogenanntes Extraordinarium ein außergewöhnlich hoher einmaliger Betrag zur Verfügung gestellt wurde. Im Antrag hatte er auf mehrere käufliche Sammlungen hingewiesen, vorwiegend von fossilen Säugetieren, und bat um einen Gesamtbetrag von 114000 Mark mit dem Argument, dass derartiges Material in der Sammlung schwach vertreten ist, denn „Beyrich beschränkte sich wesentlich auf Wirbellose" (GSTAB-47, Bl. 63) ${ }^{54}$. Branca erhielt zunächst 190254000 Mark, was später auf rund 60000 Mark erhöht wurde und für einige wenige Jahre zur Verfügung stand. Dadurch wurden die großen Unsicherheiten überwunden, die die längere Zeitdauer der Geldbeschaffung schon mehrfach mit sich gebracht hatte. Nun setzte große Betriebsamkeit zur Vorbereitung von Käufen ein, die sich aber wegen der Konkurrenz besser zahlender Museen nicht leicht arrangieren ließen. Gekauft wurden fossile Säugetiere unter anderem aus Patagonien, wohl auch die Sammlung Marty in Toulouse, zu deren Begutachtung und Entscheidung Professor Jaekel ausgesandt wurde, und später noch zahlreiche Einzelstücke, schließlich wurden auch Hilfsassistenten davon bezahlt, wie der Abschlussbe- richt zeigt (GSTAB-47, Bl. 205, vom 20.6. 1904). Säugetierreste enthielt auch die umfangreiche Schenkung, die im Jahre 1907 von den Leitern einer Expedition nach Pilcomayo, Ingenieur Wilhelm Herrmann aus Weissensee bei Berlin und Professor David Hansemann, Berlin, übergeben wurden. Es handelte sich um etliche Säugetiere aus der Pampasformation Boliviens. Branca schätzte 1908 den Wert der Fossilien auf 17600 Mark (GSTAB-48, Bl. 85). Ferner gab es 1908 auch noch eine Schenkung für die Ausstellung von dem Industriellen Andrew Carnegie aus USA. Es war ein $25 \mathrm{~m}$ langer Gipsabguss des Sauriers Diplodocus, der wegen seiner Größe im Lichthof neben den dort stehenden Skeletten rezenter Tiere aufgestellt wurde.

\section{Tendaguru-Ausgrabungen *}

Im Jahre 1907 kündigten sich große Funde in Afrika an. Der Bergbau-Ingenieur Bernhard Sattler hatte im damaligen Deutsch-Ostafrika (Tansania) sehr große Knochen entdeckt, was dem Konservator des Stuttgarter Naturalienkabinetts, Professor E. Fraas (1862-1915), kurz vor Antritt einer Reise in dieses Gebiet bekannt wurde. Diesem war es dann möglich, die Fundstelle, die am Berg Tendaguru lag, zu besuchen. Er erkannte, dass es sich um Dinosaurierknochen handelte und konnte unter Mithilfe von Sattler und einer großen Kolonne von Eingeborenen etliche, z. T. riesige Knochen ausgraben und bergen. So hatte sein Unternehmen großen Erfolg, obwohl er es infolge einer Tropenkrankheit abbrechen musste (Wild 1991). Artikel von Fraas vom Jahre 1908 brachten die Nachricht von den Funden nach Berlin, zugleich auch die Aussage über die weitere große Fundhöffigkeit (Fraas 1908), woraufhin Branca den Entschluss fasste, eine Ausgrabungsexpedition großen Stiles in Gang zu setzen. Aus seinem späteren Rechenschaftsbericht (Branca 1914) ist zu entnehmen, dass er, da eine Finanzierung weder durch den preußischen Staat noch durch das Deutsche Reich zu erreichen war, eine Spendenaktion unter der Schirmherrschaft des Herzogs Johann Albrecht von Mecklenburg (1857-1920), Regent

\footnotetext{
53 Die Allgemeine Zeitung in München brachte am 9.5.1894 folgende Meldung: „Berlin. 7. Mai. Der Kaiser gewährte der „Post" zufolge bei seinem neuerlichen Besuch des Museums für Naturheilkunde [!] die von Professor Dames vorgetragene Bitte, den von S. Majestät für das Museum erworbenen Plesiosaurus, der eine unbeschriebene Art repräsentirt, als „Plesiosaurus Guilelmi Imperatoris" in die Wissenschaft einführen zu dürfen“.

${ }^{54}$ Nicht eine „Beschränkung“ Beyrichs, sondern das zeitaufwendige Genehmigungsverfahren hatte zu dem Mangel an Wirbeltiermaterial beigetragen.

* Ausführliche Darstellung in Maier 2003 (siehe Buchbesprechung am Ende des Buches).
} 
von Braunschweig, organisierte. Da im ersten Anlauf 104000 Mark zusammenkamen, wurde zunächst für zwei Jahre eine Expedition ausgesandt und die Ausgrabungen unter Mitwirkung des Entdeckers Sattler in Gang gesetzt. Die Leitung wurde Kustos Janensch und Assistent Hennig übertragen, beide wurden 1909 nach Afrika „beurlaubt“ (Janensch 1914). Bei den Grabungen wurde mit großer Umsicht vorgegangen, um die Funde, die zu einem Teil aus mehr oder weniger vollständigen Skeletten sehr großer Saurier bestanden, unbeschädigt $\mathrm{zu}$ bergen und so $\mathrm{zu}$ verpacken und $\mathrm{zu}$ kennzeichnen, dass sie nach dem mehrtägigen Transport durch Trägerkolonnen und der Verschiffung ohne Schaden nach Berlin gelangten. Bereits im Jahresbericht 1909 der Zeitschrift Chronik der Universität Berlin ist die Rede von zahlreich eingetroffenen Dinosaurierresten und im Jahresbericht 1910 heißt es, dass das Museum wesentlich im Zeichen der Tendaguru-Expedition stand. Bis dahin waren 358 Kisten mit insgesamt $70 \mathrm{t}$ Gewicht eingetroffen, auch wird davon berichtet, dass nun auch Schädelfunde, die bisher ausgeblieben waren, gemacht werden konnten. Die große Bedeutung der Funde hinsichtlich Artenvielfalt, Vollständigkeit und Güte des Erhaltungszustandes und auch Größe der Einzelknochen zeichnete sich immer deutlicher ab. Es sollen deshalb weitere Geldmittel für nochmals zwei Jahre andauernde Grabungen eingeworben werden. Inzwischen war großer Platzmangel im Museum entstanden, sodass der Bau eines Schuppens im Hinterhof genehmigt wurde, darüber hinaus gab es ein Platzproblem für den Aufbau und die Aufstellung der riesigen Skelette, das noch zu lösen war. Glücklicherweise war es gelungen für die Zeit des Afrikaeinsatzes von Janensch und Hennig Vertreter sowie auch Hilfsassistenten einstellen zu können, sodass der große Arbeitsanfall in Berlin bewältigt werden konnte (GSTAB-48, Bl. 141). -- Das Ende der Expedition trat dann im Jahre 1913 ein, worauf hier nicht eingegangen werden kann, zumal eine abschließende Bewertung, allein schon wegen der zeitaufwendigen Präparationsarbeiten, erst weit später möglich wurde. Es zeigte sich aber bereits 1910 sehr deutlich, dass das Tendaguru-Unternehmen ein überwältigender Erfolg wird, der aber auch noch große Anstrengungen erfordert.

\section{Mineralogisch-petrographisches Institut und Sammlung 1888 bis 1910}

\section{Direktorat Carl Klein}

Die Trennung des ehemaligen Mineralogischen Museums in zwei Institutionen fiel, wie schon dargestellt, praktisch mit der am 4.3.1887 erfolgten Berufung des Mineralogen Carl Klein als Nachfolger von Websky zusammen. Klein kam aus Göttingen und stand im Alter von 45 Jahren. Seine Amtszeit dauerte zwei Jahrzehnte bis zu seinem Tod im Jahre 1907. Unter ihm vollzog sich der Umzug in das neue Gebäude, in dem die westliche Hälfte des Vorderhauses zur Verfügung stand. Im Erdgeschoss lagen die zwei Ausstellungssäle, der seitliche große Mineralsaal und der kleine Gesteinssaal an der Vorderseite des Gebäudes. Die wissenschaftliche mineralogische Hauptsammlung befand sich im 1. Geschoss. Die petrographische Sammlung, die bisher von Professor Roth als dritte Abteilung des ehemaligen Mineralogischen Museums aufgebaut worden war und die mit der Berufung von Klein der Mineralogisch-petrographischen Sammlung zufiel, kam in einen Saal, der im 2. Geschoss, genau in der Mitte der Vorderfront lag, offenbar so, wie es vor Aufhebung der Selbstständigkeit dieser Sammlung als dritte Abteilung vorgesehen worden war ${ }^{55}$. Den Umzug bewältigte Klein mit seinem Personal, bestehend aus dem schon seit 1883 vorhandenen Kustos August Tenne und dem neu eingestellten Assistenten Friedrich Rinne, sowie dem Präparator Karl Körner. Für Hilfsarbeiten zum Aufbau der Schausammlung konnte Klein auch noch vier seiner bereits promovierten Göttinger Schüler, die mit nach Berlin gekommen waren, für einige Monate gegen Vergütung einsetzen. Es handelte sich um Eduard Möller und Richard Küch sowie um Dr. Rethwisch und Dr. Stremme ${ }^{56}$. Die Schausammlung konnte dadurch am 23.5.1889 fertiggestellt werden (GSTAB-40, Bl. 321).

\section{Die Schenkung Carl Rumpff der Sammlung Erz- herzog Stephan}

Kurz danach musste die Ausstellung jedoch infolge der Schenkung einer großen Mineralsammlung geändert werden. Das Schenkungsangebot, das am 7.7.1889 bei der Regierung eintraf, war

\footnotetext{
5.5 Branca erhielt diesen Saal im Jahre 1908 für die Geologie-Paläontologie, da Liebisch, der Nachfolger Kleins, dem Drängen Brancas nachgab (Branca 1910, S. 333).

56 Über die beiden letztgenannten Helfer konnte nichts ermittelt werden Sie fehlen deshalb in der Tabelle 1 im Anhang des Artikels.
} 


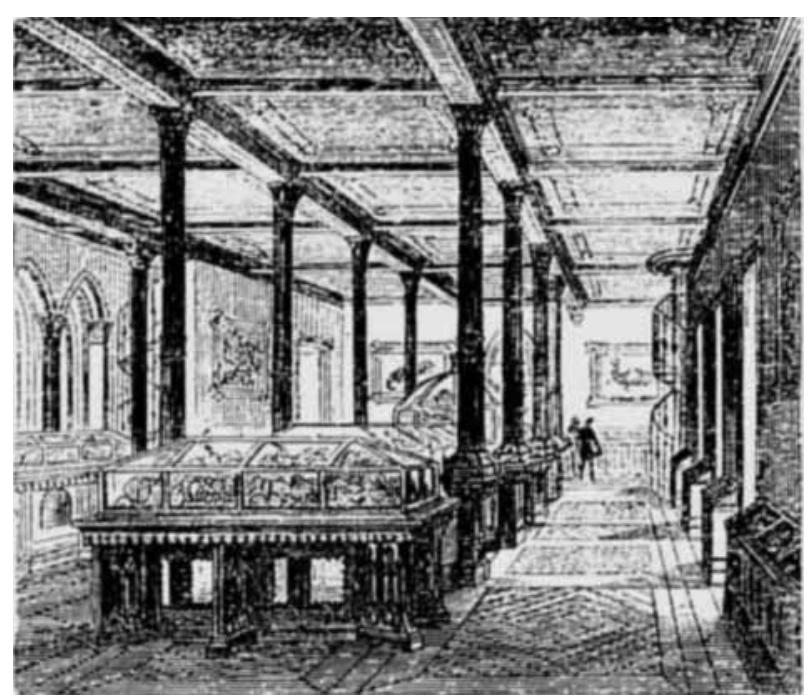

Abb. 13. Der Saal der Mineraliensammlung des Erzherzogs Stephan im Schloss Schaumburg an der Lahn. - Reproduziert aus: Anonym 1868, S. 318.

mit der Bedingung verbunden, diese Sammlung geschlossen für dauernd öffentlich auszustellen (GSTAB-44, Bl.11). Es handelte sich um die ehemalige Sammlung des verstorbenen österreichischen Erzherzogs Stephan (1817-1867), die von dem Industriellen und Mitglied des Reichstages Carl Rumpff (1839-1889), Teilhaber der Anilinfabrik Bayer in Barmen-Elberfeld, vor einigen Jahren gekauft worden war, um sie in Deutschland $\mathrm{zu}$ halten. Die Sammlung stand

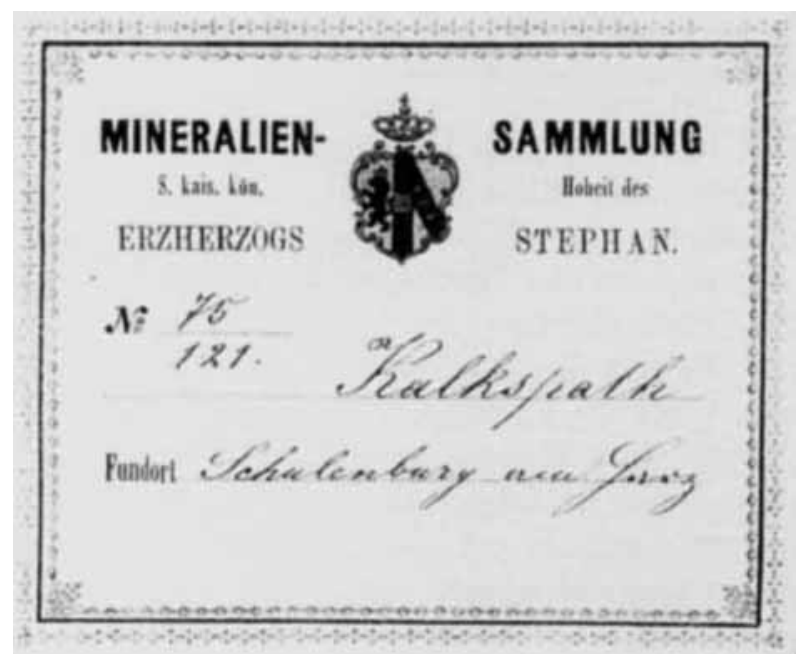

Abb. 14. Kalkspath, Schulenburg am Harz. Sammlungsetikett der ehemaligen Sammlung Erzherzog Stephan. - Original im Museum für Naturkunde, Mineralsammlung. noch im Ausstellungssaal des Schlosses Schaumburg an der Lahn (Abb. 13) und bestand aus 14400 Stücken, davon 3300 Schaustücken ersten Ranges. Sie enthielt auch die Sammlung des Hamburger Diplomaten H. C. G. Struve (17721851) und war sehr gut dokumentiert (Abb 14). Einschließlich zusätzlicher Meteorite im Werte von 20000 Mark und der Möbel hatte sie einen geschätzten Gesamtwert von 89800 Mark. Nach dem Tode Carl Rumpffs am 2.6.1888 vollzog seine Witwe Clara, geb. Bayer, durch die Schenkung den Willen ihres Mannes. Kaiser Wilhelm II. genehmigte die Annahme der Schenkung ${ }^{57}$. Die von der Regierung zunächst vorgeschlagene Aufstellung in Bonn lehnte die Witwe ab und bestand auf geschlossener Aufstellung der Sammlung im neuen Berliner Museum für Naturkunde nebst Bezeichnung des Saales mit dem Namen ihres Mannes. Klein konnte in den Verhandlungen erreichen, dass die Schaustücke der Sammlung in die bestehende Ausstellung des großen mineralogischen Ausstellungssaales eingeordnet wurden und dieser Saal die Bezeichnung „Vereinigte Staats- und Carl Rumpffsche Mineralsammlung" erhielt (GSTAB-44, Bl. 139). Kustos Tenne leitete die Überführung der Sammlung mit den Ausstellungsmöbeln nach Berlin, wofür fünf Güterwagen benötigt wurden. Drei der schönsten Schauschränke vom Schloss Schaumburg kamen in den Mittelgang des Ausstellungssaales. Wegen der kurzen Frist konnte der Ausstellungssaal zur Einweihungsfeier des Museums jedoch nur provisorisch eingerichtet werden $^{58}$.

\section{Lehre unter Klein}

Trotz dieses turbulenten Beginns stand die Lehre im Vordergrund. Klein las regelmäßig den vollen Umfang der Mineralogie, der Kristallographie und der Petrographie in drei getrennten Vorlesungen zu sechs, vier und fünf Wochenstunden. Neben ihm trat Roth, nun als o. Professor für Petrographie und allgemeine Geologie, regelmäßig mit Vorlesungen auf. Er las dreistündig über allgemeine und chemische Geologie, zweistündig über Petrographie, und einstündig über Bau, Wirkungsweise und Verteilung der Vulkane. Es gab ferner einen mineralogischen Privatdozenten, den nicht im Museum angestell-

\footnotetext{
57 Dies bedeutete zunächst aber keine Befreiung von der Schenkungssteuer, die der Schenkungsgeber zu entrichten hatte. Erst nach längeren Verhandlungen wurde Befreiung erreicht.

${ }_{58} \operatorname{Im} 2$. Weltkrieg wurden alle Ausstellungsstücke dieses Saales, auch die der Sammlung Rumpff/Erzherzog Stephan, ausgelagert und gingen dem Museum verloren.
} 
ten Hermann Traube, der von 1890 bis 1900 eine Reihe von ein- oder zweistündigen Vorlesungen gehalten hat, wie u. a. über die Lagerstätten der Erze, über nutzbare Minerale, über chemische Kristallographie, über die mikrochemische Analyse von Kristallen und über die Mineralchemie. Er folgte 1905 einem Ruf nach Greifswald. Außerdem betätigten sich auch einige Kustoden und Assistenten als Privatdozenten, was später behandelt wird. Ferner trat wie schon früher der Physikochemiker Andreas Fock mit einstündigen Vorlesungen über chemische Kristallographie, Struktur der Kristalle und ähnliche Themen auf. Daneben erschien im Vorlesungsverzeichnis der Jahre 1893 und 1895 der Physiker Eugen Blasius mit der Vorlesung über Geometrische Kristallographie in synthetischer Behandlung. Schließlich ist bei Asen (1955) noch der Physiker und Mineraloge Hermann Starke als Privatdozent genannt, der jedoch keine entsprechende Vorlesungen für Geowissenschaftler angekündigt hat.

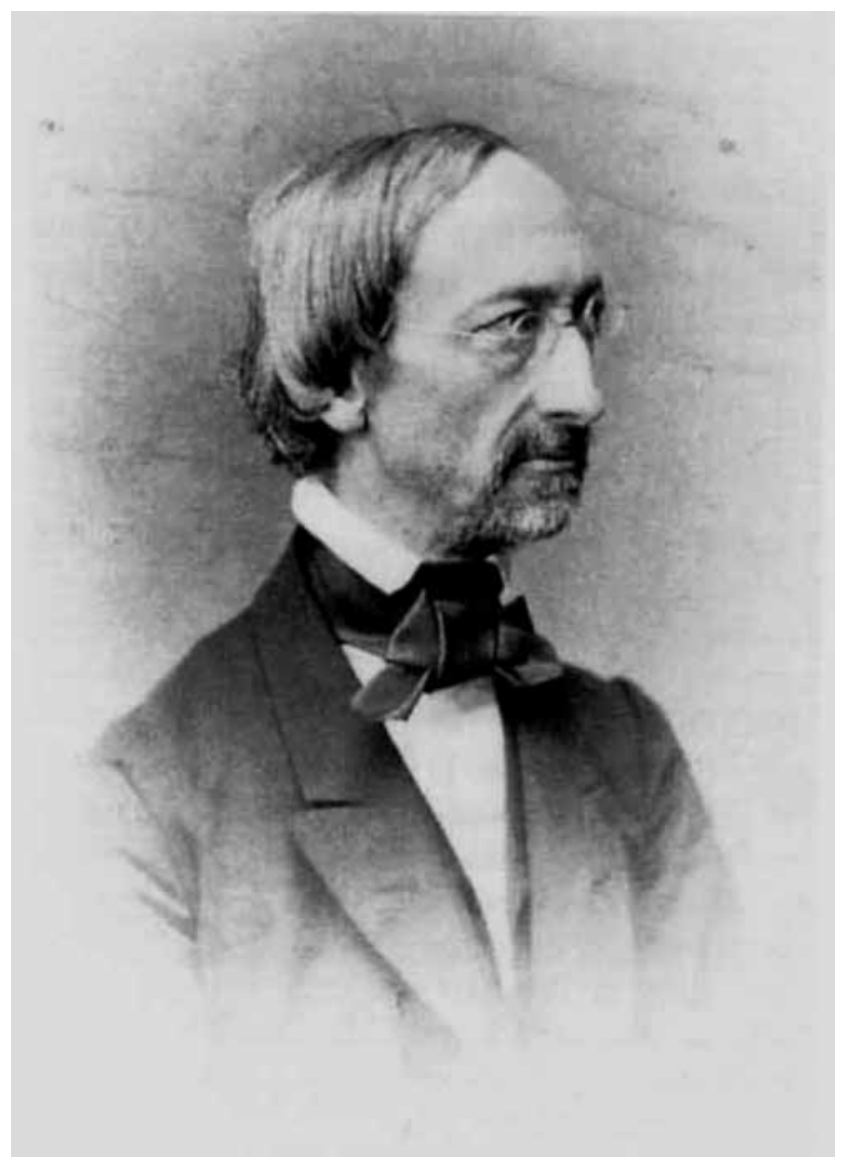

Abb. 15. Justus Roth (1818-1892). Fotografie Carl Günther. - Original in der Universitätsbibliothek der HUB zu Berlin, Porträtsammlung.

\section{Tod von Justus Roth, Würdigung}

Am 1.4. 1892 verstarb Justus Roth (Abb. 15) im Alter von 73 Jahren. Er war bis zuletzt voll tätig. Wie dargestellt, hatte sich Justus Roth an der Seite von Gustav Rose und Ernst Beyrich in das damalige Mineralogische Museum gut eingefügt und stellte zweifellos eine angemessene Lösung des Mittelgliedes zwischen Mineralogie und Paläontologie dar, was verdient hätte, fortgesetzt zu werden. Roth erwarb sich, nachdem ihm die petrographische Sammlung verantwortlich übertragen war, das nicht geringe Verdienst, eine systematischen Lehrsammlung der Petrographie und allgemeinen Geologie geschaffen zu haben, die dann aber der Mineralogie zufiel und nach seinem Tode wieder aufgelöst wurde. Seine mit hingebendem Eifer abgehaltenen Übungen wurden als besonders lehrreich gerühmt, wie Liebisch (1893) aus eigener Anschauung bestätigt hat. Als seine Lebensaufgabe stand stets die Ausarbeitung einer „Allgemeinen und chemischen Geologie" vor ihm, seit er als Professor wirkte. Zuvor hatte er sich auch mit Vulkanen, speziell dem Vesuv, beschäftigt (Roth 1857) und sich mit der chemischen Analyse von Gesteinen auseinander gesetzt (Roth 1861), aber erst seine Gesamtschau des großen Themas, in der er die mineralogischen, petrographischen, chemischen und geologischen Gesichtspunkte erfasste und verarbeitete, führte $\mathrm{zu}$ den bedeutenden Höhepunkten seines in drei Teilen erschienenen Lehrbuchs (Roth 1879, 1883, 1890).

\section{Kustoden und Assistenten unter Klein}

Der Kustos August Tenne war der einzige Mitarbeiter, den Klein nicht aus Göttingen mitgebracht hat. Durch ihn wurde die Tradition der Arbeiten an der Sammlung fortgeführt, speziell die Durcharbeitung der Sammlungsbestände, die seit Websky lief und noch lange nicht beendet war. Über die Fortschritte in dieser Hinsicht berichtete dann Klein regelmäßig in den Jahresberichten der "Chronik“. Daneben trat Tenne auch als Privatdozent auf und las jeweils einstündig über gesteinsbildende Minerale, über petrographische Untersuchungsmethoden, über Edelsteinkunde und dreistündig über die Grundzüge der Kristallographie. Tenne konnte aus den Mitteln der Tamnau-Stiftung (s. S. 40) in den Jahren 1889, 1891 und 1894 Sammelreisen nach Spanien ausführen und umfangreiches Material an Mineralen beschaffen (Tenne \& Calderon 1902). Er starb am 8. 7. $1901 \mathrm{im}$ 48. Lebensjahr. Sein Nachfolger wurde Belowski (s. u.). 
Unter Websky hatte es neben dem Kustos keinen Assistenten gegeben, nur ganz zuletzt einen Hilfsassistenten. Dies ändert sich erheblich, da 1888 zunächst sowohl eine Präparatorenstelle, auf die der aus Göttingen kommende Carl Körner gesetzte wurde, als auch eine Assistentenstelle zur Verfügung gestellt worden waren. Klein hatte es bei seiner Berufung sogar erreicht, dass sein Schüler Eduard Möller bereits 1887 als Assistent eingestellt wurde. Als dieser aber noch im gleichen Jahr wegen des Oberlehrerexamens in Göttingen ausschied, wurde der seit 1886 als Privatdozent in Berlin tätige Rinne, der bereits zuvor in Göttingen Assistent unter Klein gewesen war, als Nachfolger von Möller eingesetzt. Rinne war zugleich auch Privatdozent und hielt von 1888 an ein- oder zweistündige Vorlesungen über Vulkane und Erdbeben, über kristalline Schiefer (von ihm auch archäische Gesteine oder Gesteine der sächsischen Formation genannt), über chemische Kristallographie, über technisch wichtige Minerale und über die Entstehung der Gesteine. Rinne blieb bis 1894 und nahm dann einen Ruf an die Technische Hochschule in Hannover an.

Seit dem Jahre 1889 verfügte Klein über zwei Assistentenstellen, deshalb konnte der bereits erwähnte Eduard Möller nochmals für zwei Jahre 1889 und 1890 antreten, um dann in den Schuldienst zu gehen. Überhaupt waren zwei Jahre die normale Anstellungszeit für Assistenten, die aber auf Antrag verlängert werden konnte. Die folgenden Assistenten blieben zwei Jahre: Benno Kühn von 1890 bis 1891, Richard Herz von 1891 bis 1892, Ernst Esch von 1894 bis 1895 und Oskar Tietze von 1898 bis 1900. Kühn und Tietze gingen danach zur Preußischen Geologischen Landesanstalt. Das gleiche tat auch der weitere Assistent Adolf Klautzsch, der aber sechs Jahre von 1892 bis 1898 geblieben war. Der nächstfolgende Assistent war Max Belowsky. Er nahm eine Sonderstellung ein, da er, nachdem er von 1895 bis 1901 Assistent war, die durch den Tod von Tenne freigewordene Kustosstelle erhielt, auf der er bis zu seiner Pensionierung im Jahre 1930 verblieb. Ab 1905 trat er zugleich als Privatdozent auf und las über Edelsteinkunde und über technisch wichtige Minerale, beides zweistündig. Bis zum Jahre 1910 gab es dann noch zwei Assistenten. Der erste von 1900 bis 1907 war Ferdinand von Wolff, der bereits 1899 als Hilfsassistent zur Bearbeitung der Sammlung Janson angestellt war (s. S. 40). Nach Habilitation wurde er 1903 Privatdozent und las ab 1904 die zweistündigen Vorlesungen über
Edelsteinkunde, über kristalline Schiefer und über natürliche und künstliche Mineral- und Gesteinsentstehung, bis er im Jahre 1907 einen Ruf an die Technische Hochschule in Danzig erhielt und annahm. Zuvor hatte Klein ihm den Professorentitel verleihen wollen, was aber im Dezember 1905 vom Kultusministerium mit dem Argument abgelehnt worden war, dass er noch zu jung wäre (GSTAB-49, Bl.165). Der letzte noch $\mathrm{zu}$ nennende Assistent war Felix Tannhäuser. Auch er war zunächst von 1900 bis 1901 Hilfsassistent und dann von 1901 bis 1907 Assistent. Nach Habilitation im Jahre 1903 trat er seit 1906 als Privatdozent auf und las zweistündig über Lagerstättenlehre und über Lötrohr- und mikrochemische Analyse zur Bestimmung von Mineralen. Dies behielt er auch bei, nachdem er 1907 zur Technischen Hochschule in Berlin-Charlottenburg übergewechselt war. Zum Schluss ist noch anzufügen, dass es Klein gelang, noch einige weitere Hilfsassistenten einzustellen. Es waren Wilhelm Stellmann von 1901 bis 1902, Erich Kleffner von 1902 bis 1903, Karl Alexi von 1903 bis 1905, Carl Leitz von 1905 bis 1906, Rudolf Cramer von 1906 bis 1907 und Alfred Hintze 1907, die sämtlich für Ordnungs- und Etikettierungsarbeiten in den Sammlungen eingesetzt wurden.

\section{Entwicklung der Sammlungen}

Unter dem Direktor Klein gab es außer der Schenkung Rumpff / Sammlung Erzherzog Stephan weitere Vermehrungen der Sammlungen, von denen aber nur eine Auswahl, vor allem nach den Akten des Kultusministeriums, vorgeführt werden kann. Der erste Fall ist eine Schenkung, die auf den am 11. 5. 1892 verstorbenen Ernst Friedrich Heinrich Baron v. Knobelsdorff in Schöneiche bei Berlin zurückging. Er hatte seine Mineralsammlung von 2127 Stück testamentarisch dem Preußischen Staat ,zur Vervollständigung der Sammlung einer Universität oder einer Bergakademie" hinterlassen (GSTAB-44, Bl. 348). Damit fiel dem Staat die Auswahl der zu bedenkenden Institution zu und so kam es zur Konkurrenz des Ministeriums für Handel und Gewerbe und des Kultusministeriums, die sich für die Bergakademie Berlin bzw. für die Universität Berlin bewarben. Die Stellungnahmen der letztlichen Interessenten, Geh. Oberbergrat Wilhelm Hauchecorne und Professor Carl Klein, reklamierten die Schenkung jeder für seine Institution. Ihre vorgebrachten Argumente führten zu keinem Ergeb- 
nis ${ }^{59}$, so dass die Ministerien schließlich nur die Teilung der Schenkung als Ausweg sahen. Den Ausschlag gaben dann jedoch die Erben Knobelsdorffs, die eine Teilung ablehnten und sich im Dezember 1893 für die Universität Berlin, also für das Museum für Naturkunde, entschieden (GSTAB-45, B1. 155). Im Jahre $1897 \mathrm{kam}$ es zum Kauf einer von dem Staatssekretär Dr. v. Stephan hinterlassenen Mineralsammlung, die 601 Stück umfasste und von Klein auf 6600 Mark geschätzt wurde. Gekauft wurde sie entsprechend der Forderung der Witwe für 10000 Mark, was Klein in einem erneuten Gutachten schließlich als "guten Kauf" bezeichnete, wohl weil es ersichtlich geworden war, dass es dem Ministerium um eine großzügige Unterstützung der Witwe ging (GSTAB-46, Bl. 57).

Das Jahr 1899 brachte eine ungewöhnlich große Erwerbung. Es war der Kauf einer 14000 Stück umfassenden Mineralsammlung, die der Rittergutsbesitzer Alfred v. Janson in Gerdauen, Ostpreußen, angeboten hatte und die für 150000 Mark gekauft wurde (Liebisch 1910, S. 318). Der Besitzer war der Enkel des bedeutenden Mäzens der Berliner Mineralogie, des bereits weiter oben genannten Bankiers Friedrich Tamnau (1802-1879). Letzterer hatte seinen gesamten Dublettenbestand dem Enkel vermacht (Müller 1892) ${ }^{60}$. Der Kauf aus dem Sonderfonds des Staates wurde mit der Auflage verbunden, aus dieser Sammlung Teile zur Ergänzung bzw. zum Aufbau der Hochschulsammlungen in Königsberg, Göttingen, Greifswald, Danzig und des Museums Posen abzuzweigen. Die damit verbundenen Arbeiten waren so umfangreich, dass ein Schüler von Klein, Ferdinand v. Wolff, für ein Jahr als Hilfsassistent eingestellt wurde (GSTAB-46, Bl. 204). Nach Abgabe unterschiedlicher Anzahl von Stücken, denen noch 150 aus dem Bestand des Museums zugegeben wurden, verblieben noch knapp 11000 Stück im Museum für Naturkunde (GSTAB-46, Bl. 254). Nach dieser Aktion waren weitere Arbeiten an der Sammlung v. Janson notwendig. Auch die Ordnungs- und Etikettierungsarbeiten in den Sammlungen mussten weitergeführt werden, da sie, wie Klein am 8.11. 1900 berichtete, seit seiner Be- rufung erst etwa zur Hälfte geschafft worden waren (GSTAB-49, Bl. 1). Der Antrag auf weitere Genehmigung von Hilfsassistenten hatte Erfolg, nachdem Klein eine detaillierte Übersicht vorlegte, aus der hervorgeht, dass von den in den Sammlungen vorhandenen insgesamt 8504 Schubladen, die mit Mineralen oder Gesteinen gefüllt sind, immer noch 3869 Schubladen überprüft und etikettiert werden mussten.

\section{Meteoritensammlung}

Ein besonderes Anliegen von Klein war die Vervollständigung und Vermehrung der Meteoritensammlung, die zur Zeit von Gustav Rose, vor allem durch dessen Arbeiten, in großem Ansehen stand. Auch aus historischer Sicht war sie bedeutend, besaß sie doch unter anderem die Sammlung des berühmten Begründers der Meteoritentheorie, Ernst Florens Friedrich Chladni (1756-1827) durch testamentarische Verfügung, was bisher stets als besondere Verpflichtung empfunden worden war. Inzwischen bestand die Gefahr, dass sie von anderen Sammlungen überflügelt wurde. Nun gelang es Klein, zur Auffüllung der Lücken von 1902 bis 1906 insgesamt rund 40000 Mark als Extraordinarien zu erhalten, sodass zahlreiche Meteorite bzw. Teilstücke gekauft werden konnten. Klein konnte dann am 12. 4. 1906 den Abschlußbericht in Gestalt seiner Publikation (Klein 1906) überreichen. Er behauptete darin nach seinen Untersuchungen, dass die Struktur der Meteorite nicht von der der irdischen Gesteine abweicht (GSTAB-49, B1. 169). Der Bestand der Berliner Meteoritensammlung war durch Kleins Aktivität auf insgesamt genau 500 Meteorite angestiegen, wodurch die Sammlung erneut zu den international bedeutendsten gehörte und, wie Klein (1906) erklärte, an 3. Stelle aufrückte.

\section{Tamnau-Stifung}

Unter den wertvollen Schenkungen, die der Mineralsammlung zugute gekommen sind, nimmt die Tamnau-Stiftung eine Sonderstellung ein. Es handelt sich um die testamentarische Schenkung

\footnotetext{
59 Die gegenseitigen Argumente sind an sich deshalb von Interesse, da sie zwar unter anderem aus der bis dahin bekannten Vorgeschichte des Museums abgeleitet wurden, aber gleichzeitig beiderseitige weitgehende Unkenntnis und nebulöse, wenn auch mit dem Grundton der Überzeugung vorgebrachte Ansichten offenbaren, die den in vorigen Teilen dieser Artikelserie (Hoppe 1999, 2001b) dargestellten fehlerhaften Überlieferungen entsprechen. Auf ein näheres Eingehen an dieser Stelle wird verzichtet, zumal den Kontrahenten die erstmals bereinigenden, auf Aktenstudium basierenden Ausführungen von P. Krusch (1904) noch nicht bekannt waren.

${ }^{60}$ Die Mineralsammlung Tamnaus ohne Dubletten war als testamentarische Schenkung an das Berliner Gewerbeinstitut (die spätere TH bzw. TU) gegangen und gelangte später an die TH Darmstadt, wo sie schließlich 1967 aufgestellt wurde.
} 
eines Kapitals von 12000 Talern, dessen Kapitalerträge nach dem Statut der Stiftung (AHUB-5) ausschließlich für Auslandsreisen junger Mineralogen zum Zweck des Sammelns von Mineralen für die Vervollständigung vorwiegend der Mineralsammlung des Museums für Naturkunde in Berlin verwendet werden sollten. Der Gründer dieser Stiftung war der Berliner Mineraloge und Bankier Friedrich Tamnau (1802-1879), den Paul Groth, der Autor der bekannten „Entwicklungsgeschichte der mineralogischen Wissenschaften" (Groth 1926), als einen mineralogischen Fachmann ersten Ranges und zugleich als den großzügigsten Förderer und Sammler der Mineralogie, den Deutschland bisher gehabt hat, bezeichnet hat (Schneiderhöhn 1954). Wirksam wurde die Stiftung nach dem Auflaufen hinreichender Zinsen erst in der Zeit des Direktorats von Klein. Es konnten dann etliche Sammelreisen finanziert werden. Den Beginn machte der Berliner Kustos August Tenne mit Reisen nach Spanien in den Jahren 1889, 1891 und 1894 (Tenne \& Calderon 1902). Es folgten der Kustos der Münchener Staatssammlung Friedrich Grünling, der Ceylon (Sri Lanka) im Winter 1896/97 bereiste (Miers 1901), und der Assistent des Marburger Mineralogischen Institutes Arthur Schwantke, der 1902 auf Grönland sammelte. Die Sammelergebnisse lieferten sehr wertvolle Ergänzungen für die Mineralsammlung ${ }^{61}$.

\section{Tod von Carl Klein, Würdigung}

Carl Klein (Abb. 16) war zwei Jahrzehnte lang Direktor und starb am 23. 6. 1907 im 64. Lebensjahr. Mit ihm ist, wie sein Schüler F. v. Wolff (1907) schrieb, ein Meister der Kristallographie und Kristalloptik dahingegangen. Die Hauptrichtung seiner Arbeiten war die Untersuchung der optischen und polarisationsoptischen Eigenschaften von zahlreichen Mineralen, wodurch er die umfassende Kenntnis der Mineraloptik wesentlich förderte. Im Jahre 1876 gelang es ihm, die polarisationsoptischen Erscheinungen der Minerale auch am Mikroskop zu erkennen und zu analysieren (v. Wolff 1907), eine Entdeckung die er zeitgleich mit anderen Mikroskopikern machte und die den Anstoß gegeben hat, dass das Mikroskop zu einem Polarisationsinstrument ver-

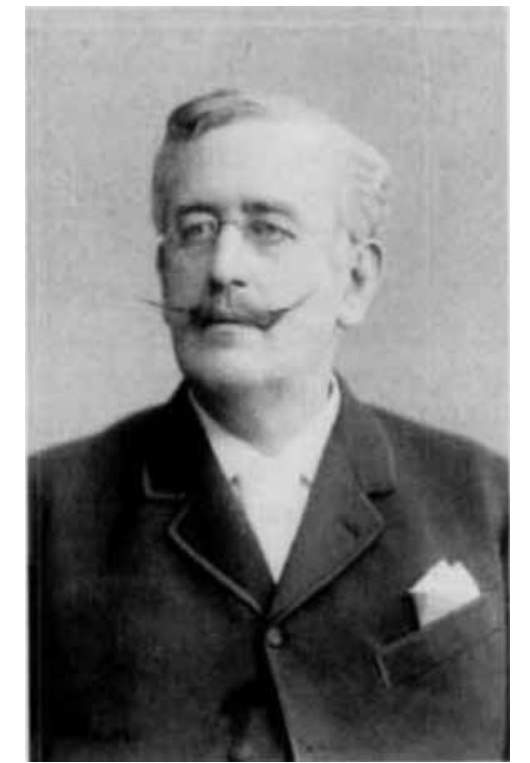

Abb. 16. Carl Klein (1842-1907). Fotografie W. Höffert. Original in der Universitätsbibliothek der HUB zu Berlin, Porträtsammlung.

vollkommnet wurde. Es war nun möglich, Minerale auch in Gesteinsdünnschliffen zu identifizieren, was der Petrographie großen Auftrieb gab. Er selbst hat zwar nur eine größere petrographische Untersuchung ausgeführt (Klein 1888), jedoch kommt ihm das Verdienst zu, dass von seinen Schülern große Teile der seit A. v. Humboldt durch zahlreiche Forschungsreisende im Berliner Museum niedergelegten Gesteinsaufsammlungen aus den südamerikanischen Kordilleren und aus anderen Gebieten mikroskopischpetrographisch untersucht wurden (v. Wolff 1907, Liebisch 1910). Auch später entwickelte Klein noch Methoden und Vorrichtungen für die Arbeiten am Polarisationsmikroskop (Klein 1893). In der gleichen Zeit hat Klein intensive Studien über die Besonderheiten der optischen Verhältnisse einer Reihe von Mineralen, vor allem solchen mit sogenannten Anomalien der Doppelbrechung ausgeführt und $\mathrm{zu}$ diesem Zweck Drehapparate konstruiert, in denen dies unter Flüssigkeiten mit angenähert gleicher Lichtbrechung ermöglicht wurde. Auf Kleins weitere Verdienste durch Fortführung der von Websky begonnenen Arbeiten zur Verbesserung des $\mathrm{Zu}-$ standes der Sammlungen und auf seine ehrgeizigen Bemühungen um die Vergrößerung der Meteoritensammlung wurde bereits hingewiesen.

\footnotetext{
61 Später folgten die Reisen des Berliner Kustos Max Belowski von 1911 und 1913 in die Vereinigten Staaten von Amerika sowie als letzte Reise die des Berliner Mineralogen Georg Silberstein im Jahre 1916 zum Kupferbergwerk Bor in Serbien. Später waren keine weiteren Reisen mehr möglich, da das Kapital der Tamnau-Stiftung durch die Geldentwertung in der Inflationszeit vernichtet wurde. - Berichtigend wird bemerkt, dass die von Hoppe \& Wappler (1998) verzeichnete Reise Silbersteins im Jahre 1906 nach Mexico nicht von der Tamnau-Stiftung finanziert worden ist.
} 
Auf eine nachteilige Eigenschaft Kleins, die Überschätzung der Bedeutung seiner eigenen Arbeitsrichtung, dürfte Kleins Äußerung hindeuten, die er im Oktober 1906 auf eine Aufforderung des Ministeriums über den künftigen Raumbedarf der Institution abgab, wonach eine Erweiterung zwar ,in geringem Maße wünschenswert, aber nicht notwendig" sei. Liebisch (1910, S. 316) führte dies auf Kleins Überzeugung zurück, dass die Institutsarbeiten auch in Zukunft auf die mikroskopische Methode zu beschränken seien. Schließlich muss noch eine in der Sammlung deponierte Niederschrift Liebischs erwähnt werden, die einen fragwürdigen, den musealen Normen nicht entsprechenden Umgang Kleins mit dem Sammlungsgut aufdeckt, da aus ihr hervorgeht, dass Klein Minerale, deren Namen in der Literatur nicht zu finden waren, aus der Sammlung entfernte und fortwarf, obwohl sie von seinem Vorgänger ordnungsgemäß etikettiert waren ${ }^{62}$.

\section{Vertretung durch Kustos Belowsky}

Bis zur Berufung eines Nachfolgers für den verstorbenen Klein führte vertretungsweise Kustos
Belowski die Geschäfte. Da die Ordnungs- und Etikettierungsarbeiten in den Sammlungen weitergehen mussten, konnte es Belowsky erreichen, dass Georg Silberstein als Hilfsassistent für die Jahre 1907 bis 1909 eingestellt wurde. Auch gelang es Belowski, die Durchführung eines vom Berliner Juwelierverein angestrebten Meisterkurses für Juweliere genehmigt zu erreichen. Für die Abhaltung schlug er sich selbst vor, da er sich wegen seiner schon seit 3 Jahren gehaltenen Vorlesungen über Edelsteinkunde geeignet hielt. Der Kurs begann am 13.10.1907 und hatte 75 selbstständige Juweliere, Gold- und Silberschmiede als Teilnehmer (GSTAB-49, Bl. 214), auch wurden vom Ministerium für Handel und Gewerbe weitere Kurse durch ihn gewünscht, was später von Kleins Nachfolger gefördert wurde.

\section{Direktorat Theodor Liebisch}

Im März 1908 wurde Theodor Liebisch (18521922) (Abb. 17) zum Nachfolger von Klein berufen. Er war kein Unbekannter, da er hier von 1876 bis 1880 als Assistent tätig gewesen ist, und erhielt nun, nachdem er an mehreren Universitäten o. Professuren der Mineralogie innegehabt

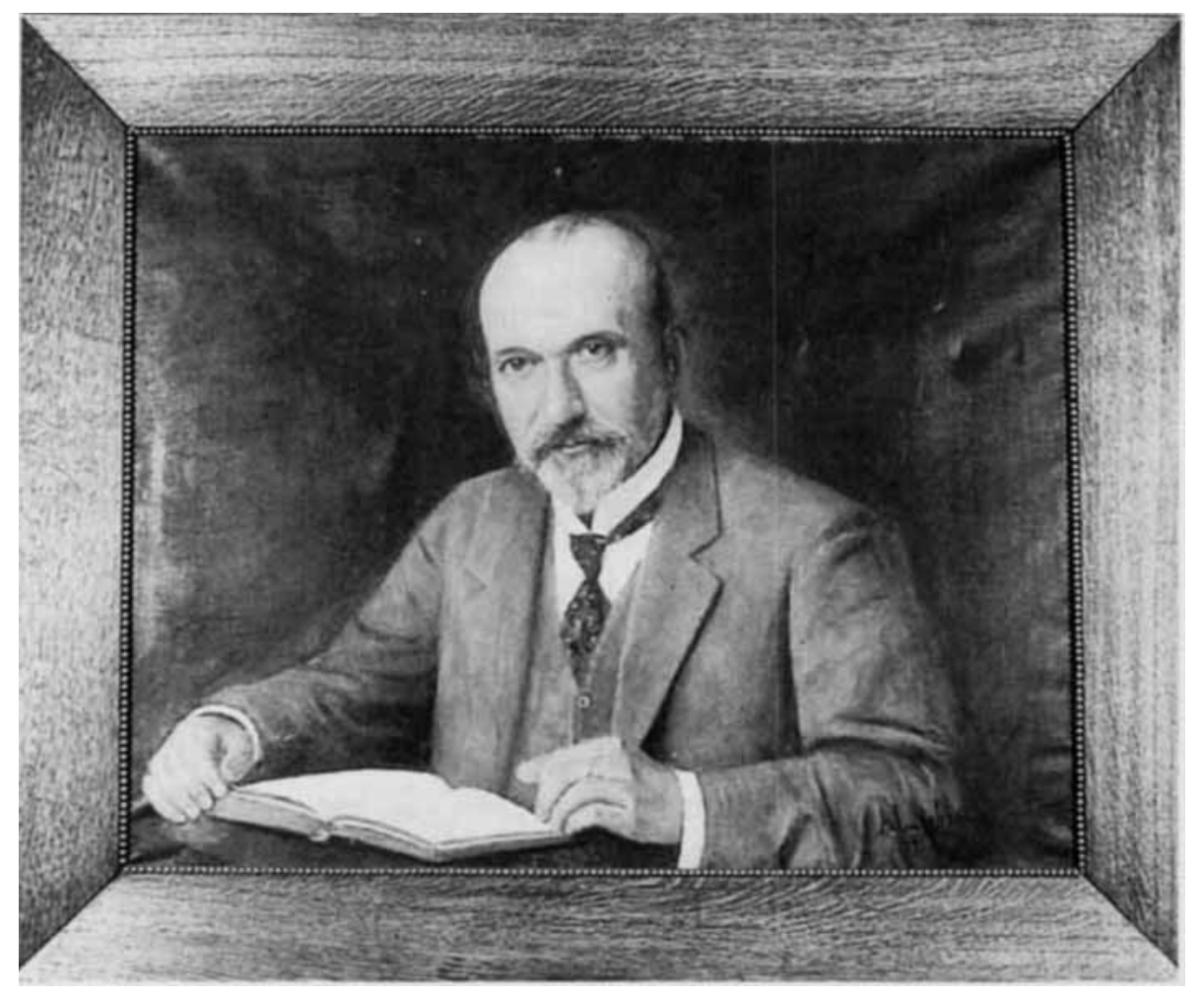

Abb. 17. Theodor Liebisch (1852-1922). Gemälde von Frau A. Liebisch 1922. - Original im Museum für Naturkunde, HHMfN-9 (Bestand: Mineralogisches Museum), Sign. B VII/1.

\footnotetext{
62 Diese Niederschrift, die mit einer von A. Tenne geschriebenen Liste von 119 Mineralnamen verbunden ist, lautet: „Nach Aussage des Kustos Prof. Dr. M. Belowsky sind diese Mineralien von C. Klein nur zum Teil eingeordnet worden. Der Rest ist, da die Mineralnamen in der Literatur nicht zu finden waren. durch C. Klein fortgeworfen worden, obwohl z. T. Etiketten von M. Websky daran befestigt waren, bald nach Tennes Tode. Berlin. 28. April 1909. Th. Liebisch."
} 
hatte, den hiesigen Lehrstuhl. Er wirkte als Direktor bis zum Jahre 1921. Da dieser Artikel nur die Jahre bis 1910 darstellt, kann nur ein sehr kleiner Ausschnitt aus seiner Tätigkeit vermittelt werden. Mit der Berufung von Liebisch kehrte nach der Unterbrechung durch Klein wieder ein Vertreter der von Weiss begründeten kristallographisch-mineralogischen Richtung zurück. In diese war Liebisch durch seinen Lehrer Websky eingeführt worden. Sein weiterer Werdegang verlief im Verlaufe der Stationen seiner akademischen Karriere zunehmend in die physikalischkristallographische Richtung, besonders als er in Königsberg einige Jahre (von 1884 bis 1887) den mineralogischen Lehrstuhl des zum Kristallphysiker gewordenen, wohl bedeutendsten Schülers von Weiss, Franz Neumann (1798-1895), noch zu dessen Lebzeiten innehatte (Johnsen 1929). Seine bedeutenden Werke über die geometrische und die physikalische Kristallographie (Liebisch 1881, 1891, 1896) belegen dies.

Als Personal stand ihm zunächst nur der schon lange in der Institution tätige Kustos Belowski zur Seite. Die vorhandenen zwei Assistentenstellen, die frei geworden waren, besetzte er mit dem aus Göttingen mitgekommenen Mineralogen Richard Nacken, der 1911 nach Leipzig berufen wurde, und mit dem Agrikulturchemiker Friedrich Späte. Als letzterer 1910 in die chemische Praxis ging, stellte Liebisch den Mineralogen Max Berek als Assistenten ein, der mit einer kristalloptischen Dissertation bei Liebisch promovierte und danach wissenschaftlicher Mitarbeiter der optischen Werke Leitz in Wetzlar wurde. Bis 1910 wurden außerdem folgende Hilfsassistenten beschäftigt: Georg Silberstein (1907-1909), Karl Schulz (1909-1910), Rudolf van der Leeden (1910) und Hermann Brand (1910).

\section{Lehre im Direktorat Liebisch}

Liebisch hielt regelmäßig die zwei vierstündigen Vorlesungen "Allgemeine Kristallographie und Mineralogie“ und „Physikalisch-chemische Mineralogie", über Petrographie las er jedoch nicht. Dies übernahm zunächst der Kustos Belowski, der 1908 den Titel eines Professors erhalten hatte, er trug 1908 über Petrographie und über die mikroskopische Physiographie petrographisch wichtiger Minerale sowie 1909 über kristalline Schiefer vor. Danach war es Liebisch gelungen, den seit 1900 in der Preußischen Geologischen Landesanstalt tätigen Otto Erdmannsdörffer zur Habilitation zu bewegen und ab 1909 als Privatdozent mit einer Einführung in die Petrographie aufzutreten sowie über petrographische Untersuchungsmethoden zu lesen und Anleitungen zu petrographischen Untersuchungen im Felde zu geben. Liebisch bemühte sich auch, eine a. $o$. Professur für ihn zu erhalten. Nachdem dies scheiterte, ging Erdmannsdörffer 1912 an die Technische Hochschule Hannover. Ferner ist zu verzeichnen, dass die Privatdozenten Fock und Tannhäuser ihre Vorlesungstätigkeit wie unter Klein fortsetzten. Darüber hinaus konnte es Liebisch beim Ministerium durchsetzen, dass ein mikroskopischer Ferienkurses zum vertieften Eindringen in die Theorie und die Verfahren der Mikroskopie, der von der Firma Carl Zeiss, Jena, angeboten worden war, für Mitarbeiter und Doktoranden durchgeführt wurde (GSTAB-49, B1. 232).

In den Sammlungen konnte das von Websky begonnene Unternehmen einer gründlichen $\mathrm{Re}$ vision nebst durchgehender systematischer Ordnung und Etikettierung nach nunmehr insgesamt 33 Jahren zum Abschluss gebracht werden (Liebisch 1910, S. 313) ${ }^{63}$. An diesen von Websky unter dem Zwang der bevorstehenden Verlagerung in den Neubau begonnenen Arbeiten hatte Liebisch selbst als Kustos teilgenommen. Sie waren danach von den Kustoden unter Mitwirkung von Hilfsassistenten weiter fortgesetzt und beendet worden ${ }^{64}$.

\section{Schlusswort}

Mit dem vorliegenden Beitrag endet die fünfteilige Artikelserie über die Vorgeschichte und Geschichte der Geowissenschaften im Museum für Naturkunde zu Berlin im Jahre 1910. Ihr Endpunkt fällt zusammen mit dem 100jährigen Bestehen der Universität zu Berlin, das von einer großen, vierbändigen Festschrift begleitet wurde

\footnotetext{
63 Gemeint ist wahrscheinlich das Jahr 1909, da die Arbeiten offiziell im Jahre 1876 begannen, als die Assistentenstelle, die Liebisch seit 1875 innehatte, in eine Kustodenstelle umgewandelt wurde.

${ }_{64}$ Nach Auskunft von Herrn Dr. Gert Wappler, langjährigem Kustos der Mineralsammlung, darf die Aussage von Liebisch nicht ganz wörtlich genommen werden, da offenbar der Altbestand einiger Minerale, u. a. des Titanit und von Teilen der Zeolithe, der frühen Revision entgangen ist. Bemerkt wurde dies bei der erneuten systematischen Durcharbeitung der gesamten Mineralsammlung, die in den letzten Jahrzehnten von 1970 an zur Behebung von Schäden infolge des 2. Weltkrieges durchgeführt wurde.
} 
(Lenz 1910), in der die Universität Rechenschaft über ihre Entstehung. Entwicklung und ihren erreichten Zustand abgelegt hat und in der auch Berichte der Direktoren des Geologisch-Paläontologischen Institutes und Museums und des Mineralogisch-Petrographischen Institutes und Museums (Branca 1910 und Liebisch 1910) enthalten sind.

Bevor als Abschluss kurz auf die Entwicklung der geowissenschaftlichen Institutionen nach 1910 geblickt wird, ist zunächst eine zusammenfassende Rückschau auf die Universitätszeit notwendig. Es war die Zeit der Herausbildung von bereits zuvor angelegten oder angedeuteten Teildisziplinen der Geowissenschaften. Dies war zunächst mit Kämpfen verbunden, da der erste, fast 5 Jahrzehnte lang in der Universitätszeit tätige Direktor, Christian Samuel Weiss, das Gesamtgebiet eifersüchtig für sich zu behaupten gesucht hatte. Nach seiner Zeit verliefen die Prozesse der Spezialisierung weniger auf interne Kämpfe hinaus und ergaben sich mehr durch die jeweils eingebrachten speziellen Ausrichtungen der in kürzeren Abständen aufeinanderfolgenden Direktoren. Insgesamt gesehen wurden um das Jahr 1910 noch alle im Laufe der Entwicklung der Geowissenschaften entstandenen Richtungen (von der Geographie abgesehen; die von Anfang an getrennt lief) in den beiden Institutionen gepflegt. Es ist aber nicht zu verkennen, dass es bereits Ansätze zu einer Tendenz der Begünstigung für die stärker an Sammlungsgut gebundenen Richtungen gab.

In der Zeit nach 1910 setzte sich dann der Wechsel der von den Direktoren bevorzugten Richtungen mit zum Teil kräftigen Ausschlägen nach verschiedenen Seiten fort. Da jedoch vorhandene Sammlungen stets den am stärksten sammlungsgebundenen Richtungen die besten Bedingungen und Rückhalt schaffen, ist dies auf die Endkonsequenz hinausgelaufen, dass Kristallographie und Geologie, die ursprünglich zum Grundbestand gehörten, in der zweiten Hälfte des 20. Jahrhundert abwanderten bzw. eliminiert wurden, was sich auch in jüngerer Vergangenheit nicht aufhalten oder rückgängig machen ließ.

\section{Danksagung}

Der Autor dankt für viele Hilfen verschiedener Art zahlreichen Kolleginnen und Kollegen im Museum für Naturkunde, ohne die die Arbeit an den fünf Teilen der Artikelreihe nicht denkbar gewesen wäre. Stellvertretend werden genannt: Frau Dozentin Dr. llse Jahn, besonders für die Starthilfe bei der Arbeit in Archiven seit 1979, und der Herausgeber, Herr Prof. Dr. Hans-Peter Schultze, für ständige Ermunterung. weiterhin in der Redaktion der Zeitschrift des Museums Frau Prof. Dr. Gloria Arratia und Frau Petra Keßling, in der Historischen Arbeitsstelle Frau Dr. Hannelore Landsberg und Frau Dr. Sabine Hackethal, im Mineralogisch-Petrographischen Institut und Museum Herr Dr. Gert Wappler, Frau Dr. Elke Wäsch, Herr Prof. Dr. Hans-Joachim Bautsch, Herr Dr. Ferdinand Damaschun, Frau Ingrid Krueger und Frau Sabine Appelt und im Paläontologischen Institut und Museum die Herren Dr. Gottfried Böhme, Dr. Wolf-Dieter Heinrich, Prof. Dr. Manfred Barthel, Dr. Stephan Schultka und Prof. Dr. Rudolf Daber sowie die Mitarbeiter der Bibliotheken im Museum für Naturkunde. Im gleichen Maße gilt auch der Dank zahlreichen Mitarbeitern von Archiven und Bibliotheken, besonders des Geheimen Staatsarchives PreuBischer Kulturbesitz, Berlin-Dahlem, des Archives der Humboldt-Universität Berlin, des Zentralarchives der BerlinBrandenburgischen Akademie der Wissenschaften Berlin und der Handschriftenabteilung der Staatsbibliothek Preußischer Kulturbesitz Berlin. Mein Dank gilt ebenfalls den Gutachtern der Artikelserie. Schließlich ist es mir ein besonderes Bedürfnis. meiner Frau Marianne für vielerlei Rat und Hilfe, auch für Geduld und Verständnis zu danken.

\section{Schriftenverzeichnis}

\section{Archivalien}

Vorbemerkung: In allen Zitaten aus historischen Quellen wurden Orthographie und Interpunktion unter Wahrung des Wortlautes behutsam modernisiert and Abkürzungen aufgelöst. - Die Numerierung der Archivalien schließt sich an den 4. Teil dieser Artikelserie an.

\section{Archiv der Humboldt-Universität Berlin}

AHUB-1 = Vorlesungs-Verzeichnisse und Index Lectionum der Universität.

AHUB-3 = Nr. 508 (Grundrisse des Universitätsgebäudes 1819-21), Bl. 9

AHUB- $4=$ NL Websky, Kasten 2 bis 4

AHUB-5 $=$ Phil. Fak. Nr.1548 (Tamnau-Stiftung)

AHUB-6 $=$ Litt. M, Nr. 15, Vol. I, 72, Bl 10 (Min. Erlass vom 23.4.1888)

Geheimes Staatsarchiv Preußischer Kulturbesitz Berlin-Dahlem

GSTAB-10 $=1-$ Rep 121, Abt D, Tit II, Sect 1, Nr.101, Vol 3. Bl. $60-61$.

GSTAB-25 = $1-$ Rep. 76, Va, Sect. 2, Tit. X, Nr. 21, Bd. 6 . [betr. Mineralogisches Museum 1834-1841]

GSTAB-26 = Wie vor., Bd. 7. [1841-1849]

GSTAB-29 $=$ Wie vor, Bd. $9 .[1858-1865]$

GSTAB-30 $=$ Wie vor, Bd. 10. [1865-1873]

GSTAB-31 $=$ Wie vor, Bd. 11. [1873-1875]

GSTAB-32 $=1-$ Rep. 76, Va, Sect. 2, Tit. X, Nr. 90, Bd. 7. [betr. Herbar 1849-1857]

GSTAB-33 = Wie vor, Bd. 8. [1858-1862]

GSTAB-34 =1 - Rep. 76, Va, Sect. 2, Tit. X, Nr. 79, Bd. 1. [betr. Physikalisches Institut 1862-1878]

GSTAB-35 = 1 - Rep. 89, Nr. 21715, Bd. 1. [betr. Bergakademie und geol. Landesanstalt]

GSTAB-36 = $1-$ Rep. 76, Va, Sect. 2, Tit. IV, Nr. 47, Bd. 8. [betr. Berufungen/Professoren]

GSTAB-37 $=1-$ Rep. 76, Vc, Sect. 2, Tit. 23, Litt. A, Nr. 40, BI 152-156. [betr. Unterstützung von Dr. phil. A. Oschatz]

GSTAB-38 = 1 - Rep. 76, Va, Sect. 2, Tit. X, Nr. 21, Bd. 12. [betr. Mineralogisches Museum 1876-1878] 
GSTAB-39 $=$ Wie vor, Bd. 13. [1878-1885]

GSTAB-40 $=$ Wie vor, Bd. 14. [1885-1889]

GSTAB-41 $=1-$ Rep. 76, Va, Sect. 2, Tit. IV, Nr. 61. [betr. Berufungen/Professoren]

GSTAB-42 = 1 - Rep. 76, Va, Sect. 2, Tit. X, Nr 127, Bd. 1. [betr. allg. Angel. des Mus. f. Nat., ab April 1887]

GSTAB-43 $=1$ - Rep. 76, Va, Sect. 2, Tit. XIX, Bd. 1-6 (unpaginiert). [betr. Bau des Mus. f. Nat., 1873-1889]

GSTAB-44 = 1 - Rep. 76, Va, Sect. 2, Tit. X, Nr. 21, Bd. 15.

[betr. Min.-petr. Slg. und Geol.-pal. Slg., 1889-92]

GSTAB-45 = Wie vor, Bd. 16. [1892-1896]

GSTAB-46 $=$ Wie vor, Bd. 17. [1896-1900]

GSTAB-47 = 1 - Rep. 76, Va, Sect. 2, Tit. X, Nr. 21, Bd. 18.

[betr. Geol. paläont. Inst. u. Museum 1900-1906]

GSTAB $48=$ Wie vor, Bd. 19. [1906-1912]

GSTAB-49 = 1 - Rep. 76, Va, Sect. 2, Tit. X, Nr. 167, Bd. 1.

[betr. Min.-petr. Slg., 1900-1908]

GSTAB-50 = Wie vor, Bd. 2. [1909-1921]

GSTAB-51 = 1 - Rep. 76, Va, Sect. 4, Tit. X, Nr. 23, Bd. 3. (unpaginiert) [betr. Min.-petr. Inst. Univ. Breslau]

Historische Bild- und Schriftgutsammlungen des Museums für Naturkunde der Humboldt-Universität zu Berlin

HHMfN-7 $=$ Bestand Zoologisches Museum

HHMfN-8 = Bestand Paläontologisches Museum

HHMfN-9 = Bestand Mineralogisches Museum

\section{Literatur}

Anonym 1868. Stephan Victor Erzherzog von Österreich. Sein Leben, Wirken und sein Tod. VIII + 397 pp., Kreidel, Wiesbaden.

Asen, J. 1955. Gesamtverzeichnis des Lehrkörpers der Universität Berlin. I. 1810-1945. 279 pp., Harrassowitz, Leipzig.

Bauer, M. 1887. Martin Websky. - Neues Jahrbuch für Mineralogie, Geologie und Paläontologie 1, 2: 1-16.

- 1900. Karl Friedrich Rammelsberg. - Centralblatt für Mineralogie 1900: 221-33, 319-29 und 342-357.

Beyrich, E. 1837. De goniatites in montibus Rhenanis occurentibus. - Dissertation Universität Berlin, $18 \mathrm{pp}$.

- 1848. Zur Kenntnis des tertiären Bodens der Mark Brandenburg. - Karsten's Archiv für Mineralogie, Geognosie, Bergbau und Hüttenkunde 22: 246-254.

- 1855. Über den Zusammenhang der norddeutschen Tertiärbildungen. - Abhandlungen der Akademie der Wissenschaften zu Berlin 38: 1-20.

- 1858. Über die Abgrenzung der oligozänen Tertiärzeit. Monatsberichte der Akademie der Wissenschaften zu Berlin 11: $51-69$.

Branco, W. 1877. Die Vulkane des Hernikerlandes bei Frosinone in Mittelitalien. - Neues Jahrbuch für Mineralogie, Geologie und Paläontologie 1877: 561-589.

- 1894. Schwabens 125 Vulkan-Embryonen und deren tufferfüllte Ausbruchröhren, das größte Gebiet ehemaliger Maare auf der Erde. 816 pp., Stuttgart.

Branco, W. von \& Fraas, E. 1901. Das vulkanische Ries bei Nördlingen in seiner Bedeutung für Fragen der Allgemeinen Geologie. - Abhandlungen der Königlich Preußischen Akademie der Wissenschaften 1901: $163 \mathrm{pp}$.

Branca, W. von. 1910. Das geologisch-paläontologische Institut und Museum an der Königl. Friedrich-Wilhelms-Universität in Berlin. In Lenz, M.: Geschichte der Universität Berlin III: $319-343$

- 1914. Allgemeines über die Tendaguru-Expedition. - Archiv für Biontologie III, 1: 3-13.

Carlé, W. E. H. 1988. Werner - Beyrich - von Koenen Stille. Ein geistiger Stammbaum wegweisender Geologen. - Geologisches Jahrbuch, Reihe A, 108: 1-499.
Chronik der Königlichen Friedrich Wilhelms-Universität zu Berlin für die Rechnungsjahre $1887 / 8$ bis 1910 . Jahrgang 1-24, Müller, Berlin; Waisenhaus, Halle.

Dames, W. 1884. Über Archaeopteryx. - Paläontologische Abhandlungen 2, 3: 119-196.

- 1898. Gedächtnisrede auf Ernst Beyrich. - Abhandlungen der Akademie der Wissenschaften zu Berlin 1898: $1-11$.

Dietrich, W. O. 1960. Geschichte der Sammlungen des Geologisch-Paläontologischen Instituts und Museums der Humboldt-Universität zu Berlin. Ein Beitrag zur Paläontologie-Geschichte. - Berichte der Geologischen Gesellschaft der DDR 5: 247-289.

Ewald, J., Roth, J. \& Eck, H. (Hrsg.). 1867/85. Leopold von Buch's Gesammelte Schriften. Bd. 1, 1867, LII + 739 pp.; Bd. 2, 1870, VIII + 783 pp.; Bd. 3, 1877 , VIII + 714 pp.; Bd. 4, 2 Hälften, 1885, XII + 1058 pp., Reimer, Berlin.

Fraas, E. 1908. Ostafrikanische Dinosaurier. - Palaeontographica 55: 105-144.

- 1908. Dinosaurier in Deutsch-Ostafrika. - Umschau 12 , 48: 943-948.

Gandert, K.-D. 1986. Vom Prinzenpalais zur Humboldt-Universität. 200 pp., Henschel, Berlin

Graefrath, R. 1989. Zur Entwurfs- und Baugeschichte des Museums für Naturkunde der Universität Berlin. Wissenschaftliche Zeitschrift der Humboldt-Universität zu Berlin, Reihe Mathematik/Naturwissenschaften 38: $279-286$

Groth, P. 1926. Entwicklungsgeschichte der mineralogischen Wissenschaften. VI + 261 pp., Springer, Berlin.

Guttstadt, A. 1886. Die naturwissenschaftlichen und medicinischen Staatsanstalten Berlins. - Festschrift für die 59. Versammlung deutscher Naturforscher und Ärzte. Darin: Das mineralogische Museum. - Hirschwald, Berlin: $149-154$.

Hauchecorne, W. 1881: Die Gründung und Organisation der Königlichen geologischen Landesanstalt für den Preussischen Staat. - Jahrbuch der Königlichen Preussischen geologische Landesanstalt und Bergakademie zu Berlin für das Jahr 1880 1881: IX-XLVII.

- 1896. Heinrich Ernst Beyrich. - Jahrbuch der Königlichen Preussischen geologische Landesanstalt und Bergakademie zu Berlin für das Jahr 1896. Berlin 17: CII-CXXXVIII

Helms, J. 1997. August Heinrich Ernst Beyrich als Paläontologe. - Zeitschrift der deutschen geologischen Gesellschaft 148: 291-308.

Hennig, E. 1915. Hans von Staff †. - Centralblatt für Mineralogie, Geologie und Paläontologie, Schweizerbart. Stuttgart 1915: 689-695.

Hohn, H. 1952: Karl Ernst Albrecht Kunth. Zur Lebensgeschichte des Berliner Geologen.. - Jahrbuch für Brandenburgische Landesgeschichte 1952: 36-42.

Hoppe, G. 1983: Ein Museumsdiebstahl vor 144 Jahren. Neue Museumskunde, Berlin 26: 20.

- 1998. Zur Geschichte der Geowissenschaften im Museum für Naturkunde zu Berlin. Teil 1. Aus der Vorgeschichte bis zur Gründung der Berliner Bergakademie im Jahre 1770. - Mitteilungen aus dem Museum für Naturkunde der Humboldt-Universität in Berlin, Geowissenschaftliche Reihe 1: $5-19$.

- 1999. Zur Geschichte der Geowissenschaften im Museum für Naturkunde zu Berlin. Teil 2. Von der Gründung der Bergakademie zur Gründung der Universität 1770-1810. - Mitteilungen aus dem Museum für Naturkunde der Humboldt-Universität in Berlin, Geowissenschaftliche Reihe 2: 3-24.

- 2000a. Zur Geschichte der Geowissenschaften im Museum für Naturkunde zu Berlin. Teil 3. Von A. G. Werner und R. J. Haüy zu C. S. Weiss - Der Weg von C. S. Weiss zum Direktor des Mineralogischen Museums der Berliner Universität. - Mitteilungen aus dem Museum für Naturkunde der Humboldt-Universität in Berlin, Geowissenschaftliche Reihe 3: 3-25. 
- 2000b. Friedrich Hessenberg (1810-1874) - Juwelier, Mineraloge und Mineralsammler. - Aufschluß. Heidelberg. 51: $259-293$.

- 2001a. Zur Geschichte der Geowissenschaften im Museum für Naturkunde zu Berlin. Teil 4: Das Mineralogische Museum der Universität Berlin unter Christian Samuel Weiss von 1810 bis 1856 . - Mitteilungen aus dem Museum für Naturkunde der Humboldi-Universität in Berlin, Geowissenschaftliche Reihe 4: 3-27.

- 2001b. Leopold von Buch (1774-1853). Der bedeutendste deutsche Geologe seiner Zeit. - Katalog der Ausstellung „Marksteine. Eine Entdeckungsreise durch Brandenburg-Preußen" des Hauses der BrandenburgischPreußischen Geschichte Potsdam, Berlin 2001: 378-380.

- 2003a. Friedrich Anton von Heinitz (Heynitz) (17251802). - Nachrichtenblatt zur Geschichte der Geowissenschaften 13: 61-73.

Hoppe, G. \& Ch. Suckow 2003. Gustav Rose. Alexander von Humboldt und die Berliner Mineralogie in der ersten Hälfte des 19. Jahrhunderts. - In Alexander von Humboldt in Berlin. Sein Einfluss auf die Entwicklung der Wissenschaften. Beiträge zu einem Symposium, hrsg. von J. Hamel, E. Knobloch, H. Pieper. - Algorismus. Studien zur Geschichte der Mathematik und der Naturwissenschaften. Hrsg. Menso Folkerts 41: 223-236. Munchen.

Hoppe, G. \& G. Wappler 1998. Das Institut für Mineralogie und seine Sammlungen im Museum für Naturkunde der Humboldt-Universität zu Berlin. - Aufschluss, Heidelberg 49: $261-276$.

Humboldt, A. v. 1862. Kosmos. Entwurf einer physischen Weltbeschreibung. 5. Band. Stuttgart. 98 pp.

Jahn, I. 1989. Der neue Museumsbau und die Entwicklung neuer museologischer Konzeptionen und Aktivitäten seit 1890. - Wissenschaftliche Zeitschrift der Humboldt-Universität zu Berlin, Reihe Math./Naturwiss. 38: 287-307.

Janensch, W. 1914. Bericht über den Verlauf der TendaguruExpedition. - Archiv für Biontologie 3: 17-58.

Johnsen. A. 1929. Liebisch, Theodor. - Deutsches Biographisches Jahrbuch 4 (für das Jahr 1922): 168-172.

Kayser, E. 1893. Karl Lossen. - Neues Jahrbuch für Mineralogie, Geologie und Paläontologie 1893 II. Nekrologe: $1-18$.

Kirchheimer, F. 1982. Die Einführung des Naturselbstdruckes und der Photographie in die erdwissenschaftliche Dokumentation. - Zeitschrift der deutschen geologischen Gesellschaft 133: $1-117$.

Klein, C. 1893. Über das Arbeiten mit dem in ein Polarisationsinstrument umgewandeltes Polarisationsmikroskop und eine vereinfachte Methode zur Bestimmung des Charakters der Doppelbrechung. - Sitzungsberichte der Königl. Akademie der Wissenschaften zu Berlin 1893: $221-245$.

- 1906. Studien über Meteoriten, vorgenommen aufgrund des Materials der Sammlung der Universität Berlin. Abhandlungen der Königlich Preußischen Akademie der Wissenschaften Berlin 1906: 1-141.

Koken, E. 1899. Wilhelm Barnim Dames. - Neues Jahrbuch für Mineralogie, Geologie und Paläontologie: 1-14.

- 1901. Die Deutsche geologische Gesellschaft in den Jahren 1848-1898 mit einem Lebensabriss von Ernst Beyrich. -69 pp., Starke, Berlin.

Krusch, P. 1904. Die Geschichte der Bergakademie zu Berlin von ihrer Gründung im Jahre 1770 bis zur Neueinrichtung im Jahre 1860. 54 pp., Verlag der Königlich Geologischen Landesanstalt und Bergakademie, Berlin.

Lenz, M. 1910. Geschichte der königlichen Friedrich-Wilhelms-Universität zu Berlin. Bd. 1. Gründung und Ausbau. $\mathrm{XV}+644$ pp. Bd. 2, 1. Ministerium Altenstein. IX +514 pp., Bd. 2, 2. Auf dem Wege zur deutschen Einheit im Neuen Reich. X11 + 512 pp.. Bd. 3. Wissenschaftliche Anstalten, Spruchkollegium, Statistik. VIII $+536 \mathrm{pp}$., Bd. 4. Urkunden, Akten, Briefe. XII +602 pp., Verlag des Waisenhauses. Halle.
Liebisch, T. 1881. Geometrische Krystallographie. XII + 464 pp., Engelmann, Leipzig.

1891. Physikalische Krystallographie. - VIII + 614 pp., Veit, Leipzig.

- 1893. Justus Roth 1818-1892. - Neues Jahrbuch für Mineralogie, Geologie und Paläontologie 1893 II, Nekrologe: $1-13$.

- 1896. Grundriss der physikalischen Krystallographie. VIII. 506 pp., Veit, Leipzig.

- 1910. Das mineralogisch-petrographische Institut und Museum. In Lenz, M. Geschichte der Universität Berlin, III: $310-319$.

Miers, H. A. 1901. The Tamnau mineralogical endowment. Nature, London 63: 453-454.

Möbius, K. A. 1884. Rathschläge für den Bau und die innere Einrichtung zoologischer Museen. - Zoologischer Anzeiger Nr. 171: 1-6.

[Müller, W.] 1892: Die Mineralien-Sammlung des Rittergutsbesitzers A. von Janson auf Schloss Gerdauen. $147 \mathrm{pp}$, Gertz, Charlottenburg.

Pompeckj, J. F. 1928. Gedächtnisrede auf Wilhelm von Branca. - Sitzungsberichte der Preußischen Akademie der Wissenschaften, Sitzung vom 5. 7. 1928, 26 pp.

Quenstedt, W. 1957. Wilhelm Barnim Dames, Paläontologe und Geologe. - Neue Deutsche Biographie 3: 499.

- 1955. Karl Wilhelm Franz v. Branca. - Neue Deutsche Biographie 2: 514-515.

Rath, G. vom 1873. Gustav Rose. Nekrolog. - Poggendorffs Annalen der Physik und Chemie, Leipzig 150: 647-652.

Reck, H. 1929. Wilhelm von Branca. - Zeitschrift für Vulkanologie 12: $1-7$.

Rose, G. 1833. Elemente der Krystallographie, nebst einer tabellarischen Übersicht der Mineralien nach den Krystallformen. VI + 173 pp., 10 Taf., Mittler, Berlin. (2. Aufl. 1838, XII + 175 pp., 10 Taf.; 3. Aufl., Hrsg. A. Sadebeck, $1873, \mathrm{VI}+181 \mathrm{pp}$.).

- 1837/1842. Mineralogisch-geognostische Reise nach dem Ural, dem Altai und dem Kaspischen Meere. 2 Bde. 1. Band: Reise nach dem nördlichen Ural und dem Altai. XXXI, 641 pp.; 2. Band: Reise nach dem südlichen Ural und dem Kaspischen Meere, Übersicht der Mineralien und Gebirgsarten des Ural. XVII + 606 pp., Sander, Berlin.

- 1851. Über die bei Schwetz aufgefundene Meteoreisenmasse. - Poggendorffs Annalen der Physik und Chemie. Leipzig 83: 594-596 (nebst Abbildung, ohne Seitenangabe).

- 1852. Das krystallo-chemische Mineralsystem. VI+ $156 \mathrm{pp}$, Engelmann, Leipzig.

- 1856. [Die Dünnschliffsammlung von Herrn Oschatz in Berlin]. - Zeitschrift der deutschen geologischen Gesellschaft 8: 534.

- 1857/59. Über die heteromorphen Zustände der kohlensauren Kalkerde. - Abhandlungen der Akademie der Wissenschaften zu Berlin für 1856, Physikalische Abhandlungen: 1-76, bzw. für 1858: 63-111.

- 1860. Das mineralogische Museum. - In: Köpke, R.: Die Gründung der Königlichen Friedrich-Wilhelms-Universität zu Berlin: 279-282.

1862. Über den Asterismus der Krystalle, insbesondere des Glimmers und des Meteoreisens. - Poggendorffs Annalen der Physik und Chemie 117: 632-637.

- 1863. Beschreibung und Einteilung der Meteoriten aufgrund der Sammlung im mineralogischen Museum zu Berlin. - Abhandlungen der Akademie der Wissenschaften zu Berlin, Physikalische Abhandlungen. 1863: $23-164$.

- 1864. Zur Erinnerung an E. Mitscherlich. - Zeitschrift der Deutschen geologischen Gesellschaft 16: 21-72.

- 1876. Kristallisation des Diamanten. (Hrsg. A. Sadebeck) - Abhandlungen der Akademie der Wissenschaften zu Berlin 1876: $85-148,4$ Taf.

Rose, G. \& Sadebeck. A. 1874. Das mineralogische Museum der Universität Berlin. Systematisches Verzeichniss seiner Schausammlungen: VII + 100 pp., Mittler, Berlin. 
Roth, J. 1857. Der Vesuv und die Umgebung von Neapel: XLIV + 539 pp., Hertz, Berlin.

- 1861. Die Gesteinsanalysen in tabellarischer Übersicht und mit kritischen Erläuterungen: LX +68 pp., Hertz, Berlin.

- 1879/1883/1890. Allgemeine und Chemische Geologie. 1. Band: Bildung und Umbildung der Mineralien. Quell-, Fluss- und Meerwasser. Die Absätze. 2. Band: Allgemeines und ältere Eruptivgesteine. 3. Band: Die Erstarrungskruste und die Lehre vom Metamorphismus: VIII + 633 pp., 639 pp., 530 pp., Hertz, Berlin.

[Schneiderhöhn, H.] 1954. Die wissenschaftliche Bedeutung Friedrich Tamnau's. Von Paul v. Groth ( $\dagger$ ). Vorbemerkung der Schriftleitung. - Neues Jahrbuch der Mineralogie, Monatshefte 1954: 69-72.

Strunz, H. 1941. Mineralogische Tabellen. - Geest u. Portig, Leipzig. [1. Aufl.]

- 1970. Von der Bergakademie zur Technischen Universität Berlin, 1770 bis 1970: $151 \mathrm{pp}$., Technische Universität, Berlin.

Tenne, C. A. 1887. [Nachruf auf M. Websky]. In Websky 1887: V-VI.

Tenne, C. A. \& S. Calderón. 1902. Die Mineralfundstätten der Iberischen Halbinsel: 341 pp., Asher, Berlin.

Tiede, A. 1899. Museen. In Baukunde des Architekten. Band 2 , 2. Teil, 2. Aufl.: 389 pp.: 1-90. E. Toeche, Berlin.
[Tiede, A. \& Kleinwächter, F.] 1889. Das Museum für Naturkunde der Königlichen Friedrich-Wilhelms-Universität in Berlin. Zur Eröffnungsfeier. 16 pp., 10 Tafeln, Ernst \& Korn, Berlin.

Völkel, H. 2002. Mineralogen und Geologen in Breslau. Geschichte der Geowissenschaften an der Universität Breslau von 1811 bis 1945. 223 pp., Haltern, Bode.

Vogel, H. 1862. Über ein einfaches Verfahren, mikroskopische Ansichten photographisch aufzunehmen. - Poggendorffs Annalen der Physik und Chemie 117: 629-632.

- 1863. Über das Verhalten des Chlorsilbers, Bromsilbers und Jodsilbers im Licht und die Theorie der Photographie. - Poggendorffs Annalen der Physik und Chemie 119: $56 \mathrm{pp}$.

Websky, M. 1879. Über die Lichtreflexe schmaler Krystallflächen. - Zeitschrift für Krystallographie 3: 241-258.

- 1887. Anwendung der Linearprojection zum Berechnen der Krystalle. (Als 3. Band von Gustav Rose's Elemente der Krystallographie): XVIII + 377 pp., Berlin, Mittler.

Wild, R. 1991. Die Ostafrika-Reise von Eberhard Fraas und die Erforschung der Dinosaurier-Fundstelle Tendaguru. - Stuttgarter Beiträge zur Naturkunde, Serie C 30: $71-76$.

Wolff, F. v. 1907. Carl Klein †. - Centralblatt für Mineralogie, Geologie und Paläontologie 1907: 641-661. 


\section{Anhang}

Tabelle 1

Das wissenschaftliche Personal des Mineralogischen Museums der Universität in Berlin und seiner Nachfolgeeinrichtungen in der Zeit von 1810 bis 1910 (in alphabetischer Reihenfolge)

\section{Abkürzungen:}

P: Professor, aoP: außerordentlicher Professor, oP: ordentlicher Professor, PmL: Professor mit Lehrauftrag, PD: Privatdozent, aG: als Gast, BR: abgeschlossenes Berg- und Hütten-Studium (Bergreferendar), HA: Hilfsassistent, A: Assistent, K: Kustos, Min: Mineralogie, Krist: Kristallographie, Petr: Petrographie, Geol: Geologie, Pal: Paläontologie, Palbot: Paläobotanik, Paläophytologie,

BA: Bergakademie Berlin, FH: Forsthochschule Eberswalde, LH: Landwirtschaftliche Hochschule Berlin, GI: Gewerbeinstitut/Gewerbeakademie Berlin, ab 1879 TH: Technische Hochschule Berlin-Charlottenburg, PrGLA: Preußische Geologische Landesanstalt Berlin, T-St: Stipendiat der Tamnau-Reisestiftung

\begin{tabular}{|c|c|c|c|c|c|c|c|}
\hline $\begin{array}{l}\text { Name, } \\
\text { Vorname }\end{array}$ & $\begin{array}{l}\text { Lebens- } \\
\text { jahre }\end{array}$ & Promotion & $\begin{array}{l}\text { Assistent } \\
\text { Kustos }\end{array}$ & Lehrkraft & Gebiet & $\begin{array}{l}\text { später tätig } \\
\text { in }\end{array}$ & Bemerkungen \\
\hline $\begin{array}{l}\text { Alexi, } \\
\text { Karl }\end{array}$ & $1880-?$ & $\begin{array}{l}1904 \\
\text { Berlin }\end{array}$ & HA 1903-5 & & Min & & \\
\hline $\begin{array}{l}\text { Arzruni, } \\
\text { Andreas }\end{array}$ & $\begin{array}{l}1847- \\
1898\end{array}$ & $\begin{array}{l}\text { Petersburg/ } \\
\text { Heidelberg }\end{array}$ & K $1880-1883$ & PD $1877-1883$ & Min & $\begin{array}{l}\text { Breslau, } \\
\text { Aachen }\end{array}$ & \\
\hline $\begin{array}{l}\text { Bauer, } \\
\text { Max Hermann }\end{array}$ & $\begin{array}{l}1844- \\
1917\end{array}$ & $\begin{array}{l}1867 \\
\text { Tübingen }\end{array}$ & A $1872-1875$ & PD $1873-1875$ & Min & $\begin{array}{l}\text { Königsberg, } \\
\text { Marburg }\end{array}$ & \\
\hline $\begin{array}{l}\text { Belowsky, } \\
\text { Max }\end{array}$ & $\begin{array}{l}1865- \\
1945\end{array}$ & $\begin{array}{l}1892 \\
\text { Berlin }\end{array}$ & $\begin{array}{l}\text { HA } 1891 / 3 \\
\text { A ab } 1895 \\
\text { K } 1901-30\end{array}$ & $\begin{array}{l}\text { PD ab } 1905 \\
(1908 \mathrm{P} \\
1921 \text { aoP })\end{array}$ & Min & & $\begin{array}{l}1909 \text { u. } 1913 \\
\text { T-St Exped. } \\
\text { USA }\end{array}$ \\
\hline $\begin{array}{l}\text { Berek, } \\
\text { Max }\end{array}$ & $\begin{array}{l}1886- \\
1949\end{array}$ & $\begin{array}{l}1911 \\
\text { Berlin }\end{array}$ & A $1910-12$ & & Min & $\begin{array}{l}\text { Wetzlar } \\
\text { (Fa. Leitz, } \\
1924 \text { P) }\end{array}$ & \\
\hline $\begin{array}{l}\text { Berendt, } \\
\text { Gottlieb }\end{array}$ & $\begin{array}{l}1836- \\
1920\end{array}$ & $\begin{array}{l}\text { BR: } 1863 \\
\text { Berlin }\end{array}$ & & aoP 1875 & $\begin{array}{l}\text { Geol } \\
\text { Pal }\end{array}$ & 1875 PrGLA & \\
\hline $\begin{array}{l}\text { Beyrich, } \\
\text { August } \\
\text { Heinrich } \\
\text { Ernst }\end{array}$ & $\begin{array}{l}1815- \\
1896\end{array}$ & $\begin{array}{l}1837 \\
\text { Berlin }\end{array}$ & $\begin{array}{l}\text { A } 1841-56 \\
\text {,2. Beamter" } \\
1856-73\end{array}$ & $\begin{array}{l}\text { PD } 1841 \\
\text { aoP } 1846 \\
\text { oP } 1865\end{array}$ & $\begin{array}{l}\text { Geol } \\
\mathrm{Pal}\end{array}$ & & $\begin{array}{l}\text { „1.“ Direktor } \\
\text { 1873-86, } \\
\text { Direktor } \\
1886-96\end{array}$ \\
\hline $\begin{array}{l}\text { Blasius, } \\
\text { Eugen }\end{array}$ & $\begin{array}{l}1861- \\
1937\end{array}$ & $\begin{array}{l}1885 . \\
\text { Straßburg }\end{array}$ & & $\begin{array}{l}\text { PD } 1891, \\
\text { aoP } 1895\end{array}$ & $\begin{array}{l}\text { Phys } \\
\text { (Krist) }\end{array}$ & & \\
\hline $\begin{array}{l}\text { Böhm, } \\
\text { Johannes }\end{array}$ & $1857-?$ & $\begin{array}{l}1884 \\
\text { Bonn }\end{array}$ & A $1895-1901$ & & $\begin{array}{l}\text { Geol } \\
\text { Pal }\end{array}$ & PrGLA & \\
\hline $\begin{array}{l}\text { Branca } \\
\text { (bis } 1907 \text { Branco), } \\
\text { Wilhelm von } \\
\text { (seit } 1895 \text { ) }\end{array}$ & $\begin{array}{l}1844- \\
1928\end{array}$ & $\begin{array}{l}1876 \\
\text { Heidelberg }\end{array}$ & & $\begin{array}{l}\text { PD 1881, } \\
1882-87, \\
\text { oP } 1899\end{array}$ & $\begin{array}{l}\text { Pal } \\
\text { Geol }\end{array}$ & $\begin{array}{l}1887-99 \text { u. a. } \\
\text { Hohenheim }\end{array}$ & $\begin{array}{l}\text { Direktor } \\
1899-1917\end{array}$ \\
\hline $\begin{array}{l}\text { Brand, } \\
\text { Hermann }\end{array}$ & $1887-?$ & $\begin{array}{l}1911 \\
\text { Berlin }\end{array}$ & HA $1910-02$ & & Min & & \\
\hline $\begin{array}{l}\text { Brandes, Georg } \\
\text { Wilhelm August }\end{array}$ & $\begin{array}{l}1878- \\
1906\end{array}$ & & $\begin{array}{l}\text { HA } 1900 \text {, } \\
\text { A } 1901-02\end{array}$ & & Geol & & \\
\hline $\begin{array}{l}\text { Bücking, } \\
\text { Hugo }\end{array}$ & $\begin{array}{l}1851- \\
1932\end{array}$ & $\begin{array}{l}1874 \\
\text { Marburg }\end{array}$ & & PD $1879-1881$ & $\begin{array}{l}\text { Min } \\
\text { Geol }\end{array}$ & $\begin{array}{l}\text { Kiel, } \\
\text { Straßburg }\end{array}$ & \\
\hline $\begin{array}{l}\text { Cramer, } \\
\text { Rudolf }\end{array}$ & $1882-?$ & $\begin{array}{l}1906 \\
\text { Berlin }\end{array}$ & HA $1906-7$ & & Min & PrGLA & \\
\hline $\begin{array}{l}\text { Dames, } \\
\text { Wilhelm Barnim }\end{array}$ & $\begin{array}{l}1843- \\
1898\end{array}$ & \begin{tabular}{|l}
1868 \\
Breslau
\end{tabular} & $\begin{array}{l}\text { A ab } 1871 \\
\text { K } 1875-91\end{array}$ & $\begin{array}{l}\text { PD ab 1874, } \\
\text { aoP } 1878, \\
\text { oP } 1891 .\end{array}$ & $\begin{array}{l}\text { Geol } \\
\text { Pal }\end{array}$ & & $\begin{array}{l}\text { Direktor } \\
1896-1898\end{array}$ \\
\hline $\begin{array}{l}\text { Davis, } \\
\text { William Morris }\end{array}$ & $\begin{array}{l}1850- \\
1934\end{array}$ & $\begin{array}{l}1906 \\
\text { Greifswald }\end{array}$ & & $\begin{array}{l}\text { 1908-09 aG, } \\
\mathrm{P} \text { der Harvard- } \\
\text { Univ. Mass. }\end{array}$ & $\begin{array}{l}\text { Geogr } \\
\text { Geol }\end{array}$ & Cambridge & $\begin{array}{l}\text { Austausch- } \\
\text { prof. }\end{array}$ \\
\hline $\begin{array}{l}\text { Dechen, } \\
\text { Heinrich von }\end{array}$ & $\begin{array}{l}1800- \\
1889\end{array}$ & $\begin{array}{l}\text { BR: } 1830 \\
\text { Bonn h. c. }\end{array}$ & & aoP $1834-1841$ & Geol & $\begin{array}{l}\text { Bonn, Univ., } \\
\text { Oberbergamt }\end{array}$ & \\
\hline
\end{tabular}




\begin{tabular}{|c|c|c|c|c|c|c|c|}
\hline $\begin{array}{l}\text { Name, } \\
\text { Vorname }\end{array}$ & $\begin{array}{l}\text { Lebens- } \\
\text { jahre }\end{array}$ & Promotion & $\begin{array}{l}\text { Assistent/ } \\
\text { Kustos }\end{array}$ & Lehrkraft & Gebiet & $\begin{array}{l}\text { später tätig } \\
\text { in }\end{array}$ & Bermerkungen \\
\hline $\begin{array}{l}\text { Emmrich, } \\
\text { Hermann }\end{array}$ & $\begin{array}{l}1815- \\
1879\end{array}$ & $\begin{array}{l}1839 \\
\text { Berlin }\end{array}$ & A $1837-1839$ & & $\begin{array}{l}\text { Geol } \\
\text { Pal }\end{array}$ & $\begin{array}{l}\text { Gymnasium } \\
\text { Meiningen }\end{array}$ & \\
\hline $\begin{array}{l}\text { Erdmannsdörffer, } \\
\text { Otto } \mathrm{H} \text {. }\end{array}$ & $\begin{array}{l}1876- \\
955\end{array}$ & $\begin{array}{l}1901 \\
\text { Heidelberg }\end{array}$ & & $\begin{array}{l}\text { PD 1908-1912 } \\
(1912 \text { P) }\end{array}$ & $\begin{array}{l}\text { Min } \\
\text { Petr }\end{array}$ & $\begin{array}{l}\text { Hannover, } \\
\text { Heidelberg }\end{array}$ & \\
\hline $\begin{array}{l}\text { Esch, } \\
\text { Ernst }\end{array}$ & $1870-?$ & BR & A $1894-1895$ & & Min & & \\
\hline $\begin{array}{l}\text { Fock, } \\
\text { Andreas Ludwig }\end{array}$ & $\begin{array}{l}1856- \\
1928\end{array}$ & $\begin{array}{l}1880 \\
\text { Straßburg }\end{array}$ & & PD 1886-1912 & $\begin{array}{l}\text { Phys.- } \\
\text { Chem } \\
\end{array}$ & & \\
\hline $\begin{array}{l}\text { Fröbel, } \\
\text { Friedrich }\end{array}$ & $\begin{array}{l}1782- \\
1852\end{array}$ & & A $1814-1816$ & & Min & $\begin{array}{l}\text { Kindergarten- } \\
\text { Gründer }\end{array}$ & \\
\hline $\begin{array}{l}\text { Futterer, } \\
\text { Karl }\end{array}$ & $\begin{array}{l}1866- \\
1906\end{array}$ & $\begin{array}{l}1889 \\
\text { Heidelberg }\end{array}$ & $\begin{array}{l}\text { HA } 1890, \\
\text { A } 1891-95\end{array}$ & PD 1893-1895 & $\begin{array}{l}\text { Geol } \\
\text { Min }\end{array}$ & Karlsruhe & \\
\hline $\begin{array}{l}\text { Girard, } \\
\text { Heinrich }\end{array}$ & $\begin{array}{l}1814- \\
1878\end{array}$ & $\begin{array}{l}1840 \\
\text { Berlin }\end{array}$ & A $1839-1849$ & PD 1844-1849 & $\begin{array}{l}\text { Min } \\
\text { Geol }\end{array}$ & $\begin{array}{l}\text { Marburg, } \\
\text { Halle }\end{array}$ & \\
\hline $\begin{array}{l}\text { Groth, } \\
\text { Paul von }\end{array}$ & $\begin{array}{l}1843- \\
1927\end{array}$ & $\begin{array}{l}1868 \\
\text { Berlin }\end{array}$ & & PD $1870-1872$ & Min & $\begin{array}{l}\text { Straßburg, } \\
\text { München }\end{array}$ & \\
\hline $\begin{array}{l}\text { Grünling, } \\
\text { Friedrich }\end{array}$ & $?$ & $\begin{array}{l}1879 \\
\text { Straßburg }\end{array}$ & & (A in München) & Min & & $\begin{array}{l}\text { T-St } 1896 \\
\text { Ceylon }\end{array}$ \\
\hline $\begin{array}{l}\text { Gumprecht, } \\
\text { Thaddäus }\end{array}$ & $\begin{array}{l}1801- \\
1856\end{array}$ & $\begin{array}{l}1835 ? \\
\text { Berlin }\end{array}$ & & PD 1843-1854 & $\begin{array}{l}\text { Geol } \\
\text { Geogr }\end{array}$ & & \\
\hline $\begin{array}{l}\text { Hennig, } \\
\text { Edwin }\end{array}$ & $\begin{array}{l}1882- \\
1977\end{array}$ & $\begin{array}{l}1906 \\
\text { Berlin }\end{array}$ & A $1906-17$ & $\begin{array}{l}\text { PD 1913-1917, } \\
\text { P } 1916\end{array}$ & Pal & Tübingen & $\begin{array}{l}\text { 1909-11 } \\
\text { Ost-Afrika, } \\
\text { Tendaguru }\end{array}$ \\
\hline $\begin{array}{l}\text { Henniges, } \\
\text { Ludwig }\end{array}$ & $1860-?$ & $\begin{array}{l}1881 \\
\text { Göttingen }\end{array}$ & HA $1886-1887$ & & Min & & \\
\hline $\begin{array}{l}\text { Hermann, } \\
\text { Rudolf }\end{array}$ & $\begin{array}{l}1881- \\
1924\end{array}$ & $\begin{array}{l}1907 \\
\text { Berlin }\end{array}$ & $\begin{array}{l}\text { HA } 1906 \\
\text { A } 1907\end{array}$ & & Geol & $\begin{array}{l}\text { Naturdenkmal- } \\
\text { Pflege }\end{array}$ & \\
\hline $\begin{array}{l}\text { Herz, } \\
\text { Richard }\end{array}$ & $1866-?$ & $\begin{array}{l}1892 \\
\text { Berlin }\end{array}$ & A $1891-1892$ & & Min & & \\
\hline $\begin{array}{l}\text { Hintze, } \\
\text { Alfred }\end{array}$ & $1880-?$ & $\begin{array}{l}1907 \\
\text { Berlin }\end{array}$ & HA $1907\left(1908^{*}\right)$ & & Min & & * ohne Gehalt \\
\hline $\begin{array}{l}\text { Hoffmann, } \\
\text { Friedrich }\end{array}$ & $\begin{array}{l}1797- \\
1836\end{array}$ & $\begin{array}{l}1823 \\
\text { Halle }\end{array}$ & & aoP 1833-1836 & $\begin{array}{l}\text { Min } \\
\text { Geol }\end{array}$ & & \\
\hline $\begin{array}{l}\text { Jaekel, } \\
\text { Otto Max } \\
\text { Johannes }\end{array}$ & $\begin{array}{l}1863- \\
1929\end{array}$ & $\begin{array}{l}1886 \\
\text { München }\end{array}$ & $\begin{array}{l}\text { HA 1891, } \\
\text { K 1892-1906 }\end{array}$ & $\begin{array}{l}\text { PD 1890-1906, } \\
\text { P 1895, } \\
\text { aoP } 1904\end{array}$ & $\begin{array}{l}\text { Geol } \\
\text { Pal }\end{array}$ & $\begin{array}{l}\text { Greifswald, } \\
\text { Kanton/China }\end{array}$ & \\
\hline $\begin{array}{l}\text { Janensch, } \\
\text { Werner Ernst } \\
\text { Martin }\end{array}$ & $\begin{array}{l}1878- \\
1969\end{array}$ & $\begin{array}{l}1901 \\
\text { Straßburg }\end{array}$ & $\begin{array}{l}\text { A 1901-06, } \\
\text { K 1906--50 }\end{array}$ & P 1912 & $\mathrm{Pal}$ & & $\begin{array}{l}\text { 1909-1911 } \\
\text { Ost-Afrika, } \\
\text { Tendaguru }\end{array}$ \\
\hline $\begin{array}{l}\text { Kayser, } \\
\text { Emanuel }\end{array}$ & $\begin{array}{l}1845- \\
1927\end{array}$ & $\begin{array}{l}1870 \\
\text { Berlin }\end{array}$ & & $\begin{array}{l}\text { PD 1872-1885 } \\
\text { (1882 P/BA) }\end{array}$ & Geol & $\begin{array}{l}\text { PrGLA, } \\
\text { Marburg }\end{array}$ & \\
\hline $\begin{array}{l}\text { Kirschstein, } \\
\text { Egon Friedrich }\end{array}$ & $1879-?$ & $\begin{array}{l}1910 \\
\text { Berlin }\end{array}$ & $\begin{array}{l}\text { HA 1902-5, } \\
\text { A } 1905-6\end{array}$ & & Geol & & \\
\hline $\begin{array}{l}\text { Klautzsch, } \\
\text { Adolf }\end{array}$ & $\begin{array}{l}1869- \\
1927\end{array}$ & $\begin{array}{l}1893 \\
\text { Berlin }\end{array}$ & A $1892-1898$ & & $\begin{array}{l}\text { Min } \\
\text { Petr }\end{array}$ & PrGLA & \\
\hline $\begin{array}{l}\text { Kleffner, } \\
\text { Erich }\end{array}$ & $?$ & $\begin{array}{l}1901 \\
\text { Berlin }\end{array}$ & HA 1902-3 & & Min & & \\
\hline $\begin{array}{l}\text { Klein, } \\
\text { Carl }\end{array}$ & $\begin{array}{l}1842- \\
1907\end{array}$ & $\begin{array}{l}1868 \\
\text { Heidelberg }\end{array}$ & & oP $1887-1907$ & $\begin{array}{l}\text { Min } \\
\text { Petr }\end{array}$ & & $\begin{array}{l}\text { Direktor } \\
1887-1907\end{array}$ \\
\hline $\begin{array}{l}\text { Knebel, } \\
\text { Walther von }\end{array}$ & $\begin{array}{l}1880- \\
1907\end{array}$ & $\begin{array}{l}1902 \\
\text { Berlin }\end{array}$ & HA 1901. 1906 & PD 1907 & $\begin{array}{l}\text { Geol } \\
\text { Pal }\end{array}$ & & $\begin{array}{l}\text { in Island } \\
\text { ertrunken }\end{array}$ \\
\hline $\begin{array}{l}\text { Koken, } \\
\text { Ernst }\end{array}$ & $\begin{array}{l}1860- \\
1912\end{array}$ & $\begin{array}{l}1884 \\
\text { Berlin }\end{array}$ & $\begin{array}{l}\text { HA } 1884-7 \text {, } \\
\text { A } 1888-90\end{array}$ & PD 1887-1890 & $\begin{array}{l}\text { Geol } \\
\text { Min }\end{array}$ & $\begin{array}{l}\text { Königsberg, } \\
\text { Tübingen }\end{array}$ & \\
\hline
\end{tabular}




\begin{tabular}{|c|c|c|c|c|c|c|c|}
\hline $\begin{array}{l}\text { Name, } \\
\text { Vorname }\end{array}$ & $\begin{array}{l}\text { Lebens- } \\
\text { jahre }\end{array}$ & Promotion & $\begin{array}{l}\text { Assistent/ } \\
\text { Kustos }\end{array}$ & Lehrkraft & Gebiet & $\begin{array}{l}\text { später tätig } \\
\text { in }\end{array}$ & Bemerkungen \\
\hline $\begin{array}{l}\text { Kronecker, } \\
\text { Wilhelm }\end{array}$ & $1884-?$ & $\begin{array}{l}1910 \\
\text { Berlin }\end{array}$ & $\begin{array}{l}\text { HA } 1908 \\
\text { A } 1909-11\end{array}$ & & Geol & & \\
\hline $\begin{array}{l}\text { Krull, } \\
\text { Daniel }\end{array}$ & $\begin{array}{l}1813- \\
1859\end{array}$ & & $\begin{array}{l}\text { HA } 1847-8 \\
\text { A } 1849-59\end{array}$ & & Min & & \\
\hline $\begin{array}{l}\text { Küch, } \\
\text { Richard }\end{array}$ & $\begin{array}{l}1860- \\
1915\end{array}$ & Leiprig & HA 1889 & & Min & Fa. Heräus & \\
\hline $\begin{array}{l}\text { Kühn. } \\
\text { Benno }\end{array}$ & $\begin{array}{l}1865- \\
1949 \\
\end{array}$ & $\begin{array}{l}1890 \\
\text { Berlin } \\
\end{array}$ & A $1890-1891$ & & Min & PrGLA & \\
\hline $\begin{array}{l}\text { Kunth, } \\
\text { Albert }\end{array}$ & $\begin{array}{l}1842- \\
1871 \\
\end{array}$ & $\begin{array}{l}1863 \\
\text { Berlin }\end{array}$ & $\begin{array}{l}\text { HA } 1866 . \\
\text { A } 1867-69\end{array}$ & PD 1870 & Geol & & $\begin{array}{l}\dagger \text { an Kriegs- } \\
\text { verwundung }\end{array}$ \\
\hline $\begin{array}{l}\text { Kurtz, } \\
\text { Fritz }\end{array}$ & $\begin{array}{l}1854- \\
1920\end{array}$ & $\begin{array}{l}1879 \\
\text { Berlin }\end{array}$ & A $1880-82$ & & Palbot & $\begin{array}{l}\text { Cordoba, } \\
\text { Argentinien }\end{array}$ & \\
\hline $\begin{array}{l}\text { Laspeyres, } \\
\text { Hugo }\end{array}$ & $\begin{array}{l}1836- \\
1913\end{array}$ & $\begin{array}{l}1864 \\
\text { Heidelberg }\end{array}$ & & PD $1867-1870$ & Min Geol & $\begin{array}{l}\text { Aachen, } \\
\text { Kiel, Bonn }\end{array}$ & \\
\hline $\begin{array}{l}\text { Leeden, } \\
\text { Rudolf van der }\end{array}$ & $1880-?$ & $\begin{array}{l}1905 \\
\text { Berlin } \\
\end{array}$ & HA $1910-$ & & Min & & \\
\hline $\begin{array}{l}\text { Leitz, } \\
\text { Carl }\end{array}$ & $1880-?$ & & HA $1905-6$ & & Min & & \\
\hline $\begin{array}{l}\text { Liebisch. } \\
\text { Theodor }\end{array}$ & $\begin{array}{l}1852- \\
1922\end{array}$ & $\begin{array}{l}1874 \\
\text { Breslau }\end{array}$ & $\begin{array}{l}\text { A } 1875 \text {, } \\
\text { K } 1876-1880\end{array}$ & $\begin{array}{l}\text { PD } 1876-1880 \\
\text { oP Bln } 1908-1921\end{array}$ & Min & $\begin{array}{l}1880-1908 \\
\text { Breslau, ... } \\
\text { Göttingen }\end{array}$ & $\begin{array}{l}\text { Direktor } \\
\text { ab } 1908\end{array}$ \\
\hline $\begin{array}{l}\text { Lieder. } \\
\text { Georg }\end{array}$ & & & HA 1890 & & Geol & $\begin{array}{l}1893 \text { als Geol. } \\
\text { in Ostafrika }\end{array}$ & \\
\hline $\begin{array}{l}\text { Lossen, } \\
\text { Karl August }\end{array}$ & $\begin{array}{l}1841- \\
1893\end{array}$ & $\begin{array}{l}1866 \\
\text { Halle } \\
\end{array}$ & & $\begin{array}{l}\text { PD ab } 1870 \\
(1883 \text { P/BA })\end{array}$ & $\begin{array}{l}\text { Petr } \\
\text { Geol }\end{array}$ & 1873 PrGLA & \\
\hline $\begin{array}{l}\text { Möller, } \\
\text { Eduard }\end{array}$ & $1862-?$ & $\begin{array}{l}1887 \\
\text { Göttingen }\end{array}$ & $\begin{array}{l}\text { A } 1887 \\
1889-1890\end{array}$ & & Min & & \\
\hline $\begin{array}{l}\text { Nacken, } \\
\text { Richard }\end{array}$ & $\begin{array}{l}1884- \\
1971\end{array}$ & $\begin{array}{l}1906 \\
\text { Göttingen }\end{array}$ & A $1908-11$ & & Min & $\begin{array}{l}\text { Leipzig, ..., } \\
\text {..., Tübingen }\end{array}$ & \\
\hline $\begin{array}{l}\text { Neumann, } \\
\text { Franz Ernst }\end{array}$ & $\begin{array}{l}1798- \\
1895\end{array}$ & $\begin{array}{l}1826 \\
\text { Berlin }\end{array}$ & $\begin{array}{l}\text { A } 1821 \\
\text { (Mai-Juni) }\end{array}$ & & $\begin{array}{l}\text { Krist } \\
\text { Phys }\end{array}$ & Königsberg & \\
\hline $\begin{array}{l}\text { Orth, } \\
\text { Albert }\end{array}$ & $\begin{array}{l}1825- \\
1915\end{array}$ & $\begin{array}{l}1867 \\
\text { Göttingen }\end{array}$ & & $\begin{array}{l}\text { ab } 1871 \\
\text { aoP/LH }\end{array}$ & $\begin{array}{l}\text { Boden- } \\
\text { kunde }\end{array}$ & LH Berlin & \\
\hline $\begin{array}{l}\text { Philippi, } \\
\text { Emil }\end{array}$ & $\begin{array}{l}1871- \\
1910\end{array}$ & $\begin{array}{l}1895 \\
\text { Straßburg }\end{array}$ & A $1897-1900$ & PD $1901-1906$ & $\begin{array}{l}\text { Geol } \\
\text { Pal }\end{array}$ & Jena & \\
\hline $\begin{array}{l}\text { Potonié, } \\
\text { Henry }\end{array}$ & $\begin{array}{l}1857- \\
1913 \\
\end{array}$ & $\begin{array}{l}1884 \\
\text { Berlin }\end{array}$ & & $\begin{array}{l}\text { PD 1901-1913 } \\
(\mathrm{P} \mathrm{1900)}\end{array}$ & Palbot & $\begin{array}{l}\text { PrGLA } \\
\text { und BA }\end{array}$ & \\
\hline $\begin{array}{l}\text { Quenstedt, } \\
\text { Friedrich August }\end{array}$ & $\begin{array}{l}1809- \\
1899\end{array}$ & $\begin{array}{l}1836 \\
\text { Berlin }\end{array}$ & A $1833-1837$ & PD 1837 & $\begin{array}{l}\text { Min } \\
\text { Geol } \\
\text { Pal }\end{array}$ & Tübingen & \\
\hline $\begin{array}{l}\text { Rammelsberg, } \\
\text { Karl Friedrich }\end{array}$ & $\begin{array}{l}1813- \\
1899\end{array}$ & $\begin{array}{l}1837 \\
\text { Berlin }\end{array}$ & & $\begin{array}{l}\text { PD } 1840, \\
\text { aoP } 1845, \\
\text { P } 1874 \\
\text { (Min u. Chem) }\end{array}$ & $\begin{array}{l}\text { Chem } \\
\text { Min }\end{array}$ & $\begin{array}{l}\text { (zugleich } \\
\text { an TH) }\end{array}$ & $\begin{array}{l}\text { nicht am Min. } \\
\text { Mus. beamtet }\end{array}$ \\
\hline $\begin{array}{l}\text { Reck, } \\
\text { Hans }\end{array}$ & $\begin{array}{l}1886- \\
1937\end{array}$ & $\begin{array}{l}1909 \\
\text { München }\end{array}$ & $\begin{array}{l}\text { HA } 1909 \\
\text { A } 1910-14\end{array}$ & aoP $1920-30$ & $\begin{array}{l}\text { Geol } \\
\text { Pal }\end{array}$ & 1912 Afrika & $\begin{array}{l}\text { ab } 1931 \\
\text { Forsch.-Reisen } \\
\text { in Afrika }\end{array}$ \\
\hline $\begin{array}{l}\text { Remelé. } \\
\text { Adolf }\end{array}$ & $\begin{array}{l}1839- \\
1915\end{array}$ & $\begin{array}{l}1864 \\
\text { Berlin }\end{array}$ & & PD 1866-1869 & Min & $1868 \mathrm{FH}(\mathrm{oP})$ & \\
\hline $\begin{array}{l}\text { Rinne, } \\
\text { Friedrich }\end{array}$ & $\begin{array}{l}1863- \\
1933\end{array}$ & $\begin{array}{l}1883 \\
\text { Göttingen }\end{array}$ & A $1887-94$ & PD 1886-1894 & Min & $\begin{array}{l}\text { Hannover, ... } \\
\text { Leipzig }\end{array}$ & \\
\hline $\begin{array}{l}\text { Rose, } \\
\text { Gustav }\end{array}$ & $\begin{array}{l}1798- \\
1873\end{array}$ & $\begin{array}{l}1820 \\
\text { Berlin }\end{array}$ & A $1822-33$ & $\begin{array}{l}\text { PD 1823, } \\
\text { aoP } 1826, \\
\text { oP } 1839\end{array}$ & Min & & $\begin{array}{l}\text { Direktor } \\
1856-1873\end{array}$ \\
\hline
\end{tabular}




\begin{tabular}{|c|c|c|c|c|c|c|c|}
\hline $\begin{array}{l}\text { Name, } \\
\text { Vorname }\end{array}$ & $\begin{array}{l}\text { Lebens- } \\
\text { jahre }\end{array}$ & Promotion & $\begin{array}{l}\text { Assistent/ } \\
\text { Kustos }\end{array}$ & Lehrkraft & Gebiet & $\begin{array}{l}\text { später tätig } \\
\text { in }\end{array}$ & Bemerkungen \\
\hline $\begin{array}{l}\text { Roth, } \\
\text { Justus Ludwig } \\
\text { Adolph }\end{array}$ & $\begin{array}{l}1818- \\
1892\end{array}$ & $\begin{array}{l}1844 \\
\text { Jena }\end{array}$ & & $\begin{array}{l}\text { PD 1861, } \\
\text { aoP } 1867 \\
\text { oP } 1887\end{array}$ & $\begin{array}{l}\text { Petr } \\
\text { Geol }\end{array}$ & & $\begin{array}{l}\text { 3. Beamter" } \\
1874-87\end{array}$ \\
\hline $\begin{array}{l}\text { Sadebeck, } \\
\text { Alexander }\end{array}$ & $\begin{array}{l}1843- \\
1879\end{array}$ & $\begin{array}{l}1865 \\
\text { Berlin }\end{array}$ & A $1865-1872$ & PD 1869--1872 & Min & Kiel & \\
\hline $\begin{array}{l}\text { Schulz, } \\
\text { Karl }\end{array}$ & $1885-?$ & $\begin{array}{l}1909 \\
\text { Berlin }\end{array}$ & HA $1909-10$ & & Min & & \\
\hline $\begin{array}{l}\text { Schwantke, } \\
\text { Arthur }\end{array}$ & $\begin{array}{l}1872- \\
1939\end{array}$ & $\begin{array}{l}1896 \\
\text { Breslau }\end{array}$ & & (A in Marburg) & Min & & $\begin{array}{l}\text { T-St } 1902 \\
\text { Grönland }\end{array}$ \\
\hline $\begin{array}{l}\text { Schwarz, } \\
\text { Hugo }\end{array}$ & $1883-?$ & $\begin{array}{l}1908 \\
\text { Berlin }\end{array}$ & A 1909 & & $\mathrm{Pal}$ & & \\
\hline $\begin{array}{l}\text { Silberstein, } \\
\text { Georg }\end{array}$ & $\begin{array}{l}1879- \\
1961\end{array}$ & & HА 1907-9 & & Min & & $\begin{array}{l}1906 \text { Mexico } \\
\text { privat; T-St } \\
1916 \text { Serbien }\end{array}$ \\
\hline $\begin{array}{l}\text { Solger, } \\
\text { Friedrich }\end{array}$ & $\begin{array}{l}1877- \\
1965\end{array}$ & $\begin{array}{l}\text { BR; } \\
1902 \\
\text { Berlin }\end{array}$ & $\begin{array}{l}\text { HA } 1899, \\
\text { A } 1900-03\end{array}$ & $\begin{array}{l}\text { PD } 1907-1909 \text {, } \\
\text { aoP ab } 1921 \text {, } \\
\text { PmL 1946-62 }\end{array}$ & $\begin{array}{l}\text { Geol } \\
\text { Pal }\end{array}$ & $\begin{array}{l}\text { 1903-9 Märk. } \\
\text { Mus. Berlin, } \\
\text { 1910-14 } \\
\text { oP Peking }\end{array}$ & \begin{tabular}{|l} 
Direktor \\
1930-1932 \\
$(1914-20$ \\
Kriegsgef. \\
in Japan) \\
\end{tabular} \\
\hline $\begin{array}{l}\text { Späte, } \\
\text { Friedrich }\end{array}$ & $1881-?$ & $\begin{array}{l}1907 \\
\text { Berlin }\end{array}$ & A $1908-1910$ & & Min & & \\
\hline $\begin{array}{l}\text { Staff, } \\
\text { Johannes (Hans) } \\
\text { von }\end{array}$ & $\begin{array}{l}1883- \\
1915\end{array}$ & \begin{tabular}{|l}
1906 \\
Breslau
\end{tabular} & A $1909-11$ & $\begin{array}{l}\text { PD 1909-15, } \\
\text { P } 1914\end{array}$ & $\begin{array}{l}\text { Geol } \\
\text { Pal }\end{array}$ & $\begin{array}{l}\text { ab } 1914 \\
\text { SW-Afrika }\end{array}$ & $\begin{array}{l}\text { Regierungs- } \\
\text { Geologe }\end{array}$ \\
\hline $\begin{array}{l}\text { Starke, } \\
\text { Hermann }\end{array}$ & $\begin{array}{l}1874- \\
1960\end{array}$ & $\begin{array}{l}1896 \\
\text { Berlin }\end{array}$ & & $\begin{array}{l}\text { 1900-1905 } \\
\text { PD Phys u. Min }\end{array}$ & $\begin{array}{l}\text { Phys } \\
\text { Min }\end{array}$ & $\begin{array}{l}\text { Greifswald, } \\
\text { Aachen }\end{array}$ & \\
\hline $\begin{array}{l}\text { Stellmann, } \\
\text { Wilhelm Carl }\end{array}$ & $1878-?$ & $\begin{array}{l}1901 \\
\text { Berlin }\end{array}$ & HA $1901-2$ & & Min & & \\
\hline $\begin{array}{l}\text { Stille, } \\
\text { Hans }\end{array}$ & $\begin{array}{l}1876- \\
1966\end{array}$ & $\begin{array}{l}1899 \\
\text { Göttingen }\end{array}$ & & $\begin{array}{l}\text { PD } 1904-1908 \\
\text { oP ab } 1932\end{array}$ & $\begin{array}{l}\text { Geol } \\
\text { Pal }\end{array}$ & $\begin{array}{l}1908-32 \\
\text { Hannover, ...., } \\
\text { Göttingen }\end{array}$ & $\begin{array}{l}\text { Direktor } \\
1932-1950\end{array}$ \\
\hline $\begin{array}{l}\text { Stremme, } \\
\text { Hermann }\end{array}$ & $\begin{array}{l}1879- \\
1961\end{array}$ & $\begin{array}{l}1903 \\
\text { Berlin }\end{array}$ & A $1903-08$ & $\begin{array}{l}\text { PD 1909-1914, } \\
1912 \text { aoP }\end{array}$ & $\begin{array}{l}\text { Geol } \\
\text { Pal }\end{array}$ & 1914 Danzig & \\
\hline $\begin{array}{l}\text { Stromer von } \\
\text { Reichenbach, } \\
\text { Ernst Wolfgang }\end{array}$ & $\begin{array}{l}1871- \\
1952\end{array}$ & $\begin{array}{l}1895 \\
\text { München }\end{array}$ & HA 1903 & & Pal & $\begin{array}{l}\text { Leiden, } \\
\text { München }\end{array}$ & \\
\hline $\begin{array}{l}\text { Tannhäuser, } \\
\text { Felix }\end{array}$ & $\begin{array}{l}1874- \\
1924\end{array}$ & $\begin{array}{l}\text { BR, } \\
1904 \\
\text { Berlin }\end{array}$ & $\begin{array}{l}\text { HA } 1900-1 \\
\text { A } 1902-07\end{array}$ & PD ab 1906 & $\begin{array}{l}\text { Min } \\
\text { Petr }\end{array}$ & $1907 \mathrm{TH}$ & \\
\hline $\begin{array}{l}\text { Tenne, } \\
\text { August }\end{array}$ & $\begin{array}{l}1853- \\
1901\end{array}$ & $\begin{array}{l}1878 \\
\text { Göttingen }\end{array}$ & K 1883-1901 & $\begin{array}{l}\text { PD 1886-1901? } \\
\text { (Tit-P) }\end{array}$ & Min & & $\begin{array}{l}\text { T-St } 1888 \\
\text { Spanien }\end{array}$ \\
\hline $\begin{array}{l}\text { Tietze, } \\
\text { Oskar }\end{array}$ & $\begin{array}{l}1874- \\
1920\end{array}$ & $\begin{array}{l}1898 \\
\text { Berlin }\end{array}$ & A $1898-1900$ & & Min & PrGLA & \\
\hline $\begin{array}{l}\text { Traube, } \\
\text { Hermann }\end{array}$ & $\begin{array}{l}1860- \\
1913\end{array}$ & $\begin{array}{l}1884 \\
\text { Greifswald }\end{array}$ & & $\begin{array}{l}\text { PD 1889-1905 } \\
\text { (Tit-P) }\end{array}$ & Min & Greifswald & \\
\hline $\begin{array}{l}\text { Vogel, } \\
\text { Hermann Wilhelm }\end{array}$ & $\begin{array}{l}1834- \\
1898 \\
\end{array}$ & \begin{tabular}{|l}
1863 \\
Göttingen
\end{tabular} & $\begin{array}{l}\text { HA } 1860-1862 \\
\text { A } 1863-5\end{array}$ & & (Min) & $\begin{array}{l}\text { GI/TH } \\
\text { (Photo-chem.) }\end{array}$ & \\
\hline $\begin{array}{l}\text { Wahnschaffe, } \\
\text { Felix }\end{array}$ & $\begin{array}{l}1851- \\
1914\end{array}$ & $\begin{array}{l}1875 \\
\text { Jena }\end{array}$ & & PD 1886-1892 & Geol & $\begin{array}{l}\text { BA und } \\
\text { PrGLA }\end{array}$ & \\
\hline $\begin{array}{l}\text { Websky, } \\
\text { Martin }\end{array}$ & $\begin{array}{l}1824- \\
1886\end{array}$ & $\begin{array}{l}\text { BR; } 1864 \\
\text { Breslau (h.c.) }\end{array}$ & & oP $1873-1886$ & $\begin{array}{l}\text { Min } \\
\text { Krist }\end{array}$ & & $\begin{array}{l}\text {,2." Direktor } \\
1873-1886\end{array}$ \\
\hline $\begin{array}{l}\text { Weiss, } \\
\text { Christian Samuel }\end{array}$ & $\begin{array}{l}1780- \\
1856\end{array}$ & $\begin{array}{l}1801 \\
\text { Leipzig }\end{array}$ & & oP $1810-1856$ & $\begin{array}{l}\text { Min } \\
\text { Krist }\end{array}$ & & \begin{tabular}{|l} 
Direktor \\
$1810-1856$
\end{tabular} \\
\hline $\begin{array}{l}\text { Wolff, } \\
\text { Ferdinand von }\end{array}$ & $\begin{array}{l}1871- \\
1952\end{array}$ & $\begin{array}{l}1899 \\
\text { Berlin }\end{array}$ & $\begin{array}{l}\text { HA } 1899, \\
\text { A } 1900-07\end{array}$ & PD 1903-1907 & $\begin{array}{l}\text { Min } \\
\text { Petr }\end{array}$ & $\begin{array}{l}\text { Danzig, } \\
\text { Halle }\end{array}$ & \\
\hline
\end{tabular}

